\title{
A new plesiosaurian from the Jurassic-Cretaceous transitional interval of the Slottsmøya Member (Volgian), with insights into the cranial anatomy of cryptoclidids using Computed Tomography
}

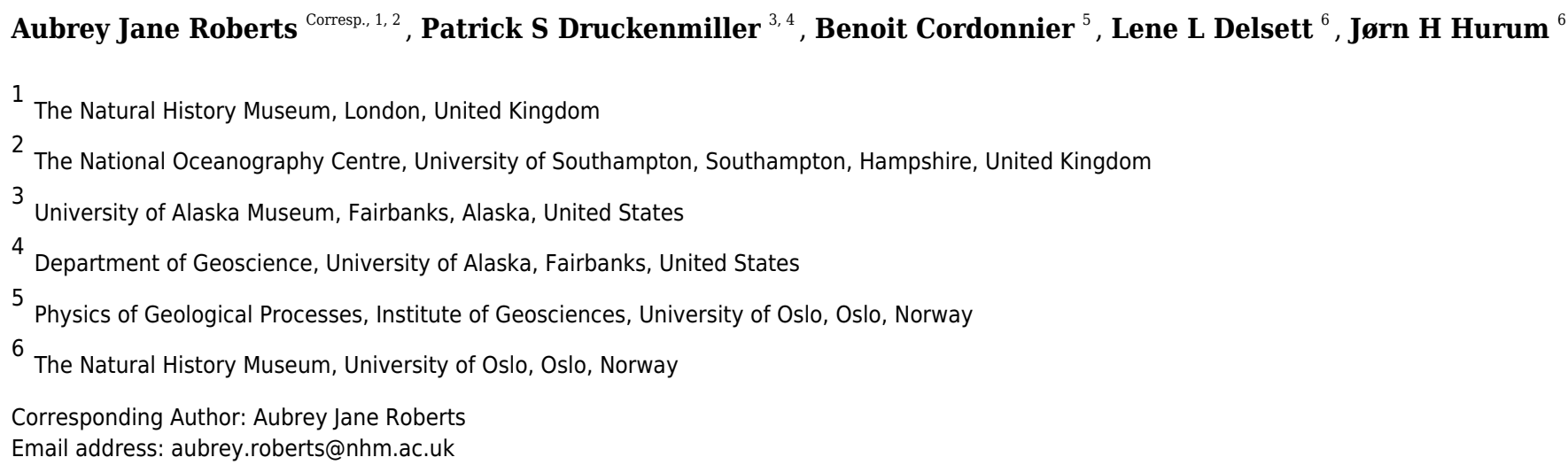

Cryptoclidids are a major clade of plesiosauromorph plesiosaurians best known from the Middle - Late Jurassic, but little is known regarding their turnover into the Early Cretaceous. Of the known cryptoclidid genera, most preserve only a limited amount of cranial material and of these Cryptoclidus eurymerus, displays the most complete, but compressed cranium. Thus, the lack of knowledge of the cranial anatomy of this group may hinder the understanding of phylogenetic intrarelationships, which are currently predominantly based on postcranial data. Here we present a nearly complete adult cryptoclidid specimen (PMO 224.248) representing a new genus and species Ophthalmothule cryostea gen et sp. nov., from the latest Jurassic to- earliest Cretaceous part of the Slottsmøya Member, of central Spitsbergen. The holotype material preserves a complete cranium, partial mandible, complete and articulated cervical, pectoral and anterior to middle dorsal series, along with the pectoral girdle and anterior humeri. High resolution micro computed tomography $(\mu \mathrm{CT})$ reveals new data on the cranial anatomy of this cryptoclidid, including new internal features of the braincase and palate thatare observed in other cryptoclidids. A phylogenetic analysis incorporating new characters, reveals a new tree topology for Cryptoclididae and particularly within the subfamily Colymbosaurinae. These results show that at least two cryptoclidid lineages were present in the Boreal Region during the latest Jurassic at middle to high latitudes. 


\section{Author cover page}

2 Corresponding author: Aubrey J. Roberts

3 aubrey.j.roberts@nhm.ac.uk 


\section{A new plesiosaurian from the Jurassic-Cretaceous \\ 5 transitional interval of the Slottsmoya Member (Volgian), \\ 6 with insights into the cranial anatomy of cryptoclidids using \\ 7 Computed Tomography}

8 Authors: Aubrey J. Roberts ${ }^{1,2}$, Patrick. S. Druckenmiller ${ }^{3,4}$, Benoit Cordonnier ${ }^{5}$, Lene L. Delsett

$9{ }^{6}$ and Jørn H. Hurum ${ }^{6}$

$10{ }^{1}$ The National Oceanography Centre, University of Southampton, Southampton, Hampshire,

11 United Kingdom

$12{ }^{2}$ The Natural History Museum, London, United Kingdom

${ }^{3}$ University of Alaska Museum, , Fairbanks, Alaska, United States

${ }^{4}$ Department of Geoscience, University of Alaska Fairbanks, United States

${ }^{5}$ Physics of Geological Processes, Institute of Geosciences, University of Oslo, Norway

${ }^{6}$ The Natural History Museum, University of Oslo, Norway

\section{Abstract}

Cryptoclidids are a major clade of plesiosauromorph plesiosaurians best known from the Middle - Late Jurassic, but little is known regarding their turnover into the Early Cretaceous. Of the known cryptoclidid genera, most preserve only a limited amount of cranial material and of these Cryptoclidus eurymerus, displays the most complete, but compressed cranium. Thus, the lack of knowledge of the cranial anatomy of this group may hinder the understanding of phylogenetic intrarelationships, which are currently predominantly based on postcranial data. Here we present a nearly complete adult cryptoclidid specimen (PMO 224.248) representing a new genus and species Ophthalmothule cryostea gen et sp. nov., from the latest Jurassic to- earliest Cretaceous part of the Slottsmøya Member, of central Spitsbergen. The holotype material preserves a complete cranium, partial mandible, complete and articulated cervical, pectoral and anterior to middle dorsal series, along with the pectoral girdle and anterior humeri. High resolution micro computed tomography $(\mu \mathrm{CT})$ reveals new data on the cranial anatomy of this cryptoclidid, including new internal features of the braincase and palate thatare observed in other cryptoclidids. 
31 A phylogenetic analysis incorporating new characters, reveals a new tree topology for

32 Cryptoclididae and particularly within the subfamily Colymbosaurinae. These results show that at least two cryptoclidid lineages were present in the Boreal Region during the latest Jurassic at middle to high latitudes.

\section{Introduction}

Plesiosauria is a clade of secondarily aquatic reptiles that predominantly inhabited marine environments during the Mesozoic Era. During the Jurassic, the plesiosaurian fossil record reveals a worldwide distribution and high level of morphological disparity (Benson, Evans and Druckenmiller, 2012). As with many other marine reptile groups, plesiosaur taxonomic diversity was heavily affected by eustatic sea-level changes during the Jurassic - Cretaceous transition (Tennant, Mannion and Upchurch, 2016), with the decline and replacement of some Jurassic clades by Xenopsaria (Benson and Druckenmiller, 2014). The Middle Jurassic - Early Cretaceous plesiosauroid family Cryptoclididae, is a species-rich clade primarily known from the Northern Hemisphere. The majority of the specimens derive from the Oxford and Kimmeridge Clay Formations of the UK. The recent recovery and description of numerous cryptoclidid specimens from the Slottsmøya Member Lagerstätte of the Agardhfjellet Formation (central Spitsbergen), now constitute a major component of overall Boreal plesiosaurian richness from the TithonianBerriasian interval (Benson and Druckenmiller, 2014; Roberts et al., 2017).

Cryptoclididae includes the subclade Colymbosaurinae Benson and Bowdler, 2014 and another clade yet to be formally named. Colymbosaurinae previously included all the described plesiosauroid taxa from the Slottsmøya Member (Djupedalia engeri, Spitrasaurus wensaasi, S. larseni, Colymbosaurus svalbardensis), in addition to Abyssosaurus nataliae, Pantosaurus striatus and Colymbosaurus megadeirus (Benson and Bowdler, 2014). As noted by Benson and Bowdler (2014), the cranial anatomy of cryptoclidids is poorly known and thus the diagnosis of Colymbosaurinae is based exclusively on postcranial characters. The new specimen described here, PMO 224.248, is significant in that it preserves a nearly complete cranium in association with a partial postcranium and represents a new genus and species of cryptoclidid plesiosaurian, Ophthalmothule cryostea. PMO 224.248 was excavated from Mt. Wiman in 2012 out the Slottsmøya Member of the Agardhfjellet Formation, from a part of the unit section encompassing the Jurassic - Cretaceous boundary. The specimen represents the fourth and youngest cryptoclidid 
61

genus described from the Slottsmøya Member and based on micro computed tomography ( $\mu \mathrm{CT})$ imaging, adds significant new data on the cranial anatomy of cryptoclidids and plesiosaurians in general. These data contribute to a revised phylogenetic hypothesis of cryptoclidids and shed light on plesiosaurian diversity at near the Jurassic - Cretaceous boundary.

\section{Geological Setting}

The Agardhfjellet Formation encompasses a thick succession of Middle Jurassic to Lower Cretaceous sedimentary rocks. The formation comprises four members; Oppdalen Member, Lardyfjellet Member, Oppdalsåta Member and the Slottsmøya Member. The Slottsmøya Member (Volgian) consists of dark-grey to black silty mudstone, which is often weathered into paper shale. There are discontinuous silty beds, with siderite concretions, in addition to siderite and dolomite interbeds. The Slottsmøya Member is overlain by the Lower Cretaceous Myklegardfjellet Bed, which defines the base of the Rurikfjellet Formation (Fig. 1A; Dypvik et al., 1991).

The Slottsmøya Member was deposited in an open marine environment under dysoxic conditions (Collignon and Hammer, 2012). These marine deposits represent deposition from the upper Tithonian (uppermost Jurassic) to the lower Berriasian (lowermost Cretaceous; Hammer, Collignon and Nakrem, 2012). The specimen (PMO 224.248) described here derives from the upper section of the Member (at $38.5 \mathrm{~m}$, estimated from the Janusfjellet log), which is increasingly condensed up section, making it difficult to precisely determine if this specimen derives from the uppermost Jurassic or lowermost Cretaceous (Fig. 1B). However, the seeps overlying the specimen in the stratigraphy are determined to be from the Early Cretaceous (Hryniewicz et al., 2012).

\section{Materials and Methods}

\section{Measurements}

Measurements were taken using a calliper or tape measure for longer measurements $(>15$ $\mathrm{cm}$ ), these are available in the supplementary information (Tables S.1-4). For some of the braincase elements that were obscured by matrix or another element, measurements were taken using the $\mu \mathrm{CT}$ scan images.

\section{«CT methodology}


89

90

91

92

93

94

100

101

102

103

104

105

106

107

108

109

110

111

112

113

114

115

116

117

The cranium, left mandible, eighth cervical vertebra and possible gut contents were scanned using $\mu$-Computer Tomography $(\mu \mathrm{CT})$ at the University of Oslo Natural History Museum (Økern Campus). Figures of the volume renderings of the complete posterior of the skull, lower jaw and $8^{\text {th }}$ cervical vertebra are shown in the supplementary materials (Figs. S.2, S.6). Due to the size limitations of the scanner, three separate scans of the cranium (posterior, middle and anterior of the cranium), were taken and then merged together to form a single high-resolution scan. For the cranium: a total volume of $7274887 \mathrm{~cm}^{3}$ was acquired using a Nikon XT H 225 ST desktop CT scanner, with a spatial resolution equal to a voxel size of $0.0753767 \mathrm{~mm}^{3}$. A $2 \mathrm{~mm}$ copper filter was utilised. For each scan, tomographic acquisition was performed under step rotation with an exposure time of $2000 \mathrm{~ms}$, the beam energy was $180 \mathrm{keV}$ and 3016 projections were taken over $360^{\circ}$. For the left mandible, two CT scans were performed and then merged, using the same settings as for the cranium. These consisted of 1583 projections taken over $360^{\circ}$, with an exposure time of $1000 \mathrm{~ms}$. The $8^{\text {th }}$ cervical vertebra was scanned with 3016 projections taken over $360^{\circ}$, with 1000 ms exposure, with the same settings as for the cranium.

Manual segmentation of the braincase was performed with the 3D analysis software Aviso Fire (V. 8.1) and Fiji (ImageJ) at the University of Southampton $\mu$-vis (Muvis) Digital Visualisation Laboratory. The automatic segmentation of the complete cranium was pre-processed with a growing algorithm developed by CB in MATLAB (V. 2016b). This eliminated some of the surrounding and internal matrix from the volume rendering using differences in density. A video of the complete volume rendered skull is available in the supplementary information. The complete raw data is available for download from Morphosaurce.org (P774).

\section{Permits}

The following permits were given by the Governor of Svalbard for the University of Oslo Natural History Museum excavations in 2007, 2010, 2011 and 2012: 2006/00528-13; RIS ID 3707; RIS ID: 4760 and 2006/00528-39.

\section{Institutional abbreviations}

CAMSM, Cambridge Sedgewick Museum, Cambridge, United Kingdom; NHMUK, Natural History Museum, London, United Kingdom; MGUH, Geological Museum, Copenhagen, Denmark; PETMG, Peterborough Museum and Art Gallery, United Kingdom; PMO, 
118 Palaeontology museum, Natural History Museum, Oslo, Norway; OUM, Oxford University 119 Museum, United Kingdom; SVB, Svalbard Museum, Norway; UW, University of Wyoming, 120 Wyoming, United States of America.

\section{Nomenclatural acts}

122 The electronic version of this article in Portable Document Format (PDF) will represent a 123 published work according to the International Commission on Zoological Nomenclature (ICZN), 124 and hence the new names contained in the electronic version are effectively published under that 125 Code from the electronic edition alone. This published work and the nomenclatural acts it contains 126 have been registered in ZooBank, the online registration system for the ICZN. The ZooBank 127 LSIDs (Life Science Identifiers) can be resolved and the associated information viewed through 128 any standard web browser by appending the LSID to the prefix http://zoobank.org/. The LSID for 129 this publication is: [LSID urn:1sid:zoobank.org:pub:3578E578-4724-45FE-8CEE130 C075D5C54F34]. The online version of this work is archived and available from the following 131 digital repositories: PeerJ, PubMed Central and CLOCKSS.

Sauropterygia Owen, 1860

Plesiosauria de Blainville, 1835

Plesiosauroidea Welles, 1934

Cryptoclididae Williston, 1925

Ophthalmothule gen. nov.

LSID urn:1sid:zoobank.org:act:63110850-0CAC-4DBA-99C2-7AC3B6B926DB

Diagnosis as for the species

Ophthalmothule cryostea $\mathrm{sp}$. Nov. 
145

146

147

148

149

150

151

152

153

154

155

156

157

158

159

160

161

162

163

164

165

166

167

168

169

170

171

172

173

(Figures 2-19)

Holotype: PMO 224.248

Occurrence: The holotype specimen PMO 224.248 was excavated from the north-facing slopes of Wimanfjellet (Mt. Wiman), from the upper part of the Slottsmøya Member, Agardhfjellet Formation, central Spitsbergen: GPS coordinates UTM 33X E523620 N8696396 (Fig. 1). The specimen was located $38.5 \mathrm{~m}$ above the yellow storm deposit marker bed ( $0 \mathrm{~m}$ in $\log )$, and is late Volgian (latest Tithonian/ early Berriasian) in age.

Etymology:_Ophthalmothule. Ophthalmo, meaning eye. Thule is a term used for the northern-most region of the world. Together they make "North eye". Species name, cryostea, meaning "frozen bones".

\section{Differential diagnosis}

A moderately sized cryptoclidid plesiosaur (estimated body length of 5.0-5.5 m), possessing the following autapomorphies unique among Cryptoclididae $(*)$ and unique character combinations: premaxilla bears 6 alveoli (5 in Tricleidus seeleyi and Muraenosaurus leedsii); medial process of premaxilla terminates anterior to the posterior margin of external naris $(*)$; maxilla estimated to contain a similar number of alveoli $(>16)$ as in in Cryptoclidus eurymerus (18)and Tricleidus seeleyi(15); frontal twice as anteroposteriorly long as parietal (subequal or shorter in Cryptoclidus eurymerus and Muraenosaurus leedsii); frontal participates in the medial and posterior margins of the external naris (participates posteriorly in Muraenosaurus leedsii); presence of an interfrontal vacuity (absent in Muraenosaurus leedsii); dorsoventrally low but mediolaterally narrow sagittal crest (flat and mediolaterally broad in Kimmerosaurus); quadrate articulates anterolaterally to the pterygoid (posteromedially in Tricleidus seeleyi and Muraenosaurus leedsii); lateral cotyle of quadrate larger than medial cotyle (reversed in Spitrasaurus larseni); basioccipital tubera mediolatteraly broad and dorsoventrally flattened (circular in Kimmerosaurus langhami and Cryptoclidus eurymerus); basioccipital tubera triangular in ventral view, following the anteromedial process of pterygoid anteriorly (cylindrical with finished bone anteriorly in Kimmerosaurus langhami); exoccipital does not contribute to occipital condyle (contributes in Kimmerosaurus langhami and Cryptoclidus eurymerus); posteromedian ridge on supraoccipital absent (present in Kimmerosaurus langhami and Muraenosaurus leedsii); 
174 palatine and vomer excludes maxilla from internal naris (maxilla participates in Muraenosaurus 175 leedsii); vomer excluded from anterior interpterygoid vacuity (participates in Muraenosaurus 176 leedsii and Cryptoclidus eurymerus); anteromedial process of pterygoid extends as far as the 177 parabasisphenoid (absent in Cryptoclidus eurymerus); dentary with a mediolaterally extended 178 alveolar surface and with laterally shifted, labially inclined alveoli (no mediolateral extension and alveoli positioned centrally in Tricleidus); deep glenoid facet of the mandible, constituting over half the dorsoventral height of the mandible (relatively shallow in Colymbosaurus spp., Cryptoclidus eurymerus and Kimmerosaurus langhami); retroarticular process slightly dorsally inclined (significantly inclined in Spitrasaurus larseni); faint longitudinal ridges on the teeth, distinct on labial side (distinct on lingual side in Muraenosaurus leedsii and Cryptoclidus eurymerus; ridging absent in Kimmerosaurus langhami); slightly recurved tooth crowns (significantly recurved in Spitrasaurus larseni and Kimmerosaurus langhami); mammilate hypophyseal eminence is present on the ventral surface of the atlas (ventral keel or keel-like morphology in Cryptoclidus eurymerus, Muraenosaurus leedsii and Tricleidus seeleyi); atlantal rib present (absent in Colymbosaurus megadeirus); 50 cervical vertebrae* (32 in Cryptoclidus eurymerus; 44 in Muraenosaurus leedsii; 41 in Colymbosaurus megadeirus; 60 in Spitrasaurus wensaasi); cervical centra are slightly amphicoelous (conspicuously concave in Djupedalia engeri and Kimmerosaurus langhami); cervical vertebra 8 with anteroposteriorly long postzygapophyses, close to the length of centrum (autapomorphic among Plesiosauria)*; anterior-most cervical neural spines low and posteriorly angled (straight in Kimmerosaurus langhami); cervical prezygapophyses unfused anteriorly and fused posteriorly (unfused throughout in Cryptoclidus eurymerus and completely fused in Spitrasaurus spp. and Djupedalia engeri); postzygapophyses fused along the midline (unfused in posterior-most cervicals in Djupedalia engeri); lateral ridges present on mid-posterior cervicals (absent in Colymbosaurus megadeirus, Cryptoclidus eurymerus, Djupedalia engeri, and Tricleidus seeleyi); posterior cervical - anterior dorsal ribs with a distinct, short ( $<$ half the rib length) longitudinal ridge along the dorsal surface of the rib*; dorsal vertebral rib facets dorsoventrally taller than wide (circular in Tatenectes laramiensis); dorsal process of scapula short and reduced (tall and extensive in Abyssosaurus nataliae and Djupedalia engeri); extended anteromedial process of coracoid (reduced in Colymbosaurus megadeirus and Abyssosaurus nataliae); humeri significantly larger than femora (femora larger than humeri in Djupedalia engeri, subequal in Colymbosaurus svalbardensis); sigmoid humerus in dorsal view, 
205

206

207

208

209

210

211

212

213

214

215

216

217

218

219

220

221

222

223

224

225

226

227

228

229

230

231

with the proximal end (capitulum) of the humerus angled anteromedially*; humeri with three to four distal articular facets (two in Cryptoclidus eurymerus and Muraenosaurus leedsii); radius slightly larger than ulna (anteroposteriorly shorter in Colymbosaurus svalbardensis).

\section{Taphonomy}

The skeleton of PMO 224.248 is well-preserved and fully articulated, with the exception of the skull, some dorsal vertebrae and distal phalangeal elements (Fig. 2). The skeleton had a ventral landing and the cranium drifted $20 \mathrm{~cm}$ from its original position, and the majority of the phalanges drifted from the limbs and were not preserved in articulation. The skeleton posterior of the sacral region was eroded, although a partial left hindlimb and femoral fragments were recovered.

The specimen preserves a near complete skull, although it is dorsoventrally crushed and damaged in places. The cranium could not be completely prepared from the matrix, as the bones where significantly fractured. The dorsal portions of the braincase were partly disarticulated due to the crushing, with the supraoccipital pushed down into the foramen magnum. The majority of the cervical vertebrae are missing portions of the right cervical rib and neural spines, due to crushing and/or pre-burial erosion. The posterior-most cervicals were disarticulated and crushed by the overlying pectoral girdle. The pectoral and anterior dorsal vertebrae are partly crushed and distorted by the overlying pectoral girdle. Most of the neural arches are missing from the dorsal vertebrae, as these were exposed to post-diagenetic erosional processes.

\section{Ontogeny}

PMO 214.248 is interpreted to be an adult based on its large size and presence of fused neurocentral sutures throughout the preserved vertebral column, in addition to the fusion of the cervical ribs to the centra (Brown, 1981). Other indicators of mature stage of are the fusion along the medial facet of the coracoids and well-formed distal facets of the humeri (Brown, 1981).

\section{Description and comparison with other cryptoclidid taxa}

\section{Cranium}

The temporal fenestrae are conspicuously small relative to the size of the orbits, being approximately $17 \%$ of total skull length, whereas the orbit constitutes approximately $29 \%$ of total 
232 skull length (Figs. 3-5). The tooth row extends about $75 \%$ of the total skull length. For selected

233 measurements of the cranium see supplementary information (Table S1).

\section{Premaxilla}

235 The premaxilla of Ophthalmothule cryostea forms the majority of the dorsal and lateral surfaces 236 of the rostrum anterior to the orbit (Fig. 3). As with all cryptoclidids (at least those few that 237 preserve cranial material), the rostrum is relatively short (Andrews, 1910; Brown and Cruickshank, 238 1994), having a preorbital to total skull length ratio of 0.43. Although this appears high in comparison to other cryptoclidids, it is due to relatively short post orbital region of the skull. Similar to Muraenosaurus leedsii, the dorsal surface of the premaxilla is rugose, forming numerous low and sharp crests, but significantly smoother than in Tricleidus seeleyi (Andrews, 1910). The premaxillae form a narrow ridge that extends along most of the rostral midline. The anterior portion of the premaxilla-maxilla suture is visible in dorsal view, extending from the rostral margin towards the external naris. The external nares of Ophthalmothule cryostea are positioned directly anterior to the orbital margin, being relatively more posterodorsally placed than in $M$. leedsii (Andrews, 1910; Brown, 1981). In O. cryostea, the dorsomedial process of the premaxilla, forms the anterior and anteromedial borders of the external naris. However, the process terminates anterior to the posterior margin of the external naris, representing an autapomorphy of this taxon among cryptoclidids. In Cryptoclidus eurymerus the morphology of this region is ambiguous in PETMG R.283.412, due to the preservation of the specimen; however, it has been reconstructed with the premaxillae excluded from most of the medial margin of the external naris by the frontal (Brown and Cruickshank, 1994). This morphology is not homologous with the condition where the anterior flange of the frontal, excludes the premaxilla from the external naris as in some rhomaleosaurids (Smith and Benson, 2014). In M. leedsii and Tricleidus seeleyi, the premaxillae form the medial margin of the external nares and either terminate at or continue past the posterior margin of the external nares (Andrews 1910; Brown, 1981). The $\mu$ CT scans of PMO 224.248 confirm that the premaxilla overlaps the anterior portion of the frontal and that this sutural contact lies approximately in line with the external naris, as in C. eurymerus (PETMG R.283.412; Andrews, 1910; Brown and Cruickshank, 1994). Furthermore, in Ophthalmothule cryostea the premaxilla-frontal suture is embayed anteriorly along the midline with the longest dimension of 
262 premaxilla taper posteriorly along the midline in C. eurymerus and M. leedsii (Andrews, 1910; 263 Brown and Cruickshank, 1994).

264

265

266

267

268

269

270

271

272

273

274

275

276

277

278

279

280

281

282

283

284

285

286

287

288

289

290

291

Among cryptoclidids the number of premaxillary alveoli varies between 5-8 teeth on each side (Brown, 1981). Based on $\mu \mathrm{CT}$ data (Fig. 4B), the premaxilla of Ophthalmothule cryostea has a total of six alveoli on each side, the same number as Cryptoclidus eurymerus (Brown and Cruickshank, 1994), but greater than that observed in Muraenosaurus leedsii, Tricleidus seeleyi and Vinialesaurus caroli (five: Brown, 1981; Gasparini et al., 2002) and less than that suggested for Kimmerosaurus langhami (minimum eight: Brown, 1981). The first and sixth alveoli are noticeably smaller in all dimensions than the other premaxillary alveoli, which are otherwise similar in size. The premaxillary-maxillary suture is visible in ventral view, just posterior to the sixth alveolus (Figs. 4-5).

\section{Maxilla}

The maxilla of Ophthalmothule cryostea forms the ventral rim and most of the anterior margin of the orbit. In dorsal view, the prefrontal-maxilla suture is equivocal due to significant breakage in this region. The lateral surface of the maxilla is lightly pitted and rugose, but not to the same extent as the premaxilla. In ventral view the alveoli are partially obscured by matrix, but can be counted using $\mu \mathrm{CT}$ images, showing a maximum of 16 alveoli on both sides when taking damage into account. This is less than Cryptoclidus eurymerus (18; Brown, 1981), but similar to other Oxford Clay Formation cryptoclidids (16 in Muraenosaurus leedsii; 15 in Tricleidus seeleyi; Brown, 1981). The maxillary alveoli vary only slightly in size and morphology, with the larger labiolingually expanded alveoli located more anteriorly and smaller, more rounded alveoli posteriorly. We interpret the slight asymmetry regarding maxillary alveolus size present in Ophthalmothule cryostea is likely due to variation in tooth replacement stage. This morphology differs from T. seeleyi, where clear anisodonty is present (Brown, 1981). As in C. eurymerus (PETMG R.283.412), the posterior extent of the maxillary tooth row in Ophthalmothule cryostea terminates in line with the position of the postorbital bar and is positioned considerably higher than the glenoid fossa in lateral view.

Ventrally, the maxilla approaches and nearly contributes to the margin of the internal naris, but is excluded by the palatine-vomer contact, similar to Cryptoclidus eurymerus (Andrews, 1910). This morphology differs from Muraenosaurus leedsii where the premaxilla and maxilla contribute 
292 to the anterior and lateral margins of the internal naris respectively (Andrews, 1910; Brown and 293 Cruickshank, 1994).

\section{Prefrontal}

295 The region anterior to the orbit in PMO 224.248 is difficult to interpret, due to poor preservation. 296 There are two possible sutures that could represent the lateral and medial margins of a prefrontal, 297 with the position of these sutures confirmed by differences in bone orientation using $\mu \mathrm{CT}$ images 298 (Supplementary Information, Fig. S.1). Using these margins, the prefrontal would be constrained to a small wedge-shaped section directly anterior to the orbital rim, separated from the external naris by a dorsal process of the maxilla. The element is thickened along the orbital margin and posterodorsally overlaps the frontal in a pointed process. The prefrontal is rarely described in Callovian cryptoclidids, with the exception of Muraenosaurus leedsii (Andrews, 1910; Brown, 1981). This has been attributed to either poor preservation of this area in most specimens, or because the element is indiscernible due to fusion with the maxilla (Brown, 1981; pers. obs. PSD).

\section{Frontal}

306

307

In Ophthalmothule cryostea, the anteroposterior length (measured along the midline) of the frontal is 2.3 times longer than the length of the parietal, whereas in other taxa the relative lengths are nearly the same (= 0.9 Cryptoclidus eurymerus PETMG R.283.41; = 1 Cryptoclidus eurymerus NHMUK R2860; = 0.8 Muraenosaurus leedsii using Andrews, 1910; = 1.4 Tricleidus seeleyi NHMUK R3539). Anteriorly, the frontal participates in the medial and posterior margins of the external naris. In $M$. leedsii, the frontal participates in the margin of the external naris, but lacks the same degree of anterior extension seen in Ophthalmothule cryostea (Andrews, 1910). As in $M$. leedsii, the greatest mediolateral width of the frontal occurs directly in line with the anterior margin of the orbit, in contrast to C. eurymerus where this occurs more posteriorly along the middle orbital margin (Andrews, 1910; Brown and Cruickshank, 1994). At the point of articulation with the parietal the mediolateral width of the element is roughly a third of the maximum mediolateral width. Along the dorsal margin of the orbit, the frontal has a concave margin, differing considerably from the straight frontal margin of Muraenosaurus specimens (M. leedsii; NHMUK R.2678) and from C. eurymerus, where it is convex (C. eurymerus; PETMG R.283.412). The relationships of the postfrontal and postorbital to the skull roof are not preserved. 
321

322

323

324

325

326

327

328

329

330

331

332

333

334

335

336

337

338

339

340

341

342

343

344

345

346

347

348

349

The frontals form a long, slit-like interfrontal vacuity at their mid-length. At their anteriorand posterior-most ends (adjoining the premaxillary and parietal contacts, respectively), the frontals are fully in contact and fused along the midline. However, along the remainder of their length they lack a firm midline contact and enclose a narrow and elongate slit-like opening, referred to here as the interfrontal vacuity. This vacuity is not homologous to the "frontal foramen" observed near the anterior margin of the frontal in some polycotylids, which is not located along the midline (Carpenter, 1996; Fischer et al., 2018). However, this vacuity does bear some resemblance to the dorsomedian frontal foramen described in Brancasaurus brancai (Sachs, Hornung and Kear, 2016). The most conspicuous development of the interfrontal vacuity occurs in the anterior half of the frontals where it can be recognised by having smooth, finished bone medially and a slight concavity following the midline. An interfrontal vacuity is also clearly present in several other cryptoclidids (e.g. Kimmerosaurus langhami; Tatenectes laramiensis; Tricleidus seeleyi; possibly Cryptoclidus eurymerus) and could represent a new synapomorphy for a subclade of Cryptoclididae (see Discussion). The dorsal surface of the frontal in PMO 224.248 is generally smooth, but is textured with a few small indentations adjacent to the interfrontal vacuity.

The morphology of the ventral surface of the frontal in Ophthalmothule cryostea is visible in the $\mu \mathrm{CT}$ images and tapers medially in cross section. On the ventral surface of the frontal in Kimmerosaurus langhami, Cryptoclidus eurymerus and Muraenosaurus leedsii a trough is present on either side of the interfrontal vacuity or frontal midline. In K. langhami these are clearly seen, starting posteriorly in line with the pineal foramen and terminate at the preserved anterior end of the frontal (pers. obs. AJR, NHMUK R8431). These structures are absent in Tricleidus seeleyi (NHMUK R3539) and in O. cryostea based on the $\mu \mathrm{CT}$ images.

The frontal-parietal suture is somewhat obscured in dorsal view due to gypsum mineralization and the presence of rugosities in the anterior portion of the parietal. However, $\mu \mathrm{CT}$ images show that the posterior margin of the frontal interdigitates with the anterior margin of the parietal and that the frontal envelopes the anterior rim and most of the lateral rims of the pineal foramen (Fig. 6).

\section{Parietal}


350 The anterior extent of the parietal lies approximately in line to the level of the temporal bar. In

351 dorsal view, the parietal bears a mediolaterally narrow sagittal crest that is slightly flattened

352 dorsally, exhibiting an intermediate condition between the tall and sharp crest seen in Tricleidus

353 seeleyi, Muraenosaurus leedsii and Cryptoclidus eurymerus (Brown, 1981; Brown and

354 Cruickshank, 1994) and the broad, flat sagittal crest seen in Kimmerosaurus langhami (Brown,

355 1981). In lateral view, the apex of the sagittal crest is straight and gently inclines posterodorsally.

356 In contrast, this morphology differs from the dorsally convex sagittal crest seen in C. eurymerus.

357 The squamosal-parietal contact is indiscernible.

358

359

360

361

362

363

364

365

366

367

368

369

370

371

372

373

374

375

376

377

The $\mu \mathrm{CT}$ images reveal the presence of two large dorsoventrally oriented fossae in the parietals that open onto the posteroventral surface, but do not extend to the dorsal surface (Fig. 6). This feature is also present in another undescribed Slottsmøya Member cryptoclidid (PMO 212.662). In Kimmerosaurus langhami (NHMUK R.8431), these parietal fossae are likely absent, as they are not visible on the ventral surface (Brown, 1981). In Cryptoclidus eurymerus (NHMUK R.2860) and Muraenosaurus leedsii (NHMUK R.2422) the parietals are partly obscured by the supraoccipital and parietal fossae cannot be identified. Although the function of these fossae is currently unclear, CT scanning of additional specimens could infer whether this is a cryptoclidid feature or more constrained to a specific clade.

\section{Squamosal}

In lateral view, the suspensorium is near vertically inclined, although the dorsal half of the squamosal dorsal ramus is inflected abruptly anteriorly (supplementary information, Fig. S.2). The squamosal bears a dorsoventrally tall anterior ramus which curves slightly medially, following part of the anterior margin of the temporal fenestra. The ventromedial process of the squamosal is short, extending ventrally to roughly half the dorsoventral length of the quadrate shaft. The dorsal margin of the squamosal-quadrate suture is visible in posterior view, where a small groove is present (Fig. 7). However, this suture could not be located dorsally in $\mu \mathrm{CT}$ scan images (supplementary information 6, Fig. S.2). The relationships between the squamosal and the jugal and postorbital cannot be discerned due to poor preservation in this area.

\section{Quadrate}

Peer] reviewing PDF | (2019:04:37185:2:0:NEW 17 Jan 2020) 
378 Due to a fracture running along the middle of the right quadrate, the left quadrate is better 379 preserved. Similar to Djupedalia engeri and Kimmerosaurus langhami, the lateral cotyle of the

380

381

382

383

384

385

386

387

388

389

390

391

392

393

394

395

396

397

398

399

400

401

402

403

404

405

406

quadrate condyle in Ophthalmothule cryostea is slightly larger in anteroposterior length and dorsoventral extent than the medial cotyle (Brown, Milner and Taylor, 1986; Knutsen, Druckenmiller and Hurum, 2012a). This differs from Spitrasaurus larseni, where the opposite state is present (Knutsen, Druckenmiller and Hurum, 2012b). There is no indication of a quadrate foramen.

\section{Basioccipital}

The anterior and dorsal surfaces of the basioccipital of Ophthalmothule cryostea are obscured by matrix and other skull elements, but can be described fully using the $\mu \mathrm{CT}$ segmentation (Fig. 8). The occipital condyle lacks both a notochordal pit and a constriction on the dorsal and ventral surfaces; however, a slight constriction is visible on the lateral surfaces. As in Spitrasaurus larseni, the exoccipital facets reach, but do not contribute to the occipital condyle (Knutsen, Druckenmiller and Hurum, 2012b). In contrast, the exoccipitals in Kimmerosaurus langhami and in some specimens of Cryptoclidus eurymerus form a portion of the condyle (Andrews, 1910; Brown, 1981). In posterior view, the condyle is mediolaterally wider than dorsoventrally tall. The heightto-width ratio $(\mathrm{H} / \mathrm{W})$ of the condyle $(\sim 0.82)$ is comparable to that of Spitrasaurus larseni $(0.8)$ and Kimmerosaurus langhami (0.85) (Knutsen, Druckenmiller and Hurum, 2012b), but differ from Muraenosaurus leedsii and T. seeleyi that possess more circular condyles (H/W $\sim 1)$.

Similar to Tricleidus seeleyi and another undescribed Slottsmøya Member cryptoclidid specimen (PMO 212.662), the basioccipital tubera of Ophthalmothule cryostea are dorsoventrally flattened and triangular in general outline as seen in ventral view and their ventral surfaces are gently concave in occipital view (supplementary information, Fig. S.2). The entire anterolateral margin of the tubera meet and extend parallel to the pterygoid extending to the basisphenoid margin. This morphology contrasts to the pillar-like (circular in cross section) and laterally-facing tubera in Cryptoclidus eurymerus and Kimmerosaurus langhami (Andrews, 1910; Brown, 1981). In addition to this morphology, K. langhami displays finished bone along the anterolateral basioccipital margin between the basisphenoid facet and tubera (Brown, 1981; Brown and Cruickshank, 1994).

Peer] reviewing PDF | (2019:04:37185:2:0:NEW 17 Jan 2020) 
The posterior floor of the foramen magnum is visible, forming part of a shallow but

408

409

410

411

412

413

414

415

416

417

418

419

420

421

422

423

424

425

426

427

428

429

430

431

432

433

434

435

436 mediolaterally broad concavity between the two exoccipital-opisthotics. Anteriorly, there is a low anteroposteriorly oriented ridge that terminates near the contact with the basisphenoid (Fig. 8B). Two paired foramina open on to the dorsal surface of the basioccipital and extend into the body of the element, where they are visible in the $\mu \mathrm{CT}$ images, but terminate before reaching the ventral surface. Similar to Kimmerosaurus langhami, the ventral surface of the basioccipital is relatively flat, with a short anteroposteriorly oriented median ridge that terminates at the rim of the anterior margin (Brown, 1981).

\section{Parabasisphenoid}

The demarcation between the parasphenoid and basisphenoid of PMO 224.248 is indiscernible. In dorsal view on the posterior margin of the body of the parabasisphenoid, a small fossa is present along the suture with the basioccipital ('dmp', Fig. 8A). This structure appears homologous with the "dorsal median pit" described in Muraenosaurus leedsii (Andrews, 1910), hypothesised to mark the embryonic basicranial fenestra. However, the foramen present in PMO 224.248, is significantly reduced in comparison to M. leedsii (Andrews, 1910). A deep fossa is present on the anterior margin of the basisphenoid body interpreted to be the pituitary (or hypophyseal) fossa, similar to that described in Tricleidus seeleyi, Kimmerosaurus langhami and M. leedsii (Andrews, 1910; Brown, Milner and Taylor, 1986). The ventral floor of the pituitary fossa, including parts of both the basisphenoid and parasphenoid (Andrews, 1910), is missing likely due to taphonomic loss. In lateral view the internal carotid foramen is visible opening into the pituitary fossa (not visible on right). In dorsal view on the posterior margin of the parabasisphenoid, a small fossa is present along the suture with the basioccipital. In palatal view, the basal articulation of plesiosauroids is often visible in ventral view through the posterior interpterygoid vacuity (Buchy, Frey and Salisbury, 2006). In PMO 224.248, the basal articulation is visible on the $\mu C T$ scans and is better preserved on the left side and positioned dorsally in respect to the rest of the palate

The parabasisphenoid appears to bear posterolaterally located facets for the anteromedial process of the pterygoid similar to Tricleidus seeleyi, but in contrast to Muraenosaurus leedsii and Cryptoclidus eurymerus where the pterygoid simply articulates to the basioccipital tuber (Andrews, 1910; Brown, 1981). In T. seeleyi, the pterygoid facets of the parabasisphenoid are circular in outline and are slightly anterolaterally projecting, whereas in PMO 224.248 the facet 
437 surface appears uniform and triangular in shape in the $\mu \mathrm{CT}$ images. The presence of a pterygoid

438 facet on the body of a parabasisphenoid is also present in another Slottsmøya Member cryptoclidid 439 (PMO 212.662) and has been suggested to be present in Kimmerosaurus langhami (NHMUK 440 R10042; Benson and Druckenmiller, 2014: Appendix S2). That a minimum of three cryptoclidid 441 taxa share this palatal configuration over a long temporal span (Callovian - Volgian), suggests that 442 this morphology is more widespread in cryptoclidids than previously believed.

443 Anteriorly, the parabasisphenoid is very thin and somewhat damaged, making this region 444 difficult to segment out of the $\mu \mathrm{CT}$ images. The anterior portion (parasphenoid) appears to separate 445 the pterygoids along the midline and forms the entire posterior margin of the anterior 446 interpterygoid vacuity, although it seemingly lacks a projecting cultiform process, like that seen in 447 some polycotylids and basal plesiosaurians (Buchy, Frey and Salisbury, 2006; Carpenter, 1996; 448 O'Keefe, 2001; Vincent and Benson, 2012). The anterior margin of the posterior interpterygoid 449 vacuity is formed by a lateral extension of the parabasisphenoid.

450

451

452

453

454

455

456

457

458

459

460

461

462

463

464 465

\section{Exoccipital-opisthotic}

Both exoccipital-opisthotics are preserved in partial articulation, but are damaged and displaced venterolaterally due to compression. As only the posterior view of these elements is visible on the specimen (Fig. 7), the following description is largely based on $\mu \mathrm{CT}$ images (Fig. 9).

The body of the exoccipital-opisthotic in Ophthalmothule cryostea is dorsoventrally taller than mediolaterally wide. In posterior view, the paraoccipital process is visible extending laterally from the body of the element. The cross-sectional shape of the paraoccipital process shaft is dorsoventrally taller than wide. Similar to Muraenosaurus leedsii, the length of the paraoccipital process is close to the dorsoventral height of the exoccipital, in contrast to Tricleidus seeleyi and Djupedalia engeri, which have more elongate paraoccipital processes (Andrews, 1910; Brown, 1981; Knutsen, Druckenmiller and Hurum, 2012a). As in Kimmerosaurus langhami and Cryptoclidus eurymerus, the paraoccipital process is expanded distally where it contacts the squamosal (Brown, 1981).

63 On the medial surface, a large anteroposteriorly oriented cavity is present at the centre of the exoccipital-opisthotic body. Although the structure is distorted, it may represent the recess for the utriculus as described for Muraenosaurus leedsii and Tricleidus seeleyi (Andrews, 1910). Two 
466 semicircular canal openings are visible in medial view: a dorsally orientated vertical posterior 467 semicircular canal and a horizontal anterior semicircular canal. The posterior vertical semicircular 468 canal is positioned just anterior to the supraoccipitial facet and runs ventrally into a cavity 469 interpreted to be for the utriculus, similar to Kimmerosaurus langhami and Cryptoclidus eurymerus 470 (Andrews, 1910; Brown, 1981). The horizontal anterior semicircular canal is located directly ventral to most of the prootic facet and opens posteriorly into the utricular cavity.

In lateral view (Fig. 9B), a large foramen could either be for the exit for cranial nerve $\mathrm{X}$, or may be formed of multiple cranial nerve openings which have merged due to crushing. The posterior portion of the fenestra ovalis is located along the anterior margin of the exoccipital, ventral to anterior horizontal canal and the prootic facet.

\section{Supraoccipital}

477 The supraoccipital remains in articulation with the parietal, but has rotated anteriorly so that its posterior surface faces dorsally. The element is anteroposteriorly thickest at the exoccipitalopisthotic facet and thins dorsally. Compared to the relative dorsoventral height of the exoccipitalopisthotic, the supraoccipital contributes roughly half of the total height of the foramen magnum. The foramen magnum appears to be oval in shape, unlike the more hour-glass outline seen in Kimmerosaurus langhami (Brown, Milner and Taylor, 1986). Ophthalmothule cryostea lacks a posteromedian ridge on the supraoccipital, as seen in K. langhami and Muraenosaurus leedsii (Brown, Milner and Taylor, 1986). A small foramen located on the midline of the dorsal border with the parietal, a feature that is also present in C. eurymerus (Brown, 1981, Fig. 2), but notably absent in M. leedsii and possibly K. langhami (Brown, 1981; Brown, Milner and Taylor, 1986; pers. obs. AJR, NHMUK R.10042).

\section{Prootic}

Two crushed and slightly disarticulated elements visible anterior to the exoccipital-opisthotics in warrant further description. 
493 The anterior extent of the vomers in Ophthalmothule cryostea (PMO 224.248) is unclear, however 494 they are mediolaterally narrowest anteriorly (Fig. 4). Posterior to the internal nares, the vomer

495

496

497

498

499

500

501

502

503

504

505

506

507

508

509

510

511

512

513

514

515

516

517

518

519

520

521

522

expands in mediolateral width, becoming broadest near their posterior margin, similar to that observed in Muraenosaurus leedsii (Andrews, 1910). The left and right vomers are in full contact along the midline, though unfused and the ventral surface is convex and lacks ornamentation. This differs from the clear fusion seen in Vinialesaurus caroli (Gasparini, Bardet and Iturralde-Vinent, 2002) and partial fusion and ridged ventral surface in an undescribed juvenile Callovian cryptoclidid specimen (pers obs. AJR, NHMUK R 2853). As in most other cryptoclidids, the vomer forms the medial and at least part of the anterior border (Andrews, 1910). As in some other plesiosauroids that preserve this region (e.g. M. leedsii; Andrews, 1910), the vomers have posterolaterally expanded margins that partially lie ventral to the palatines, an orientation confirmed by the $\mu \mathrm{CT}$ images in cross section. The posterior contact with the pterygoids consists of an interdigitating suture. The vomer forms the anterior border of the anterior interpterygoid vacuity, in contrast to M. leedsii and Cryptoclidus eurymerus where the pterygoids meet anteriorly along the midline and exclude the vomer from participation in margin of the anterior interpterygoid vacuity (Andrews, 1910; Brown and Cruickshank, 1994).

\section{Palatine}

The palatine of Ophthalmothule cryostea form the posterolateral border of the internal naris (Fig. 4). As is typical of cryptoclidids, the palatines do not meet anteriorly along the midline, but are separated anteriorly by the vomer (Buchy, Frey and Salisbury, 2006). Similar to Cryptoclidus eurymerus and Muraenosaurus leedsii a suborbital fenestra is absent (Andrews, 1910; Brown and Cruickshank, 1994). The posterior margin of the palatine is presumed to terminate at the anterior margin of the ectopterygoid, although it is difficult to discern the nature of this contact due to poor preservation in this area. The ectopterygoid area lacks a boss or flange of the pterygoid.

\section{Pterygoid}

The pterygoid of Ophthalmothule cryostea is mediolaterally narrow anteriorly and gradually increases in width posteriorly, as in Cryptoclidus eurymerus and Muraenosaurus leedsii (Andrews, 1910; Brown, 1981; Brown and Cruickshank, 1994). The anterior region of the pterygoids is separated along the midline, by a prominent and mediolaterally broad anterior interpterygoid vacuity (Fig. 4). The mediolaterally broad morphology of the anterior pterygoid vacuity is similar

Peer) reviewing PDF | (2019:04:37185:2:0:NEW 17 Jan 2020) 
523 to Tricleidus seeleyi and does not narrow anteriorly to the same degree as in Muraenosaurus leedsii 524 (Andrews, 1910).

525 The pterygoid forms the lateral margins of the posterior interpterygoid vacuity, which is 526 anteroposteriorly short compared to Cryptoclidus eurymerus and Muraenosaurus leedsii 527 (Andrews, 1910; Brown, 1981). The pterygoids do not meet along the midline posterior to the 528 posterior interpterygoid vacuity, as is the case in some polycotylids and leptoclidids (e.g. 529 Edgarosaurus muddi, Umoonasaurus demoscyllus; Druckenmiller, 2002; Kear, 2006). The 530 posterior interpterygoid vacuity is located entirely posterior to the anterior margin of the 531 subtemporal fossa, as in Tricleidus seeleyi (Andrews, 1910).

As in Tricleidus seeleyi, the pterygoid bears a narrow, prong-like anteromedial process 533 (basisphenoid process of the pterygoid; Andrews 1910) that contacts the parabasisphenoid. The anteromedial process parallels the anterolateral margin of the basioccipital, but does not form a distinct facet for it. The anteromedial process in Ophthalmothule cryostea is similar in relative length to that of $T$. seeleyi; however, it differs from $T$. seeleyi in being anteromedially curved rather than straight and greater in dorsoventral height (based on CT imaging) in lateral view (Andrews, 1910).

The quadrate ramus of the pterygoid deflects posterolaterally towards the pterygoid ramus of the quadrate and is dorsoventrally taller than wide. The pterygoid forms a broad medially facing facet for the quadrate, similar to Kimmerosaurus langhami (Brown, 1981).

\section{Mandible}

Each mandibular ramus is disarticulated from the cranium of PMO 224.248 and the anterior portions of each are missing, including the symphyseal region (Fig. 10). Based on corresponding measurements from the upper jaws, the left mandible lacks the anterior $10.5 \mathrm{~cm}$ of the ramus, providing an estimated total mandibular length of $27 \mathrm{~cm}$.

The left mandible, which is more complete and the basis for the following description, preserves the dentary, splenial, angular, surangular and articular (see supplementary information Fig. S.3). The Meckalian canal is visible on the left mandible, suggesting that the prearticular and splenial are damaged. A disarticulated element either representing the prearticular or splenial is 
552 facet or suture on the surangular for the coronoid, as seen clearly in Tricleidus seeleyi (Andrews, 553 1910; Brown, 1981).

554 In dorsal view, the alveolar row is laterally positioned relative to the parasagittal long axis 555 of the ramus, resulting in a mediolaterally expanded dorsal portion of the dentary that preserves 556 fourteen alveoli (inferred from $\mu \mathrm{CT}$ images). The alveoli are strongly labially angled $\left(\sim 60^{\circ}\right.$ from 557 the parasagittal plane), which increases slightly anteriorly. This differs from the more dorsally558 directed alveoli in Tricleidus seeleyi (Andrews, 1910). In dorsal view, only a couple of the primary 559 alveoli for the replacement teeth are visible, as these are partially covered by matrix. The 560 mediolateral expansion of the dentary preserves finished bone medial to the alveoli, contributing 561 to at least a third of the lateromedial width of the dentary dorsal surface. Ventrally, the mediolateral 562 expansion abruptly decreases in width. In cross section, the anterior portion of the element (at the 563 mid-point of the dentary) is subtriangular due to the expanded mandibular dorsal surface. Similar 564 expanded mediolateral dorsal surfaces are also observed in Spitrasaurus larseni, Djupedalia 565 engeri and Muraenosaurus leedsii (Andrews, 1910; Knutsen, Druckenmiller and Hurum, 2012a; Knutsen, Druckenmiller and Hurum, 2012b). In Kimmerosaurus langhami a mediolaterally expansion of the dentary is present in one of the referred specimens (pers. obs. AJR, NHMUK R.10042), but it appears absenton the holotype specimen (Brown 1981). This morphology differs from the other taxa, where a mediolateral expansion is either missing entirely (Tricleidus seeleyi), or a lateral expansion is only present on the posterior half of the dentary (Cryptoclidus eurymerus; 'Picrocleidus' beloclis) and lacks the abrupt ventral constriction observed in Ophthalmothule cryostea, S. larseni and Muraenosaurus leedsii (Andrews, 1910; Brown, 1981; Knutsen, Druckenmiller and Hurum, 2012b). This feature is proposed as a new phylogenetic character (see Discussion).

The lateral surface of the dentary is gently striated. Dorsomedially, a partial suture between the splenial and dentary is visible. Posteriorly, there is no clear suture between the dentary and surangular. The angular-surangular suture is partly visible in lateral and medial views. In Kimmerosaurus langhami and Cryptoclidus eurymerus the ventral margin of the angular is convex ventral to the glenoid, becoming concave anteriorly along the ventral margin (Brown, 1981; Brown and Cruickshank, 1994). This morphology is reduced in PMO 224.248 and Tricleidus seeleyi, 
582 articular (Andrews, 1910; Brown, 1981). The surface of the glenoid is slightly undulated 583 posteriorly and dorsoventrally deep, being over half the dorsal-ventral height of the mandible. This 584 is distinct from the shallow and smooth articular facet of Colymbosaurus, Cryptoclidus eurymerus, 585 Muraenosaurus leedsii and Kimmerosaurus langhami (Brown, 1981; Roberts et al., 2017).

In Ophthalmothule cryostea, the retroarticular process is uniform in dorsal-ventral thickness until it reaches the posterior terminus. Similar to Kimmerosaurus langhami (Brown, 1981), The retroarticular process is nearly twice as long as it is dorsoventrally tall, in contrast to the even longer than tall retroarticular process in Spitrasaurus larseni (Knutsen, Druckenmiller and Hurum, 2012b) and Muraenosaurus leedsii (Andrews, 1910). The process is dorsally inclined at $\sim 15^{\circ}$ with respect to the longitudinal axis of the mandibular ramus. This is significantly less than the in strong inclination seen in $S$. larseni $\left(35^{\circ}\right)$ and greater than Colymbosaurus indet. (OUM J. $\left.3300 ; 9^{\circ}\right)$ and Tricleidus seeleyi $\left(10^{\circ}\right.$; Brown, 1981). A mediolateral deflection of the retroarticular process is absent.

\section{Dentition}

596 Eight partial to complete but displaced teeth, along with several fragments were found adjacent to the anterior region of the skeleton. Fully erupted teeth are absent in all of the dentigerous portions preserved in PMO 224.248, but several unerupted replacement teeth are visible in situ on the $\mu \mathrm{CT}$ images. The individual teeth vary slightly in size, but not morphology, indicating that the minor size difference represents stages of tooth replacement and not anisodonty as suggested by the alveoli. The crowns are gracile in comparison to the more robust teeth in Tricleidus seeleyi and Cryptoclidus eurymerus (Brown 1981). The largest and most complete tooth preserved (Fig. 11A), measures $\sim 4 \mathrm{~cm}$ in length from apex of the crown to the root. In axial (mesial/distal) view, the complete tooth (Fig. 11A), is lingually curved along the crown, straightens at the start of the root and terminates in a slightly lingually curved root terminus. This morphology differs from the significantly lingually curved teeth of Kimmerosaurus langhami (75º; Brown, 1981) and Spitrasaurus larseni Knutsen, Druckenmiller and Hurum, 2012b). The enamelled crown represents a third of the total length of the tooth and displays a gradual transition to the root. A smaller, but fractured tooth (Fig. 11B-E), bears fine longitudinal ridges on the enamel, which gradually fades towards the apex. The ridging is most prominent on the labial side, unlike the prominently lingually ridged teeth of Muraenosaurus leedsii and Cryptoclidus eurymerus (Brown, 
612 1981). On some teeth, the mesial or distal margin of the crown bears a more pronounced enamelled 613 ridge. This ridge could represent the edge of a partial wear facet, as it has no distinct shared 614 morphology between teeth and has a variable presence on the preserved tooth crowns 615 (supplementary information, Fig. S.5). Close to the tip of the crown, the labial side is flattened 616 compared to the convex lingual surface resulting in a D-shaped cross section, similar to 617 Kimmerosaurus langhami, Spitrasaurus larseni and some elasmosaurids (Brown, 1981; Knutsen, 618 Druckenmiller and Hurum, 2012b; Sato, Hasegawa and Manabe, 2006). This morphology differs 619 from the more oval-shaped cross section in M. leedsii and C. eurymerus (Brown 1981). The shaft 620 of the root is subcircular in cross section and slightly expanded in diameter at the start of the crown, 621 by a gently undulating surface that decreases in width towards the root. One of the teeth 622 (supplementary information, Fig. S.5), has a clear reabsorption facet on the lingual side of the root. 623 The root is straight and abrupt, whereas other cryptoclidids show a more gradual reduction in 624 diameter at the root (e.g. K. langhami and C. eurymerus; PETMG R.283.412).

\section{Axial skeleton}

626 Fifty cervical vertebrae are preserved in PMO 224.248, including the atlas-axis complex. This is 627 greater than in Callovian cryptoclidids (Cryptoclidus eurymerus, 32: Brown, 1981; 628 Muraenosaurus leedsii, 44: Brown, 1981) and some Tithonian - Early Cretaceous taxa 629 (Colymbosaurus megadeirus, 41: Benson and Bowdler, 2014; Abyssosaurus, 44-51: Berezin, 630 2011; Djupedalia engeri, >40: Knutsen, Druckenmiller and Hurum, 2012a). PMO 224.248 631 preserves fewer cervical vertebrae than that described in Spitrasaurus wensaasi (60; Knutsen, 632 Druckenmiller and Hurum, 2012b). In total, the neck of PMO 224.248 is estimated to be 633 approximately $2 \mathrm{~m}$ in length including the preserved intervertebral spacing prior to preparation. 634 Selected measurements from the axial skeleton can be found in the supplementary information, 635 (Table S2).

636 Atlas-axis

637 Reflecting the advanced ontogenetic status of PMO 224.248, the atlas-axis complex is completely 638 fused; however, part of the suture between the atlas and axis centrum remains visible (Fig. 12). 639 The complex is approximately twice as anteroposteriorly long as mediolaterally wide, whereas in 640 Spitrasaurus larseni and Colymbosaurus megadeirus, the complex is only slightly 
641 anteroposteriorly longer than wide (Benson and Bowdler, 2014; Knutsen, Druckenmiller and 642 Hurum, 2012b). The long and narrow morphology of the atlas-axis in Ophthalmothule cryostea is 643 more similar to that of Muraenosaurus leedsii and some elasmosaurids, such as Aristonectes 644 parvidens (Andrews, 1910; Brown, 1981; Gasparini et al., 2003).

645 In anterior view, the atlantal cup is concave and subcircular in outline. In the absence of a 646 visible suture, it is not possible to confirm atlantal centrum (odontoid) participation in the ventral 647 portion of the atlantal cup, a feature common in cryptoclidids, including Colymbosaurus 648 megadeirus and Spitrasaurus (Benson and Bowdler, 2014; Knutsen, Druckenmiller and Hurum, 649 2012b). Ventrally, the atlantal intercentrum forms a low anteroventrally directed hypophyseal 650 eminence, similar to C. megadeirus, Abyssosaurus nataliae and Spitrasaurus (Benson and 651 Bowdler, 2014; Berezin, 2011; Knutsen, Druckenmiller and Hurum, 2012b), that is positioned in 652 the anterior half of the element, although this is positioned more centrally in C. megadeirus 653 (Benson and Bowdler, 2014). This morphology differs from the ventral keel formed by the ventral 654 surface of the atlas present in the Oxford Clay Formation cryptoclidids (Andrews, 1910) and 655 Cretaceous elasmosaurids; (Gasparini et al., 2003).

As in most cryptoclidids (with the exception of Colymbosaurus megadeirus) an atlantal rib is present and is set posteriorly on the atlas centrum (Benson and Bowdler, 2014). The axial rib is single-headed and occupies most of the ventrolateral length of the axial centrum, where it is fused. This differs from C. megadeirus, where the axial rib is borne partly on the posterolateral portion of the atlantal centrum (Benson and Bowdler, 2014). The ventral surface of the axis is generally concave, with a rounded, low and anteroposteriorly orientated ridge running from the anterior edge of the axis. The neural arch of the atlas-axis complex is fused and bears a dorsoventrally short, but anteroposteriorly elongate neural spine.

664

\section{Cervical vertebrae (3-50)}

The articular surfaces of the centra are weakly amphicoelous, although not to the degree of concavity observed in Kimmerosaurus langhami (Brown, Milner and Taylor, 1986). The anterior cervical vertebrae are mediolaterally wider than anteroposteriorly long (supplementary information, Table S2). This relationship shifts gradually in the mid-cervical region as the length to width ratio steadily decreases posteriorly. The posterior cervical vertebrae $(\sim 35-50)$ are mediolaterally wider than anteroposteriorly long, unlike the more equal dimensions seen in 
671 Cryptoclidus eurymerus (Andrews, 1910) and a partial cryptoclidid specimen from Greenland 672 (MGUH 28378; Smith, 2007).

673 The lateral surfaces of the anterior centra are conspicuously concave, becoming more 674 convex posteriorly in the series (Fig. 13). A structure that could represent a lateral ridge is present 675 in some of the mid-posterior cervical vertebrae in Ophthalmothule cryostea and is visible in the 676 cervical vertebrae 32-38 (Fig. 14). This should not be confused with the raised convex dorsal 677 margin of the rib facet, which is present in most of the cervical vertebrae. This transverse ridge 678 crosses the lateral surface of the centrum, positioned in between the neural arch pedicles and rib 679 facet. A lateral ridge may have been present in more anterior/posterior vertebrae, but cannot be 680 unambiguously identified due to the preservation. In Spitrasaurus, a lateral ridge is present 681 throughout most of the cervical series, located dorsal to the cervical rib facet (Knutsen, Druckenmiller and Hurum, 2012b). The ventral surface of the anterior - middle cervical vertebrae bear paired foramina separated by a sharp ridge in the anterior cervicals, which disappears posteriorly in the series. The presence of a ventral ridge is shared with some cryptoclidids (e.g., Tricleidus seeleyi; Andrews, 1910), but is completely absent in Colymbosaurus megadeirus 686 (Benson and Bowdler, 2014).

In dorsal view, the prezygapophyses are mediolaterally narrower than the width of the centrum and positioned directly above the centrum, similar to C. megadeirus, Abyssosaurus nataliae and Djupedalia engeri (Benson and Bowdler, 2014; Berezin, 2011; Knutsen, Druckenmiller and Hurum, 2012a). Similar to Kimmerosaurus langhami (Brown, Milner and Taylor, 1986), in the anterior-most cervicals (3-6) of PMO 224.248, the prezygapophyses are separate along their entire length. However, in the following cervicals the prezygapophyses partially fuse medially along the anteroventral margin beginning approximately at cervical 15 , the prezygapophyses are completely fused medially. This morphology differs from Spitrasaurus spp. and Djupedalia engeri, where the prezygapophyses are either partially or completely ventrally fused throughout the entire neck (Knutsen, Druckenmiller and Hurum, 2012a; Knutsen, Druckenmiller and Hurum, 2012b). In Cryptoclidus eurymerus the prezygapophyses remain unfused (Andrews, 1910; Brown, 1981). As in Spitrasaurus, the postzygapophyses are fused throughout the entire cervical series and extend posterior to the posterior margin of the centrum. 
701 regions significant posterior elongation is preserved: on the eighth cervical, the postzygapophysis 702 length approaches the anterior-posterior length of the entire centrum (supplementary information, 703 Fig. S.6). When articulated with the ninth cervical, there is a larger intervertebral space in between 704 the two centra, than in preceding and following cervical vertebrae.

705

706

The neural spines in the anterior-most cervical vertebrae (3-10) are low, anteroposteriorly extended and angled posteriorly, being positioned over the postzygapophyses. Where the neural spine is completely preserved, the dorsal margin is slightly rounded. This morphology differs from the relatively straight, tall and dorsally flattened margins of the neural spines of the anterior-most cervical vertebrae in Kimmerosaurus langhami, Spitrasaurus and Djupedalia engeri (Brown, Milner and Taylor, 1986; Knutsen, Druckenmiller and Hurum, 2012a; Knutsen, Druckenmiller and Hurum, 2012b). In the $7^{\text {th }}$ cervical, the neural spine is less than half the dorsoventral height of the centrum, when measured from the top of the postzygapophyses. The anterior - mid cervical neural spines (10-18) are posteriorly shifted; so that the middle of the dorsal margin of neural spine is positioned directly over the posterior margin of the centrum (Fig. 13F). In lateral view the neural spines are triangular to trapezoid in outline, becoming more rectangular posteriorly and increase in height. The neural spines on the posterior cervicals are anteroposteriorly long, dorsally flattened and more centred over the centrum. Although positioned more centrally, the posterior margin of the neural spine still reaches the anterior half of the next centrum due to the anteroposterior length of the neural spine (Fig. 14). Some of the mid and the posterior cervicals show a mild anterior inclination of the neural spine. This morphology is comparable to that seen in Spitrasaurus wensaasi and "Picrocleidus" beloclis (pers. obs. AJR, NHMUK 3698; NHMUK 1965); however, the neural spines of Ophthalmothule cryostea do not consistently angle anteriorly as in Spitrasaurus spp. (Knutsen, Druckenmiller and Hurum, 2012b). The neural canal is oval in anterior view.

\section{Cervical ribs}

The cervical rib facets receive single-headed ribs, which are fused to the centrum throughout the entire series (Figs. 13-14). In the anterior cervicals, the cervical ribs are relatively short, hatchetshaped due to a small anterior process and terminate laterally in a posterodistal point. In the midcervical vertebrae, the anterior process is further reduced, gradually increasing in prominence in the posterior cervicals. This differs from Djupedalia engeri, where the anterior process on the 
731 cervical ribs is clearly present in the entire cervical series (Knutsen, Druckenmiller and Hurum, 732 2012a). In the mid-cervicals, the ribs are distally short and lack anteroposterior curvature. From 733 the $40^{\text {th }}$ cervical, the ribs start to elongate exceeding the length of the centrum. Similar to 734 Djupedalia engeri, the posterior cervical ribs become anteroposteriorly narrower and curve 735 posteriorly (Knutsen, Druckenmiller and Hurum, 2012a). This morphology differs from MGUH 73628378 (Cryptoclididae indet.), where the posterior cervical ribs are straight and to Spitrasaurus 737 wensaasi, where they are only slightly posteriorly curved (Knutsen, Druckenmiller and Hurum, 738 2012b; Smith, 2007). From the $44^{\text {th }}$ cervical and posteriorly, the cervical ribs bear a longitudinal, 739 dorsally positioned ridge, starting from the proximal head and terminating around the midpoint of 740 the rib shaft, an autapomorphy of this taxon. This longitudinal ridge is also present on the pectoral 741 and anterior dorsal ribs and represents a muscle attachment site (Noè, Taylor and Gómez-Pérez, 742 2017).

\section{Pectoral vertebrae}

744 At least two pectoral vertebrae (Fig. 15A-F) can be unambiguously identified (sensu Sachs, Kear and Everhart, 2013), with the possibility of a third (Fig. 15G). As in Colymbosaurus megadeirus

746 (Benson and Bowdler, 2014), the centra are significantly mediolaterally wider than dorsoventrally tall in anterior view (supplementary information, Table S2), although this may be partially due to taphonomic compression. As in Cryptoclidus eurymerus, pectoral vertebrae 1 and 2 have clear circular rib facets and the subcentral foramina are widely spaced compared to the cervicals (Brown, 1981). The neural arch is poorly preserved and cannot be described in detail. A third poorly preserved vertebra could represent the third pectoral (Fig. 15G). This element was slightly disarticulated posteriorly from the two pectorals and located just posterior to the medial symphysis of the scapula during preparation. The neural arch and centrum contribute to the dorsoventrally tall and laterally extended rib facet, which almost forms a transverse process on the right side. This rib facet morphology is also present in the pectoral and sacral vertebrae of Colymbosaurus megadeirus (CAMSM J.29640; Benson and Bowdler, 2014). As such the location and similar morphology to other posterior pectorals in Colymbosaurus, supports the argument that this element can be identified as the third pectoral vertebrae. 
Several pectoral ribs are preserved, either in articulation with or adjacent to the pectoral

760

761

762

763

764

765

766

767

768

769

770

771

772

773

774

775

776

777

778

779

780

781

782

783

784

785

786

787 vertebrae. These share the same morphology as the posterior cervical ribs, but are more distally elongate.

\section{Dorsal vertebrae}

Ten dorsal vertebrae are preserved, however, the posterior-most of these are poorly preserved and some are fused together by diagenesis during lithification. The dorsal vertebrae are mediolaterally narrower than the posterior-cervical and pectoral vertebrae (Fig. 16) but not to the degree as in Spitrasaurus wensaasi (Knutsen, Druckenmiller and Hurum, 2012b). The neural arches are crushed and the transverse processes flattened; however, taking into account the shape of the dorsal rib heads and deformation of the transverse process, the rib facets are dorsoventrally taller than wide, being oval in outline as in Spitrasaurus wensaasi (Knutsen, Druckenmiller and Hurum, 2012b). This contrasts to the more circular dorsal rib facets described in Tatenectes and most Oxford Clay Formation cryptoclidids (Andrews, 1910; O'Keefe et al., 2011). The anterior dorsal centra preserve either singular or paired subcentral foramina on the ventrolateral surface.

\section{Dorsal ribs}

The majority of the dorsal ribs are incomplete due to erosion. Two ribs remain complete(an anterior- (Fig. 16I) and a mid-dorsal rib), but are somewhat crushed. The rib heads are robust and single headed with an oblong ovoid facet (Fig. 16H), being dorsoventrally taller than anteroposteriorly wide as in Colymbosaurus megadeirus (Benson and Bowdler, 2014) and a specimen referable to Muraenosaurus (NHMUK R.2427). The mid-dorsal rib was in partialarticulation with the 5 th dorsal vertebrae and is $66.5 \mathrm{~cm}$ in actual length. This rib is curved along the proximal half of the shaft and then straightens out towards the expanded distal end. On the proximal end, a ridge is present on the posterolateral margin. The cross section is subcircular in shape along most of the shaft, but increases in mediolateral width proximally. A groove is present on the posterior surface of the proximal and distal regions of the rib. On the anterior dorsal ribs a longitudinal ridge is present, as described for the posterior cervical- and pectoral ribs.

\section{Gastralia}

The gastral basket of PMO 214.248 is well-preserved, with at least ten sets of gastralia identified. These form a tight gastral basket, where the first set butts against the posterior margin of the 
788

789

790

791

792

793

794

795

796

797

798

799

800

801

802

803

804

805

806

807

808

809

810

811

812

813

814

815

coracoid. Each set contains a medial gastralium, which in turn articulates with 2-3 lateral gastralia on either side. Some of the gastralia are partially fused, which is attributed to the sideritic cement covering the dorsal surface.

\section{Stomach content}

The posterior region of the gastral basket, was covered in a rusted silt layer in PMO 224.248. This sediment predominately silty matrix includes a large number of small worn gravel and bone fragments; thus, we interpret this area as stomach contents containing gravel. The "gastroliths" are small, ranging from $<2 \mathrm{~cm}$ in diameter and are significantly smaller than true gastroliths described from Late Cretaceous elasmosaurids (Cicimurri and Everhart, 2001; Everhart, 2000). A section of the layer along with a section of the underlying gastralia was $\mu \mathrm{CT}$ scanned, revealing a large amount of material embedded in the matrix. However, due to the small size of the stones, it may suggest these are simply picked up during feeding in bottom sediments (Noè, Taylor and GómezPérez 2017). The material requires further analysis to derive the source of the gravel and the origin of the bone material, which is beyond the scope of this paper.

\section{Appendicular skeleton}

\section{Clavicle and interclavicle}

Two clavicles and an interclavicle are preserved in articulation with the scapula. Due to the hard matrix in this region, it was not possibly to separate the elements from the scapula and overlying vertebrae. The clavicles (dorsal to interclavicles) are only visible in cross section, are dorsoventrally thin and are reduced in comparison to the interclavicle, as in Muraenosaurus leedsii (Andrews, 1910; Brown, 1981). The interclavicle forms the anterior-most margin of the pectoral girdle along the midline, resembling the triangular element present in Muraenosaurus leedsii (Andrews, 1910; Brown, 1981).

12 Scapula

13 The scapulae of PMO 224.248 are preserved in articulation with the rest of the pectoral elements and humeri (Fig. 17). Selected measurements of these elements can be found in supplementary information, Table S3. The anterior and medial margins of the scapulae are difficult to interpret, 
816 due to poor preservation and crushing by overlying elements (clavicles, interclavicle). As in all

817 adult cryptoclidids with the exception of Abyssosaurus nataliae, the scapulae meet ventromedially

818 along most of the medial margin to the posteromedial process, forming a dorsoventrally thickened

819 symphysis (Andrews, 1910; Berezin, 2011; O’Keefe and Street, 2009). The posteromedial process

820 of the scapula contacts the anteromedial process of the coracoid along an ovate facet, producing a

821 complete pectoral bar.

822 Ophthalmothule cryostea bears a short and broad dorsal process of the scapula, in contrast 823 to cryptoclidids from the Oxford Clay and Plesiopterys wildi from the Lower Toarcian of 824 Germany, where the extension of the dorsal process can exceed half the total anteroposterior length 825 of the element (Andrews, 1910; O'Keefe, 2004). Although the process is somewhat eroded on the 826 right scapula, it is complete, although fractured anteriorly on left (Fig. 17). This morphology also 827 differs from Abyssosaurus nataliae and Djupedalia engeri, where the dorsal process forms a large 828 part of the anterior portion of the element, being both anteroposteriorly extensive and dorsally 829 extended (Berezin, 2011; Knutsen, Druckenmiller and Hurum, 2012a). The glenoid region is 830 dorsoventrally thickened in comparison to the rest of the element and bears a facet for the glenoid 831 and coracoid that are subequal in length, similar to that observed in Abyssosaurus nataliae 832 (Berezin, 2011), but differing from that seen in Cryptoclidus eurymerus and Djupedalia engeri, 833 where the coracoid facet is the larger of the two facets (Andrews, 1910; Knutsen, Druckenmiller 834 and Hurum, 2012a) and to Spitrasaurus wensaasi where the coracoid facet is significantly smaller 835 (Knutsen, Druckenmiller and Hurum, 2012b). In PMO 224.248, the glenoid facet is deeply 836 concave, whereas the coracoid facet is nearly flat, but rugose on the articular surface.

\section{Coracoid}

838

Both coracoids are articulated, although somewhat fragmented posteriorly and medially. The coracoids bear a large anteromedial process, which has a slight bifurcation anteriorly, extending further anteriorly than the scapular facet. The anteromedial process forms most of the medial margin of the ovate pectoral fenestrae, differing from Colymbosaurus megadeirus and Abyssosaurus nataliae where this margin is mainly formed by the scapula (Benson and Bowdler, 2014; Berezin, 2011) and Tatenectes laramiensis where both contribute equally (O'Keefe and Street, 2009). The anterior portion of the medial symphysis is dorsoventrally thickened in comparison to the rest of the element, creating a shelf along the anterior margin (posterior from 
846 the pectoral fenestra), as in most derived plesiosauroids (Benson and Bowdler, 2014). The

847 ventrally projecting medial symphysis of the coracoids in Ophthalmothule cryostea articulate 848 along the medial symphysis so that the ventral margins form an angle close to $180^{\circ}$. In anterior 849 view the dorsal margins are nearly uniform. The almost uniform dorsal surface in PMO 224.248, 850 could be due to dorsoventral compression. This morphology is similar, although less angled than 851 the more dorsolaterally orientated coracoids of Cryptoclidus eurymerus (Andrews, 1910; pers. obs. 852 AJR, NHMUK R2616) and Colymbosaurus megadeirus (Benson and Bowdler, 2014; Roberts et 853 al., 2017). The medial symphysis continues posteriorly throughout the preserved medial margin of 854 the coracoid (Fig. 17). The lateral margin of the coracoid is concave and terminates posterolaterally 855 in a distinct posteriorly curved cornu, which just exceeds the lateral margin of the glenoid in the 856 parasagittal plane. The posterior margin is concave and a groove is present medial to the cornu, 857 possibly to articulate with the anterior gastralia.

\section{Humerus}

859 Both humeri are predominantly uncrushed and well-preserved, except for the tuberosity which is 860 crushed on both (See supplementary information, Table S5 for measurements). In dorsal view, the 861 proximal portion of the humerus is angled slightly anteriorly, resulting in a slightly sigmoidal 862 shape in dorsal view similar to some leptocleidids and polycotylids (e.g. Hampe, 2013; 863 Schumacher and Martin, 2016). Ventrally, a prominent rugosity is present near the proximal end, 864 forming the dorsoventrally thickest point of the humerus (Fig. 18). As in Djupedalia engeri, the anteroposterior shortest point is just proximal to the ventral rugosity, after which the humeral shaft gradually distally expands in anteroposterior width (Knutsen, Druckenmiller and Hurum, 2012a). This morphology differs from the more distally constricted morphology observed in Spitrasaurus, Muraenosaurus leedsii, Tricleidus seeleyi, Pantosaurus striatus and Cryptoclidus eurymerus, where the shaft is anteroposteriorly shortest towards the midshaft and anteroposteriorly expanded at the proximal and distal ends (Andrews, 1910; Benson and Bowdler, 2014; Brown, 1981; Knutsen, Druckenmiller and Hurum, 2012b; O'Keefe and Wahl, 2003). Posteriorly, there are at least three nutritive foramina perforating the posterior surface near the mid-point of the shaft, an uncommon trait in cryptoclidids, but it is also observed in Spitrasaurus wensaasi (Knutsen, Druckenmiller and Hurum, 2012b). 
Distally, there is little to no preaxial expansion. A large, posteriorly expanded postaxial

876 flange is present, although not to the same degree as seen in Colymbosaurus svalbardensis 877 (Knutsen, Druckenmiller and Hurum, 2012c; Roberts et al., 2017). PMO 214.248 lacks an 878 anteroposteriorly oriented bisecting ridge on the distal epipodial facets, as observed in some 879 specimens of Colymbosaurus megadeirus (Benson and Bowdler, 2014). The distal articular end of 880 the humerus bears three conspicuous convex facets for the radius, ulna and a postaxial accessory 881 element. Along the anterior margin, a rugosity is present, possibly representing a facet for a 882 preaxial accessory element found in articulation on one of the limbs (supplementary information, 883 Fig. S.7). The postaxial flange has at least one facet angled posterodistally, although a secondary 884 postaxial facet could be present directly posteriorly. Whether this posterior-most facet is an actual 885 facet or for connective tissue attachment is equivocal, as no element was found in articulation. The 886 distal facet morphology in Ophthalmothule cryostea differs from the two distal facets seen in 887 Lower Jurassic plesiosauroids, Microcleidus spp. and Plesiopterys wildi (Bardet, Godefroit and 888 Sciau, 1999; O'Keefe, 2004) and the Middle Jurassic taxon Muraenosaurus leedsii and (Andrews, 889 1910), the three seen in Colymbosaurus (a single postaxial ossicle facet; Roberts et al., 2017) and 890 the four seen in 'Plesiosaurus' manselii (two postaxial facets; Hulke, 1870) and Tricleidus seeleyi (Andrews, 1910).

\section{Epipodials and mesopodials}

893 The radius, ulna and postaxial ossicle element are fused through taphonomic processes to one 894 another and likewise the radius is partially fused to the humerus. In addition, the right forelimb preserves an in situ oval preaxial element found adjacent to the preaxial facet (supplementary information, Fig. S.8). Arguable, this element could have drifted into its current position, but based on its shape, size and position could also represent a preaxial element, is similar to those of Spitrasaurus wensaasi (Knutsen, Druckenmiller and Hurum, 2012b). In proximal view, there is a shallow groove present on the radius and ulna for articulation with the convex distal margin of the humerus. In contrast to the Oxford Clay Formation cryptoclidids with advanced adult ossification

901 (e.g., Cryptoclidus eurymerus; Andrews, 1910; Brown, 1981), an epipodial foramen (spatium 902 interosseum) is absent. 
905

906

907

908

909

910

911

912

913

914

915

916

917

918

919

920

921

922

923

924

925

926

927

928

929

930

931

932

933

934

svalbardensis, where the radius is proximodistally longer, but anteroposteriorly shorter than the ulna (Roberts et al., 2017) and Spitrasaurus spp., Djupedalia engeri and Pantosaurus striatus, where the radius is at least twice the size of the ulna in all dimensions (Knutsen, Druckenmiller and Hurum, 2012a; b; O'Keefe and Wahl, 2003). In dorsal view, the outline of the radius has a convex anterior margin which slopes posterodistally, resembling that of Spitrasaurus larseni (Knutsen, Druckenmiller and Hurum, 2012b). In proximal view the radius is dorsoventrally thickest posteriorly and thinnest along its anterior margin. The radius has four dorsoventrally thick facets for the humerus, ulna, intermedium, radiale and an anterior facet for a preaxial ossicle (supplementary information, Fig. S.9). The facet for a preaxial accessory element is shared between the anterior margins of the radius and radiale, as described for Spitrasaurus larseni (Knutsen, Druckenmiller and Hurum, 2012b). Two small elements, although disarticulated adjacent to the right forelimb along the preaxial margin, could represent part of an anterior accessory row (supplementary information. Fig. S.8).

The ulna is anteroposteriorly wider than proximodistally long, although significantly less than the extremely anteroposteriorly elongated ulna observed in Colymbosaurus svalbardensis (Roberts et al., 2017). As in Pantosaurus striatus (O'Keefe and Wahl, 2003), the ulna of Ophthalmothule cryostea has five facets, with the largest facet for the humerus, two smaller anterior and posterior elements for the radius and postaxial ossicle respectively, and two distal facets of subequal size for the intermedium and ulnare.

The postaxial ossicle has three facets for the humerus, ulna and ulnare, and is convex along its posterior margin. As the postaxial element was fused to the ulna, it is possible to reconstruct its position relative to the humerus accurately. Based on this interpretation, the preserved postaxial element, occupies only a small portion of the postaxial margin of the humerus. This is somewhat different from "Plesiosaurus" manselii, according to the reconstruction by Hulke (1870), where the postaxial elements occupy the entire distal postaxial margin.

The mesopodial elements were partially articulated and identified either by their position relative to the epipodial elements or their morphology. In both forelimbs all the mesopodial elements are preserved. The radiale is the largest of the three and bears five facets; the largest being for the radius, the smallest for the intermedium, two facets for the $1^{\text {st }}$ and $2^{\text {nd }}$ distal carpal and a facet along the anteroproximal margin for a preaxial ossicle. The intermedium bears six 
935 facets, two proximal facets for the radius and a longer facet the ulna and three smaller facets for

936 the ulnare, $3^{\text {rd }}$ distal carpal and radiale. The ulnare is bears five facets, two proximal subequal

937 facets for the ulna and postaxial ossicle and three subequal facets for the intermedium, $3^{\text {rd }}$ carpal

938 and $2^{\text {nd }}$ post axial element.

939 Metacarpals and phalanges

940 The metacarpals were disarticulated; the distal carpals are small and their articulation to the rest 941 of the limb uncertain. Two of the carpals are proximodistally reduced and rounded in dorsal 942 outline. This morphology differs from the more elongated and angular distal carpals seen in most 943 cryptoclidids (Colymbosaurus svalbardensis, Cryptoclidus eurymerus, Muraenosaurus leedsii, 944 Tricleidus seeleyi; Andrews, 1910; Brown, 1981; Roberts et al., 2017). A possible $5^{\text {th }}$ metacarpal 945 was identified based on the unusual morphology of the element and on its proximal position and 946 articulating elements. This element seems to be nearly entirely shifted into the distal carpal row.

947 Twenty-nine phalanges and/or metacarpals are preserved in the right forelimb and twenty948 two in the left. Many of these were removed during excavation, although their location was noted. 949 The proximal phalanges are hourglass-shaped, with flat articular surfaces, whereas the more distal 950 phalanges, are proximodistally shorter and more compact, similar to that observed in 951 Colymbosaurus svalbardensis (Roberts et al., 2017).

\section{Femora}

953 Fragments of the femora from PMO 224.248, were located downslope from the skeleton. These 954 consist of fragments of the distal, mid-shaft and proximal sections of the femur and were identified 955 based on the amount of weathering. The left limb was partly preserved with the rest of the body 956 and was therefore more proximal to the rest of the skeleton and less weathered. The partial femur 957 interpreted as the left, consists of a distal end, shaft fragments and part of the proximal end (supplementary information, Fig. S.10). The bone texture and shape suggests that the femur had a postaxial flange, although not preserved. On the distal fragment of the left femur, part of the distal surface is preserved, which is smooth and slightly convex. When comparing the femoral crosssections to the complete humeri in PMO 224.248, it is clear that the femora have a smaller circumference than the humeri along the shaft. 
964

965

966

967

968

969

970

971

972

973

974

975

976

977

978

979

980

981

982

983

984

985

986

987

988

989

990

991

992

993

\section{Hind limb elements}

Distal elements from the left hind limb, including the meso- and metatarsals and several phalanges, are preserved in PMO 224.248 and are partially articulated although heavily weathered (supplementary information, Fig. S.10). Five mesopodial elements are preserved in left hind limb, representing the fibulare, astragalus, tibiale and the two distal tarsal elements. The $5^{\text {th }}$ metatarsal appears to be entirely shifted into the distal tarsal row. Several complete and partial phalanges are preserved. As seen in Colymbosaurus, the largest element in dorsal view of the mesopodial elements is the fibulare (Knutsen, Druckenmiller and Hurum, 2012c; Roberts et al., 2017). The fibulare has six facets, with the largest being for the fibula. Along the posterior margin of the fibula there are two facets, one proximally for the postaxial ossicle and another distally possibly for a second ossicle. The astragalus is oval in outline, but bears a proximal convexity, to separate the facets for the fibula and tibia. The element is dorsoventrally thicker than proximodistally long (excluding the proximal surface convexity). The tibiale is the smallest of the three elements and bears five facets, a proximal facet for the tibia, two short proximal facets for the astragalus and second distal tarsal, a long distal facet for the first distal tarsal and a short anterior facet, possibly for a preaxial row. The distal lengths of the tibia and fibula can be estimated, based on the close articulation between the tibiale, astragalus and fibula. This suggests that at least, the distal anteroposterior extent of the fibula, appears to be longer than that of the tibia. Four metatarsals are preserved, the second, third, fourth and possibly the fifth. As in most cryptoclidids, the forth metatarsal is the largest (Knutsen, Druckenmiller and Hurum, 2012c).

\section{Discussion}

\section{Phylogenetic analysis and interrelationships of Cryptoclididae}

Ophthalmothule cryostea (PMO 224.248) was scored into the data matrix of Roberts et al., (2017), which stems from the matrix from Benson and Druckenmiller (2014). Based on the results of the present study, three new characters (Characters 271-273) were created, relying on features relevant for cryptoclidids and include two cranial and one post-cranial features (See Data S1 for further discussion and description). Alternative scores and additional information on how to discern the character states of individual cryptoclidid taxa are available in the supplementary information. The first new cranial character relates to the resence of an interfrontal vacuity and the second relates to the dorsal surface of the dentary. We edited a previously used postcranial 
994 character related to the fibular morphology and included it in the matrix. The resulting matrix totals 995273 unordered morphological characters and 76 OTUs.

996

997

998

999

1000

1001

1002

1003

1004

1005

1006

1007

1008

1009

1010

1011

1012

1013

1014

1015

1016

1017

1018

1019

1020

1021

1022

The analysis was performed in TNT (V.1.5) (Goloboff and Catalano, 2016) using theparsimony ratchet, followed by a heuristic search using Tree bisection reconnection (TBR), that used the trees recovered from the parsimony ratchet analysis. The analysis used 1000 iterations, with 10 random addition sequences and 10 random seed. The memory in TNT (V.1.5) was increased to hold 10000 trees. Additional functions in TNT (V.1.5) such as drift, tree fusing and sect. search were not utilised. All trees were kept and auto constrain turned off and all characters were equally weighted. Yunguisaurus was defined as the outgroup taxon (Cheng et al., 2006). The bremer function in TNT (V.1.5) was used to calculate Bremer support (decay index). Bootstrap resampling (1000 replications), was also performed (Fig. S.5). The scripts stats.run was used to calculate CI and RI. The complete consensus tree for plesiosauroidea is available in supplementary information (Fig. S.14).

A posteriori time scaling of the strict consensus tree was comouted in the R Statistical environment (Cran) and utilised data collected from PBDB (Palaeontological Database, paleobiodb.org), in addition to personal observations from museum collections (See Data S.1). The Datephylo function from the R package strap (Bell and Lloyd, 2014) using equal lengths was utilised to form the time scaled tree (See Data.S1 for data and script).

\section{Results of the phylogenetic analysis}

The strict consensus tree of 144 MPTs (most parsimonious trees) shows the monophyly of Cryptoclididae is relatively well supported (Fig. 19) with a Bremer support of four, as in previous studies (Benson and Bowdler, 2014).

Cryptoclididae is supported by the following seven synapomorphies, where only character 144 is non-homoplastic (character number/state): (144/1) the atlantal centrum participates in the anterior rim of the atlantal cup (state 0 Tatenectes laramiensis); 202/0 the anterolateral margin of the scapula is flat/gently convex; $(235 / 1)$, in the forelimb the digits/tarsal/carpal axis extends posterodistally relative to propodial long axis because proximodistal length of radius/tibia is substantially greater than that of the ulna/fibula; (245/1), the preaxial expansion on the distal margin of the humerus is smaller than the postaxial expansion (2 in Cryptoclidus eurymerus and 
1023 ambiguous between $1 \& 2$ in Spitrasaurus sp.); (255/3), ratio of tibia length to maximum width is $1024>0.75$ (state 1 in Pantosaurus striatus and state 2 in Colymbosaurus megadeirus); (261/2), an 1025 epipodial foramen is absent (state 0 in Muraenosaurus leedsii, 1 in 'Picrocleidus' beloclis and 1026 Tricleidus seeleyi, 1\&2 in Cryptoclidus eurymerus depending on ontogeny, ambiguous in 1027 Abyssosaurus nataliae); (262/1), the ratio of maximum radius length to maximum ulna length is 1028 between 1.4-1.7 (state 0 in Ophthalmothule cryostea, state 2 in Cryptoclidus eurymerus). It is 1029 noteworthy that all of these synapomorphies are postcranial features, due to the lack of complete 1030 and/or well-preserved cranial material in this clade. In the analysis of Benson and Bowdler (2014) 1031 only one of these characters (144) was recovered as a synapomorphy in their diagnosis. 1032 Ophthalmothule cryostea can be referred to the family Cryptoclididae on the basis of sharing three 1033 of seven synapomorphies (two could not be scored for Ophthalmothule cryostea).

As found in Benson and Bowdler (2014), Cryptoclididae is split into two subclades, one of 1035 which has been formally named as Colymbosaurinae. In Benson and Bowdler (2014), this 1036 subfamily includes Colymbosaurus, Spitrasaurus, Djupedalia engeri, Pantosaurus striatus, 1037 "Plesiosaurus" manselii and Abyssosaurus nataliae. As cranial material for these taxa is either

1038 1039

1040

1041

1042

1043

1044

1045

1046

1047

1048

1049

1050

1051

1052

1053

limited or unavailable, the synapomorphies include only post-cranial features. This is problematic, as there could be a conflicting signal between cranial and post-cranial characters in the data matrix. PMO 224.248 could be scored for a significant number of cranial and post cranial characters in the matrix. Although not recovered in the subfamily, Ophthalmothule cryostea shares three of the five Colymbosaurinae synapomorphies described in Benson and Bowdler (2014). The addition of this new taxon to the data set, along with the three new characters, created a new topology for the cryptoclidid clade. Although the two major subclades are still present, the Slottsmøya Member taxa Spitrasaurus spp., Djupedalia engeri and $O$. cryostea were removed from the Colymbosaurinae subfamily and placed as a sister group to Cryptoclidus eurymerus, Tatenectes laramiensis and Kimmerosaurus langhami. Although this configuration is supported with higher Bremer support values than those reported in Benson and Bowdler (2014), most of the internal structure of the cryptoclidid tree was not retained after running a resampling bootstrap analysis and all nodes received low support $(>50)$. However, this analysis does show that a revision is required of the diagnostic features of Colymbosaurinae in light of the new taxon (Ophthalmothule cryostea). As a result, four synapomorphies for the reduced Colymbosaurinae clade were recovered, which are unique within Cryptoclididae with some exceptions: (197/0) the anteromedial 
1054 margin of the coracoid does not contact the scapula; (209/2), the coracoid anteromedial process is 1055 short and subtriangular; (224/1), the anteroposterior width of the ilium is expanded, between 1.510562.0 times the minimum anteroposterior width of the shaft and (256/1), the anterior margin of the 1057 radius is straight or convex (Also present in Djupedalia engeri and Spitrasaurus spp.).

1058

Although the precise position of Ophthalmothule cryostea (PMO 224.248) as sister taxon 1059 to Spitrasaurus spp. is weakly supported (Bremer Support =2), the clade incorporating Djupedalia 1060 engeri, Spitrasaurus spp. and O. cryostea receives higher support (Bremer Support $=3)$. This clade 1061 is shares three synapomorphies: $(152 / 5)$ the number of cervical vertebrae is between $50-60 ;(157 / 2)$

1062 the anterior cervical neural spines are inflected anterodorsally (ambiguous in PMO 224.248) and 1063 (234/1), the presence of preaxial ossicles. The separation of this Slottsmøya Member restricted 1064 clade from Colymbosaurinae, suggests that at least two separate clades of cryptoclidids were 1065 present in the Boreal region during the Late Jurassic.However, this conclusion may change in light 1066 of new specimens from other Boreal and sub-Boreal localities.

1067 Palaeobiological implications

1068

\section{Cranial morphology and feeding ecology}

1069 The skull of Ophthalmothule cryostea displays relatively large orbits compared to the temporal 1070 fenestrae (both measured as anteroposterior length; = 1.7) in comparison with other cryptoclidid 1071 taxa for which this can be measured (Cryptoclidus eurymerus, $\sim 0.93$; Muraenosaurus leedsii, 1072 0.58). However, a comparison of orbit versus total skull length in PMO $224.248(=0.29)$, is 1073 closer, but still considerably different to that of other cryptoclidid plesiosaurs (Cryptoclidus 1074 eurymerus, $\sim 0.21$; Muraenosaurus leedsii, $\sim 0.17$ ). When compared to estimated body length (skull length/estimated body length), the skull of PMO 224.248 is considerably smaller compared to the 1076 published body size estimates in other cryptoclidids (Brown, 1981). In Ophthalmothule cryostea 1077 (PMO 224.248), the skull represents an estimated 4\% of total estimated body length (5-5.5m), 1078 while in Muraenosaurus leedsii specimen NHMUK R.2422, the skull is estimated to constitute 1079 $7-8 \%$ of the total body length (see supplementary information 3 ). exit angle for the teeth from the alveoli in Ophthalmothule cryostea and is extremely similar to the 1082 morphology seen in Spitrasaurus larseni (Knutsen, Druckenmiller and Hurum, 2012b). In 
1083 Ophthalmothule cryostea the maximum cross-sectional diameter of one of the crowns (at crown1084 root transition) is $\sim 5.5 \mathrm{~mm}$ and is somewhat larger to that described for Kimmerosaurus langhami 1085 and S. larseni ( $<5 \mathrm{~mm}$; Brown, 1981; Knutsen, Druckenmiller and Hurum, 2012b). Some of the 1086 teeth of PMO 224.248 show wear facets, which could indicate a tight fit between the lower and 1087 upper jaw teeth or wear due to diet. This differs from the teeth described for K. langhami, where 1088 no abrasion or wear is visible on the crowns (Brown, 1981). The preserved teeth of O. cryostea 1089 are not as recurved as those in $S$. larseni and $K$. langhami, and therefore probably displayed a more 1090 protruding dentition than these taxa. Based on their phylogenetic position in the plesiosaurian tree, 1091 a similar morphology evolved independently in the elasmosaurid Aristonectes parvidens 1092 (Gasparini et al., 2003). However, the morphology is A. parvidens is more extreme as the alveoli 1093 face directly laterally in the mandible (Gasparini et al., 2003; Otero, Soto-Acuňa and O'Keefe, 1094 2018).

Calculations of mechanical advantage can be used to suggest the strength of the jaw in 1096 reptiles (Stubbs et al., 2013; Foffa, 2018). Two calculations of mechanical advantage were 1097 completed on different cryptoclidid taxa (See supplementary information 3 for methodology and 1098 measurements), anterior mechanical advantage (AMA) and posterior mechanical advantage 1099 (PMA). The mechanical advantage of the jaw of Ophthalmothule cryostea was estimated to be 1100 0.13/0.44 (AMA/PMA), using the rostral length as a proxy for the anterior extend of the mandible. It is important to mention that these calculations are computed as ratios and are thus dimensionless. This numbers are low, illustrating a low mechanical advantage, similar to Kimmerosaurus 1103 langhami (0.13/0.51) and Spitrasaurus larseni (0.11/0.31). In comparison the mechanical advantage calculated was somewhat higher in Callovian cryptoclidids: Cryptoclidus eurymerus (PETMG R283: 0.19/0.73), Muraenosaurus leedsi (NHMUK R2422: 0.20/0.64) and Tricleidus seeleyi (NHMUK R3539: 0.18/0.72). The mechanical advantage of these cryptoclidids is generally lower than those calculated for larger macro predatory marine reptiles (Stubbs et al., 2013). This suggests, particularly in the case of $O$. cryostea and Spitrasaurus, that these marine reptiles had a 1109 low bite force and would have been unable to eat large, armoured prey as suggested by tooth morphology. 
1113 and has additional area for light intake, thereby increasing the capability of the animal to see in

1114 low-light conditions (e.g.deep, murky water, at night or during darker seasons; Motani, Rothschild 1115 and Wahl, 1999; Fernández et al., 2005; Fischer et al., 2014). Ophthalmothule was present in a 1116 northern, although not Arctic region and would have experienced seasonality (Galloway et al., 1117 2013). This alone may have been the purpose for higher visual acuity, or may have been in addition 1118 to deep-diving (Berezin, 2018). Enlarged orbits in comparison to the temporal region are also 1119 described for the Cretaceous sub-Boreal Russian cryptoclidid Abyssosaurus nataliae (Berezin, 1120 2018). In A. nataliae this morphology is suggested to be a paedomorphic feature; large orbits and 1121 short temporal region is a common juvenile feature in reptiles, including marine reptiles (Johnson,

1122

1123

1124

1125

1126

1127

1128

1129

1130

1131

1132

1133

1134

1135

1136

1137

1138

1139

1140

1141

1142 1977). Phylogenetically, A. nataliae and Ophthalmothule cryostea are in two separate clades of cryptoclidids. Although this feature may not be paedomorphic, it does suggest that a high orbital/cranial ratio is present in at least two lineages of Late Jurassic - Early Cretaceous cryptoclidids.

In conclusion, to accommodate high visual acuity in the small cranium of Ophthalmothule cryostea, pressure to reduce the size of other areas of the cranium such as the temporal region may have been increased. However, a more likely scenario is that this odd adaptation is a result of dietary selection. In $O$. cryostea, this gracile and trap-like dentition in combination with the enlarged orbit relative to temporal fenestral size and low mechanical advantage, suggests that $O$. cryostea may have fed on small, "soft-bodied" prey from the water column or sea floor and the large orbital size may have increased visual acuity in these environments (Fig. 20) (Massare, 1987; Fischer et al., 2014; Noè, Taylor and Gómez-Pérez, 2017). Further analysis into the ancestral state of skull morphology and visual acuity of this family, may be key to highlighting the changes in skull morphology in this particular lineage, but is beyond the scope of this paper.

\section{Conclusion}

Ophthalmothule cryostea (PMO 224.248) represents the temporally youngest occurrence of a plesiosaurian from the Slottsmøya Member (Agardhfjellet Formation) of central Spitsbergen. $O$. cryostea represents the fourth genus described from the member, although several other cryptoclidid specimens remain to be described. Ophthalmothule cryostea is one of the few cryptoclidids with detailed cranial osteology available, providing much needed morphological 
1143 information for understanding the intrarelationships of cryptoclidids. In addition, this specimen 1144 uniquely preserves a complete cervical series found in articulation, offering future possibilties to 1145 test current hypotheses on plesiosaurian neck-flexibility and evolution. As the specimen was found 1146 in the section encompassing the Jurassic - Cretaceous boundary, Ophthalmothule cryostea along 1147 with the Russian Abyssosaurus nataliae represent the youngest cryptoclidid genera in boreal and 1148 sub-boreal regions. The phylogenetic results of this study indicate that two separate clades of 1149 cryptoclidids were present in the latest Jurassic in the Boreal region of Spitsbergen and the sub1150 Boreal region of Russia.

\section{Acknowledgements}

The authors wish to thank the museum curators and researchers that assisted AJR during 1153 collection visits; S. Chapman and L. Steel (NHMUK), M. Riley (CAMSM), E. Howlett (OUM), M. Evans (LEICS), M. Fernández (MOZ, MLP), G. Wass (PETMG), N. Clark (GLAHM), G. Cuny (MGUH), K. Sherburn (MANCH), L. A. Vietti (UW). D. Foffa, S. Etches, V. E. Nash, D. Legg, A. S. Smith, V. Fischer, J. Wujek, E. M. Knutsen and E. Martin-Silverstone are thanked for discussion. M-L K. Funke, C. Ekeheien, M. Koevoets and V. E. Nash are thanked for assistance during the preparation of the specimen. $\varnothing$. Hammer is thanked for assistance with the computed tomography and O. Katsamensis is thanked for access to the visualisation laboratory ( $\mu$-vis) in Southampton. M. J. Benton is thanked for comments on an earlier version of the manuscript. The reviewers V. Fischer and N. Zverkov are thanked for their comments, which helped to improve the manuscript. The Willi Hennig Society is acknowledged for their sponsorship of TNT (Trees with New Technology). Gratitude is warranted to all the volunteers of the Spitsbergen Mesozoic Research Group, who participated in the 2012 excavations during their holidays. The authors 1165 warmly thank the palaeoartist Esther van Hulsen for illustrating PMO 224.248. 


\section{References}

1168

1169

1170

1171

1172

1173

1174

1175

1176

1177

1178

1179

1180

1181

1182

1183

1184

1185

1186

1187

1188

1189

1190

1191

1192

1193

1194

1195

Andrews CW. 1910. A descriptive catalogue of the Marine Reptiles of The Oxford Clay Based on the Leeds Collection in the British Museum (Natural History). British Museum (Natural History), London. 205 pp.+x plates

Bardet N, Godefroit P, Sciau J. 1999. A new elasmosaurid plesiosaur from the Lower Jurassic of Southern France. Palaeontology 42: 927-952.

Bell, MA, Lloyd, GT. 2014 strap: an R package for plotting phylogenies against stratigraphy and assessing their stratigraphic congruence. Palaeontology 58:379-389.

Benson RBJ, Bowdler T. 2014. Anatomy of Colymbosaurus megadeirus (Reptilia, Plesiosauria) from the Kimmeridge Clay Formation of the U.K., and high diversity amoung Late Jurassic plesiosauroids. Journal of Vertebrate Paleontology 34:1053 - 1071.

Benson RBJ, Evans M, Druckenmiller PS. 2012. High Diversity, Low Disparity and Small Body Size in Plesiosaurs (Reptilia, Sauropterygia) from the Triassic-Jurassic Boundary. PLOS ONE 7:e31838.

Benson RBJ, Druckenmiller PS. 2014. Faunal turnover of marine tetrapods of the JurassicCretaceous transition. Biological Reviews 89:1-23.

Berezin AY. 2011. A New Plesiosaur of the Family Aristonectidae from the Early Cretaceous of the Center of the Russian Platform. Paleontological Journal 45:648-660.

Berezin AY. 2018. Craniology of the plesiosaur Abyssosaurus natalie Berezin (Sauropterygia, Plesiosauria) from the Lower Cretaceous of the Central Russian Platform. Paleontological Journal 52:328-341.

Brown DS. 1981. The English Upper Jurassic Plesiosauridae (Reptilia) and a review of the phylogeny and classification of the Plesiosauia. Bulletin of the British Museum (Natural History), Geology 35:253-347.

Brown DS, Milner AC, Taylor MA. 1986. New material of the plesiosaur Kimmerosaurus langhami Brown from the Kimmeridge Clay of Dorset. Bulletin of the British Museum (Natural History), Geology Series 40:225-234.

Brown DS, Cruickshank ARI. 1994. The skull of a Callovian plesiosaur Cryptoclidus eurymerus, and the sauropterygian cheek. Palaeontology 37:941-953. 
1196

1197

1198

1199

1200

1201

1202

1203

1204

1205

1206

1207

1208

1209

1210

1211

1212

1213

1214

1215

1216

1217

1218

1219

1220

1221

1222

1223

1224

1225

Buchy M-C, Frey E, Salisbury SW. 2006. The internal cranial anatomy of the Plesiosauria (Reptilia, Sauropterygia): evidence for a functional secondary palate. Lethaia 39:289303.

Carpenter K. 1996. A review of short-necked plesiosaurs from the Cretaceous of the western interior, North America. Neues Jahrbuch für Geologie und Paläontologie. Abhandlungen 201:259p.

Cheng Y-N Sato T, Wu X-C, Li C. 2006. First complete pistosauroid from the Triassic of China. Journal of Vertebrate Paleontology 26:501-504

Cicimurri DJ, Everhart MJ. 2001. An elasmosaur with stomach contents and gastroliths from the Pierre Shale (Late Cretaceous) of Kansas. Transactions of the Kansas Academy of Science 104:129-143.

Collignon M, Hammer Ø. 2012. Petrography and sedimentology of the Slottsmøya Member at Janusfjellet, central Spitsbergen. Norwegian Journal of Geology 92:89-101.

Delsett LL, Novis LK, Roberts AJ, Koevoets MJ, Hammer Ø, Druckenmiller PS, Hurum JH. 2016 The Slottsmøya marine reptile Lagerstätte: depositional environments, taphonomy and diagenesis. Geological Society Special Publications 434:165-188.

Druckenmiller, PS. 2002. Osteology of a new plesiosaur from the Lower Cretaceous (Albian) Thermopolis Shale of Montana. Journal of Vertebrate Paleontology 22:29-42.

Druckenmiller PS, Hurum JH, Knutsen EM, Nakrem HA. 2012. Two new ophthalmosaurids (Reptilia: Ichthyosauria) from the Agardhfjellet Formation (Late Jurassic: Volgian/Tithonian), Svalbard, Norway. Norwegian Journal of Geology 92:311-339.

Dypvik H, Nagy J, Eikeland TA, Backer-Owe K, Andresen A, Johansen K, Elverhoi A, Haremo P, Bjaerke T. 1991. The Janusfjellet Sugroup (Bathonian to Hauterivian) on central Spitsbergen: a revised lithostratigraphy. Polar Research 9:21-43.

Everhart MJ. 2000. Gastroliths associated with plesiosaur remains in the Sharon Springs Member of the Pierre Shale (Lat Cretaceous), Western Kansas. Transactions of the Kansas Academy of Science 103:64-75.

Fernández MS, Arcguby F, Talevi M, Evner R. 2005. Ichthyosaurian eyes: paleobiological information content in the sclerotic ring of Caypullisaurus (Ichthyosauria, Ophthalmosauria). Journal of Vertebrate Paleontology 25:330-337. 
1226 Fischer V, Arkhangelsky MS, Uspensky GN, Stenshin IM. 2014. A new Lower Cretaceous

1227

1228

1229

1230

1231

1232

1233

1234

1235

1236

1237

1238

1239

1240

1241

1242

1243

1244

1245

1246

1247

1248

1249

1250

1251

1252

1253

1254

1255 ichthyosaur from Russia reveals skull shape conservatism within Ophthalmosaurinae. Geological Magazine 151: 60-70.

Fischer V, Benson RBJ, Druckenmiller PS, Ketchum HF, Bardet N. 2018. The evolutionary history of polycotylid plesiosaurians. R. Soc. Open Sci 5: 172177.

Foffa, D. 2018. The ecology and evolution of the marine reptile faunas of the Jrassic sub-Boreal Seaway. PhD thesis. The University of Edinburgh. Edinburgh. United Kingdom.

Galloway JM, Sweet AR, Swindles GT, Dewing K, Hadlari T, Embry AF, Sanei H. 2013. Middle Jurassic to Lower Cretaceous paleoclimate of Sverdrup Basin, Canadian Arctic Archipelago inferred from the palynostratigraphy. Marine and Petroleum Geology 44:240-255.

Gasparini Z, Bardet N, Iturralde-Vinent M. 2002. A new cryptoclidid Plesiosaur from the Oxfordian (Late Jurassic) of Cuba. Geobios 35:201-211.

Gasparini Z, Bardet N, Martin JE, Fernández MS. 2003. The elasmosaurid plesiosaur Aristonectes Cabrera from the latest Cretaceous of South America and Antarctica. Journal of Vertebrate Paleontology 23:104-115.

Goloboff PA, Catalano SA. 2016. TNT version 1.5, including a full implementation of phylogenetic morphometrics. Cladistics 32:221-238.

Hammer Ø, Collignon M, Nakrem HA. 2012. Organic carbon isotope chemostratigraphy and cyclostratigraphy in the Volgian of Svalbard. Norwegian Journal of Geology 92:103112.

Hampe O. 2013. The forgotten remains of a leptocleidid plesiosaur (Sauropterygia:

Plesiosauroidea) from the Early Cretaceous of Gronau (Münsterland, Westphalia, Germany). Paläontologisches Zeitschrift 87:473-491.

Hryniewicz K, Hammer Ø, Nakrem HA, Little CTS. 2012. Microfacies of the VolgianRyazanian (Jurassic-Cretaceous) hydrocarbon seep carbonates from Sassenfjorden, central Spitsbergen, Svalbard. Norwegian Journal of Geology 92:113-131.

Hulke JW. 1870. Note on some Plesiosaurian Remains obtained by J. C. Mansel Esq. F.G.S., in Kimmeridge Bay, Dorset. Quarterly Journal of the Geological Society of London 26:611-622. 
1256 Johnson R. 1977. Size independent criteria for estimating relative age and relationships among

1257

1258

1259

1260

1261

1262

1263

1264

1265

1266

1267

1268

1269

1270

1271

1272

1273

1274

1275

1276

1277

1278

1279

1280

1281

1282

1283

1284

1285 growth parameters in a group of fossil reptiles (Reptilia-ichthyosauria). Canadian Journal of Earth Sciences 14:1916-1924.

Kear BP. 2006. Plesiosaur remains from Cretaceous high-latitude non-marine deposits in Southeastern Australia. Journal of Vertebrate Paleontology 26:196-199.

Knutsen EM, Druckenmiller PS, Hurum JH. 2012a. A new plesiosaurid (Reptilia-Sauropterygia) from the Agardhfjellet Formation (Middle Volgian) of central Spitsbergen, Norway. Norwegian Journal of Geology 92:213-234.

Knutsen EM, Druckenmiller PS, Hurum JH. 2012b. Two new species of long-necked plesiosaurians (Reptilia-Sauropterygia) from the Upper Jurassic (Middle Volgian) Agardhfjellet Formation of central Spitsbergen. Norwegian Journal of Geology 92:187212.

Knutsen EM, Druckenmiller PS, Hurum JH. 2012c. Redescription and taxonomic clarfication of 'Tricleidus' svalbardensis based on new material from the Agardhfjellet Formation (Middle Volgian). Norwegian Journal of Geology 92:175-186.

Massare JA. 1987. Tooth morphology and prey preference of Mesozoic marine reptiles. Journal of Vertebrate Paleontology 7:121-137.

Motani R, Rothschild BM, Wahl W. 1999. Large eyes in deep diving ichthyosaurs. Nature 402:747.

McHenry CR, Cook AG, Wroe S. 2005. Bottom-feeding plesiosaurs. Science 310:75.

Noè LL, Taylor MA, Gómez-Pérez M. 2017. An integrated approch to understanding the role of the long neck in plesiosaurs. Acta Palaeontologica Polonica 62:137-162.

O'Keefe FR. 2001. A cladistic analysis and taxonomic revision of the Plesiosauria (Reptilia: Sauropterygia). Acta Zoologica Fennica 214:1-63.

O'Keefe FR. 2004. Preliminary description and phylogenetic position of a new plesiosaur (Reptilia: Sauropterygia) from the Toarcian of Holzmaden, Germany. Journal of Paleontology 78: 973-988.

O'Keefe FR, Street HP. 2009. Osteology of the cryptocleidoid plesiosaur Tatenectes laramiensis, with comments on the taxonomic status of the Cimoliasauridae. Journal of Vertebrate Paleontology 29:48-57. 
1286

1287

1288

1289

1290

1291

1292

1293

1294

1295

1296

1297

1298

1299

1300

1301

1302

1303

1304

1305

1306

1307

1308

1309

1310

1311

1312

1313

1314

1315

O'Keefe FR, Street HP, Wilhelm CDR, Zhu H. 2011. A new skeleton of the cryptoclidid plesiosaur Tatenectes laramiensis reveals a novel body shape among plesiosaurs. Journal of Vertebrate Paleontology 31:330-339.

O'Keefe FR, Wahl W. 2003. Current taxonomic status of the plesiosaur Pantosaurus striatus from the Upper Jurassic Sundance Formation, Wyoming. Paludicola 4:37-46.

Otero RA, Soto-Acuňa. O'Keefe FR. 2018. Osteology of Aristonectes quiriquiensis (Elasmosauridae, Aristonectinae) from the upper Maastrichtian of central Chile. Journal of Vertebrate Paleontology 38:e1408638.

Roberts AJ, Druckenmiller PS, Delsett LL, Hurum JH. 2017. Osteology and relationships of Colymbosaurus Seeley, 1874, based on new material of C. svalbardensis from the Slottsmøya Member, Agardhfjellet Formation of central Spitsbergen. Journal of Vertebrate Paleontology 37:e1278381.

Sachs S, Hornung JJ, Kear BP. 2016. Reappraisal of Europe's most complete Early Cretaceous plesiosaurian: Brancasaurus brancai Wegner, 1914 from the "Wealden facies" of Germany. PeerJ 4:e2813.

Sachs S, Kear BP, Everhart MJ. 2013. Revised Vertebral Count in the "Longest-Necked Vertebrate" Elasmosaurus platyurus Cope 1868, and Clarification of the Cervical-Dorsal Transition in Plesiosauria. PLOS ONE 8:e70877.

Sato T, Hasegawa Y, Manabe M. 2006. A new elasmosaurid plesiosaur from the Upper Cretaceous of Fukushima, Japan. Palaeontology 49:467-484.

Schumacher BA, Martin JE. 2016. Polycotylus latipinnis Cope (Plesiosauria, Polycotylidae), a nearly complete skeleton from the Niobara Formation (early Campanian) of southwestern South Dakota. Journal of Vertebrate Paleontology 36: e1031341.

Serratos DJ, Druckenmiller PD, Benson RBJ. 2017. A new elasmosaurid (Sauropterygia, Plesiosauria) from the Bearpaw Shale (Late Cretaceous, Maastrichtian) of Montana demonstrates multiple evolutionary reductions of neck length within Elasmosauridae. Journal of Vertebrate Paleontology:10.1080/02724634.2017.1278608.

Smith AS. 2007. The back-to-front plesiosaur Cryptoclidus (Apractocleidus) aldingeri from the Kimmeridgian of Milne Land, Greenland. Bulletin of the Geological Society of Denmark 55:1-7. 
1316 Smith AS, Benson RBJ. 2014. Osteology of Rhomaleosaurus thorntoni (Sauropterygia:

1317

1318

1319

1320

1321

1322

1323

1324

1325

1326

1327
Rhomaleosauridae) from the Lower Jurassic (Toarcian) of Northamptonshire, England. Monograph of the Palaeontographical Society 168:40pp, 35 pls.

Stubbs, TL, Pierce, SE, Rayfield, EJ, Anderson PSL. 2013. Morphological and biomechanicaldispariy of crocodile-line archosaurs following the end-Triassic extinction. Proceedings of the Royal Society B 280:20131940

Tennant JP, Mannion PD, Upchurch P. 2016. Sea level regulated tetrapod diversity dynamics through the Jurassic/Cretaceous interval. Nature Communications 7:12737

Vincent P, Benson RBJ. 2012. Anningsaura, a basal plesiosaurian (Reptilia, Plesiosauria) from the Lower Jurassic of Lyme Regis, United Kngdom. Journal of Vertebrate Paleontology 32:1049-1063. 


\section{Figure 1}

Map of locality and stratigraphy of the Upper Jurassic (middle Volgian) to the Early Cretaceous part of the Slottsmøya member of the Agardhfjellet Formation (the lowest unit not included, see text) with described cryptoclidid positions.

(A) Geological map of the field site in central Spitsbergen. The arrow points to the excavation site of PMO 224.248 (Modified from Dallmann et al., 2001 and Hurum et al., 2012). Scale bar equals $1 \mathrm{~km}$. (B) The stratigraphic position of PMO 224.248 (in bold) in relation to the other described cryptoclidids specimens (PMO 219.718 - Spitrasaurus wensaasi; PMO 222.663, PMO 216.838 - Colymbosaurus svalbardensis; PMO 216.839 - Djupedalia engeri; SVB 1450 Spitrasaurus larseni). Note the uncertain position of the Jurassic - Cretaceous boundary. Modified from Delsett et al. 2016). 


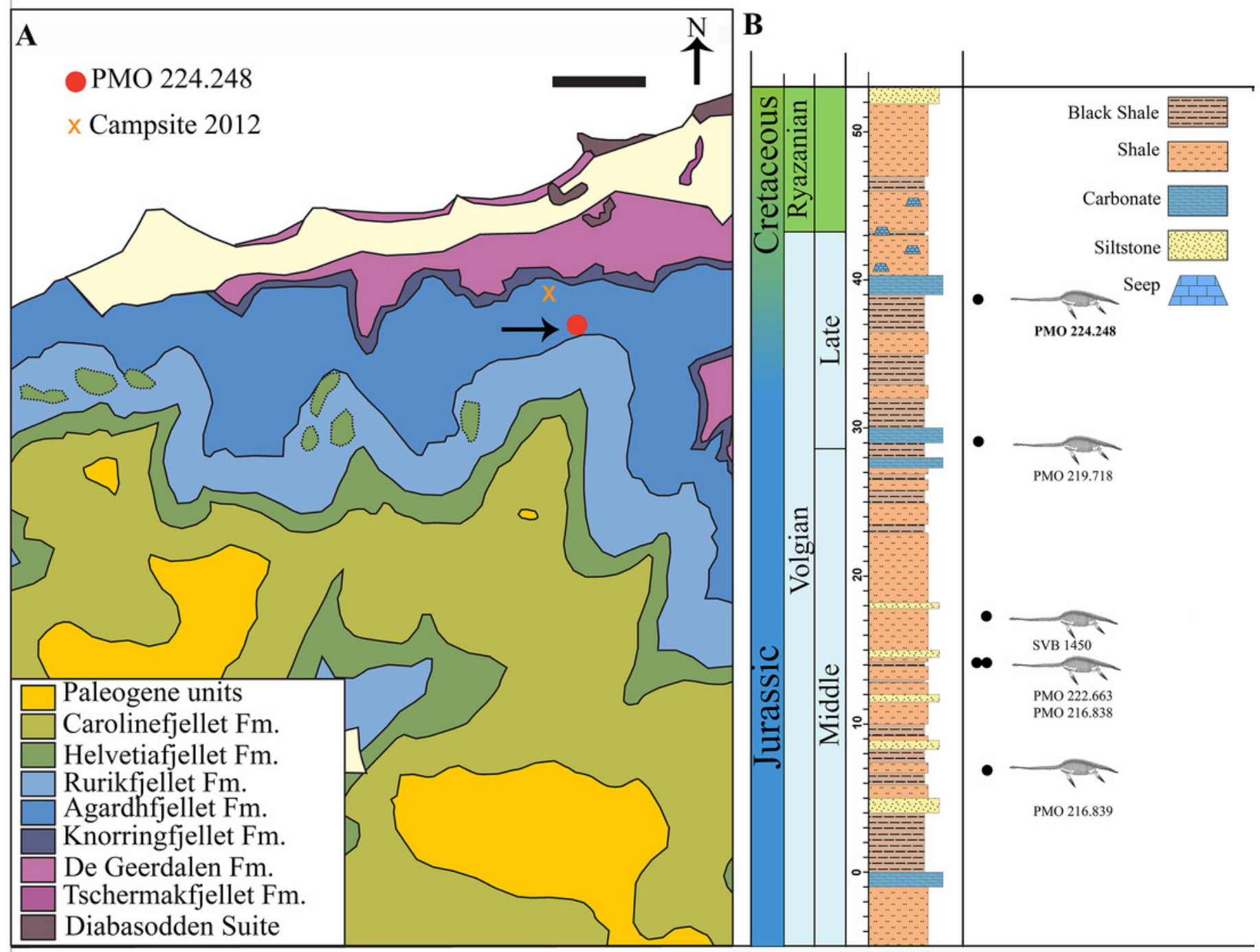


Figure 2

Quarry map and reconstruction of PMO 224.248.

(A) drawing from a combination of field and laboratory drawings in ventral view (modified from Delsett et al., 2016); (B) skeletal reconstruction of PMO 224.248, where red indicates preserved elements. Scale bar equals $50 \mathrm{~cm}$. Drawn by Aubrey Jane Roberts

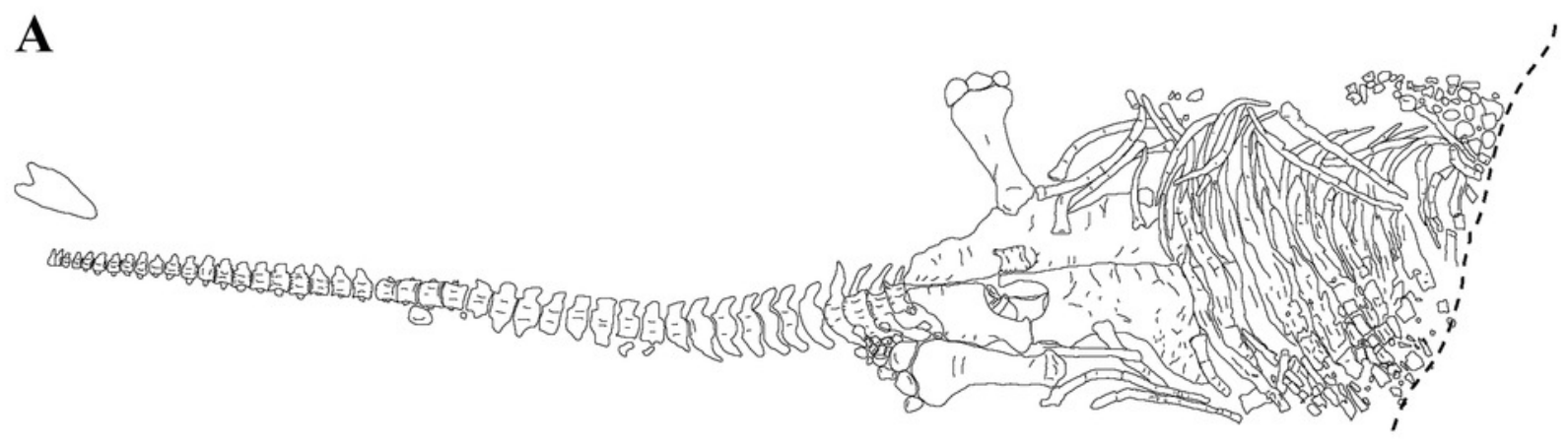

B

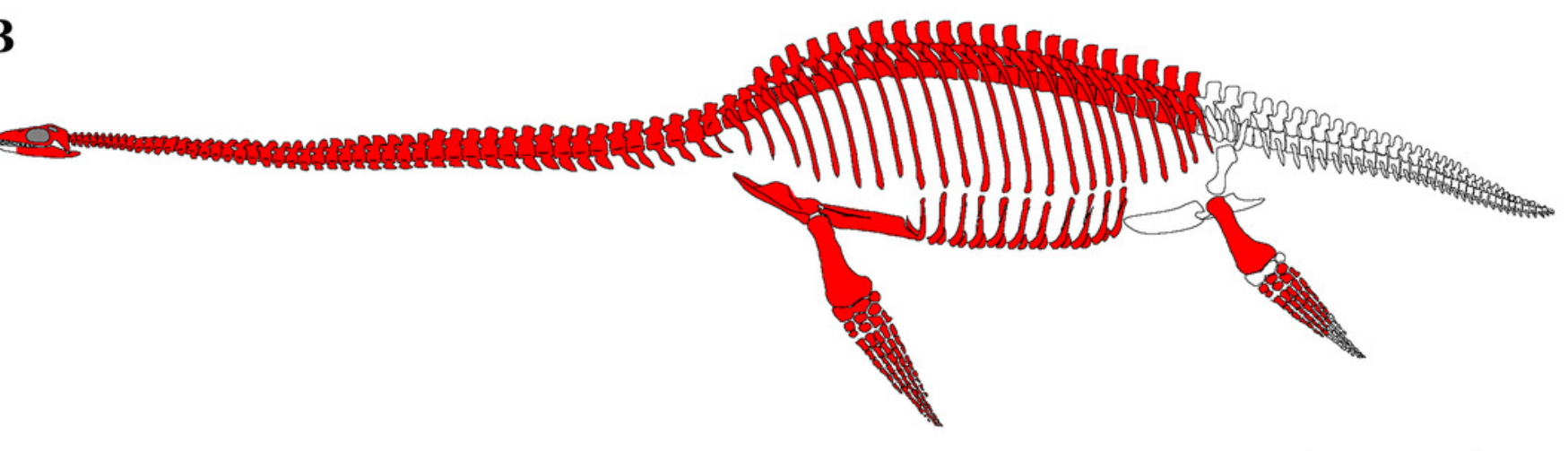




\section{Figure 3}

The cranium of Ophthalmothule cryostea, PMO 224.248 in dorsal view.

(A) photo of PMO 224.248, (B) $\mu C T$ reconstruction and (C) interpretation. Abbreviations: bo, basioccipital; en, external naris; ex-op, exoccipital-opisthotic; f, frontal; ifv, interfrontal vacuity; mx, maxilla; $p$, parietal; pif, pineal foramen; pm, premaxilla; pop, paraoccipital process; q, quadrate; so, supraoccipitial; sq, squamosal; tfen, temporal fenestra. Scale bar equals $5 \mathrm{~cm}$. Photograph and reconstruction by Aubrey Jane Roberts 


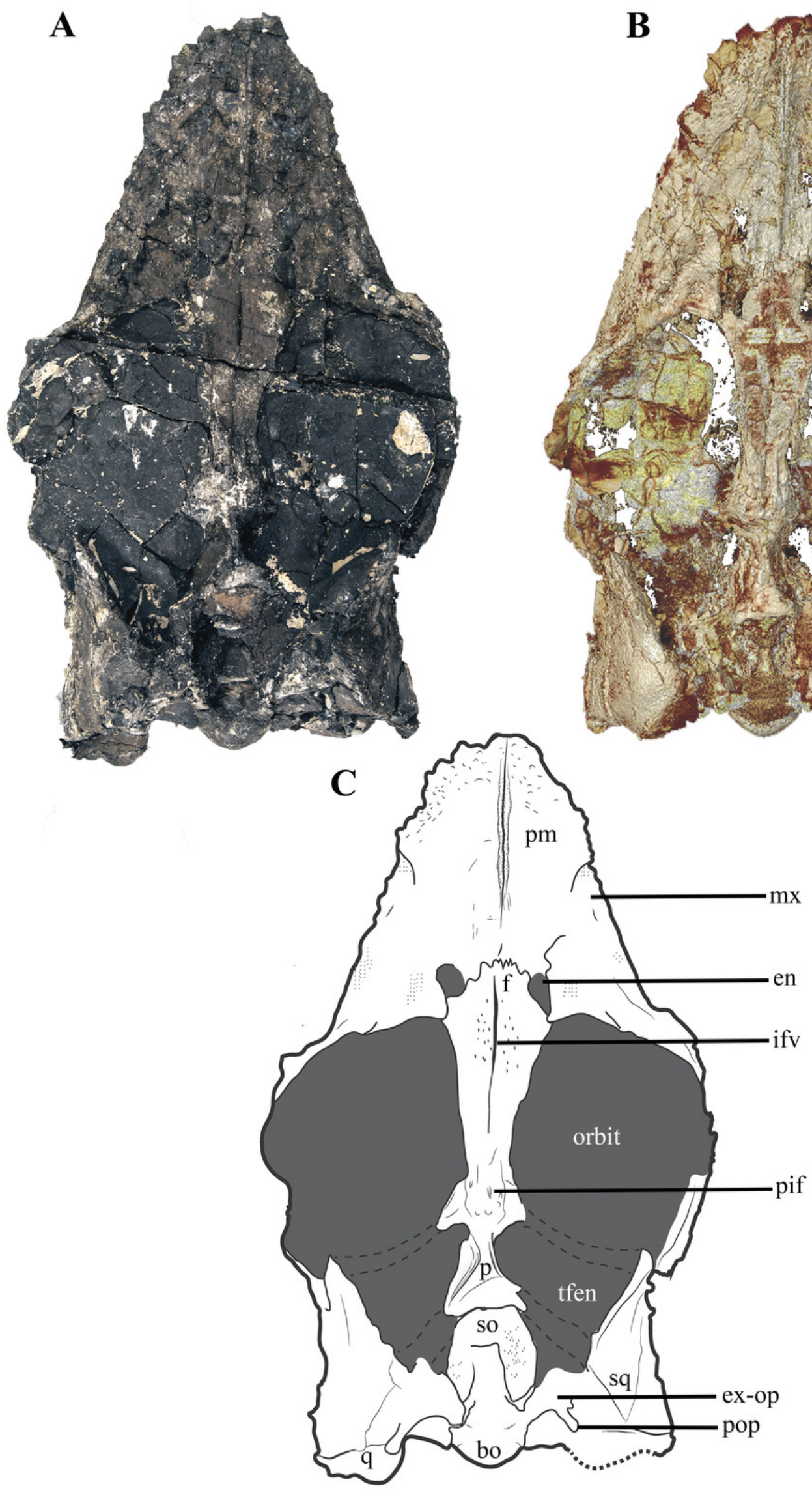




\section{Figure 4}

The cranium of Ophthalmothule cryostea, PMO 224.248 in palatal view.

(A) photo, (B) $\mu C T$ reconstruction and (C) interpretation. Abbreviations: aiv, anterior interpterygoid vacuity; bo, basioccipital; in, internal naris; mx, maxilla; pal, palatine; pbs, parabasisphenoid pitf, pituitary fossa; piv, posterior interpterygoid vacuity; pm, premaxilla; pt, pterygoid; q, quadrate; sq, squamosal; stfen, subtemporal fenestra; v, vomer. Scale bar equals $5 \mathrm{~cm}$. Photograph and reconstruction by Aubrey Jane Roberts 

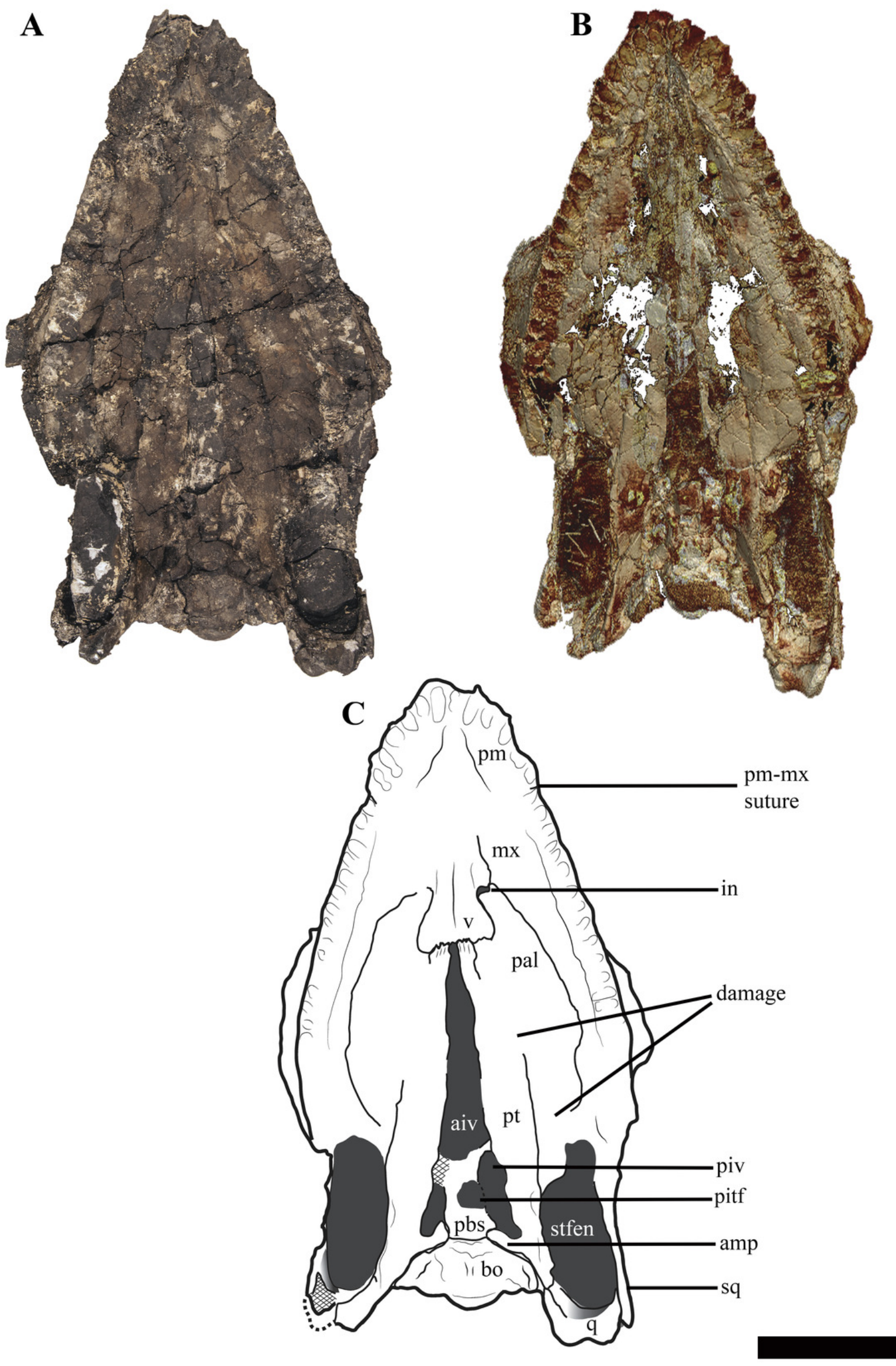


\section{Figure 5}

Reconstructions of the cranium of Ophthalmothule cryostea, PMO 224.248.

(A) dorsal, (B) palatal and (C) posterior views. Abbreviations: aiv, anterior interpterygoid vacuity; ba, basal articulation; bo, basioccipital; boc, basioccipital condyle; bot, basioccipital tuber; en, external naris; ex-op, exoccipital-opisthotic; f, frontal; ifv, interfrontal vacuity; in, internal naris; $m x$, maxilla; $p$, parietal; pal, palatine; pbs, parabasispenoid; pif, pineal foramen; pitf, pituitary fossa; piv, posterior interpterygoid vacuity; pm, premaxilla; pt, pterygoid; q, quadrate; so, supraoccipital; sq, squamosal; stfen, subtemporal fenestra; tfen, temporal fenestra; $v$, vomer. Scale bar equals $5 \mathrm{~cm}$. Drawing by Aubrey Jane Roberts 

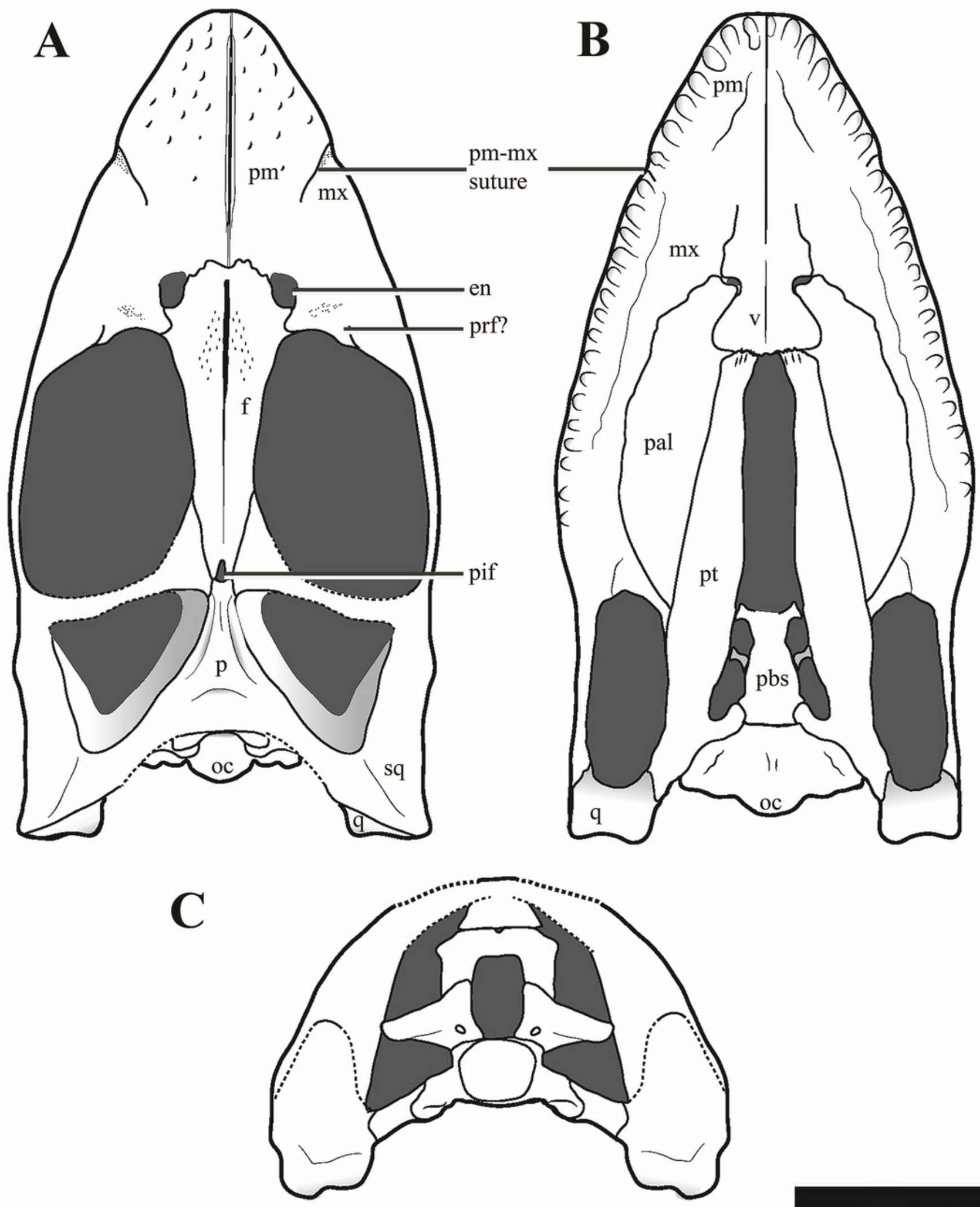
Figure 6

A $\mu C T$ slice (cross section) of the posterior part of the skull roof and braincase of Ophthalmothule cryostea, PMO 224.248, illustrating the parietal fossae and pineal foramen.

Abbreviations: bo, basioccipital; f, frontal; p, parietal; pfos, parietal fossae; pif, pineal foramen; pop, paraoccipital process. Scale bar equals $1 \mathrm{~cm}$. 


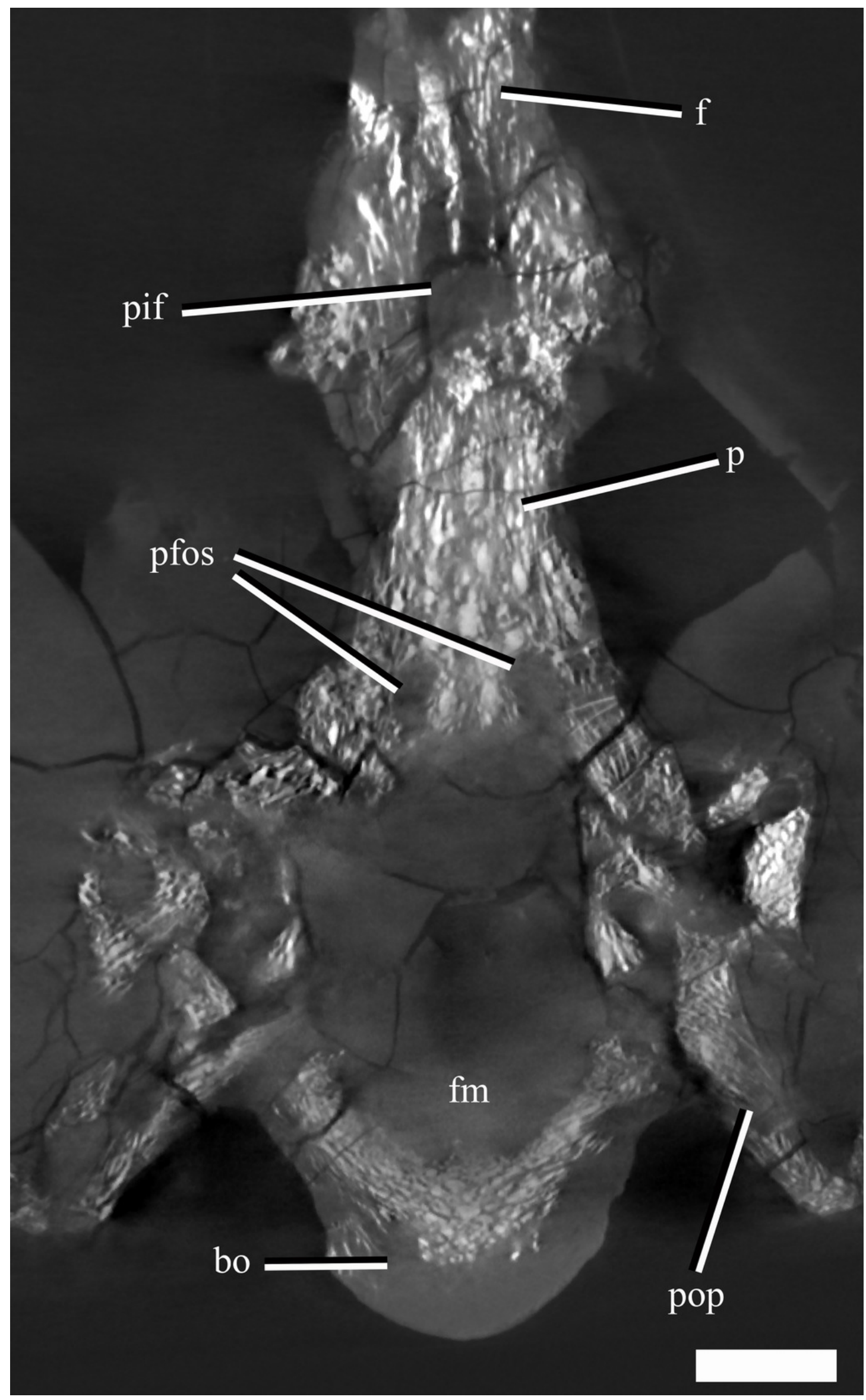




\section{Figure 7}

The cranium of Ophthalmothule cryostea, PMO 224.248 in posterior view.

Abbreviations: boc, basioccipital condyle; ex-op, exoccipital opisthotic; q, quadrate; sq, squamosal. Scale bar equals $1 \mathrm{~cm}$. Photograph by Aubrey Jane Roberts

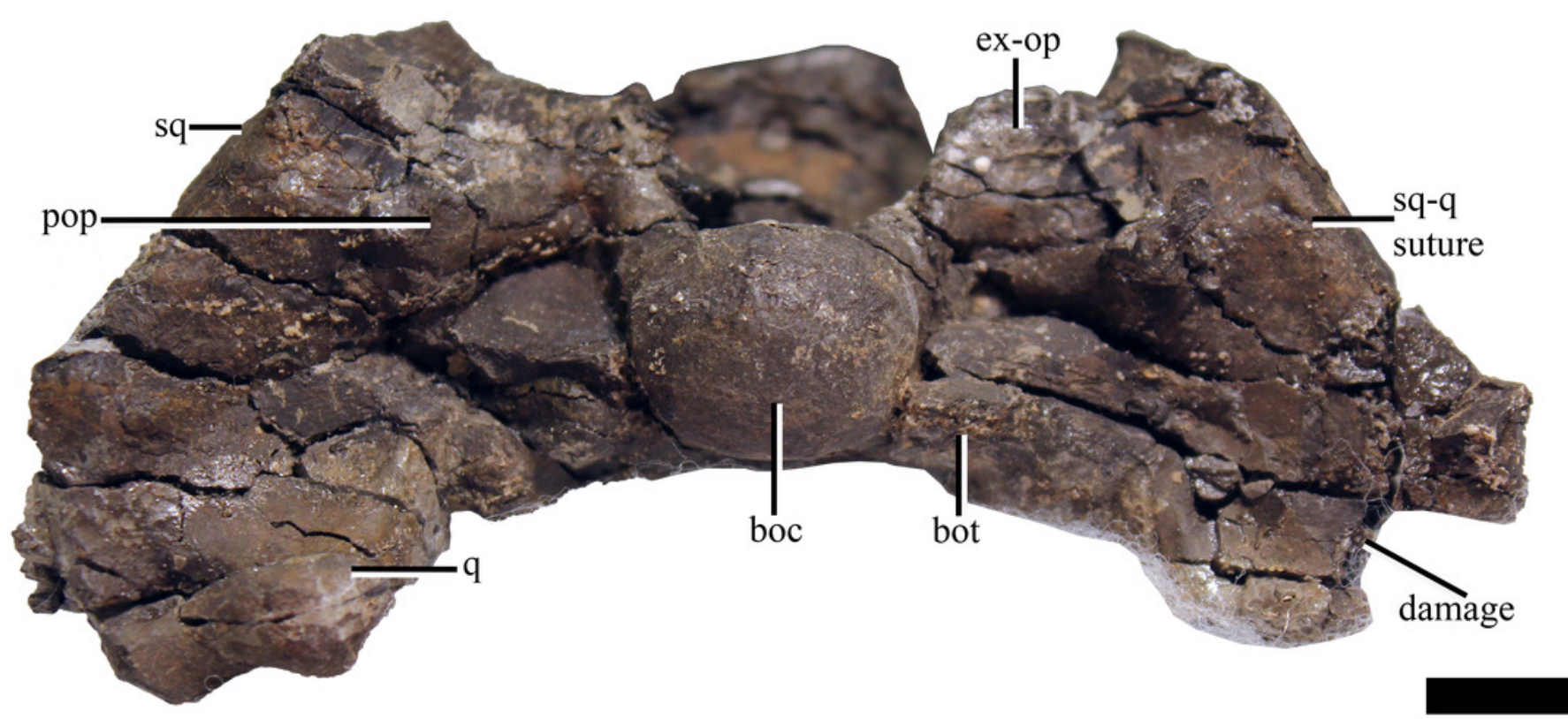




\section{Figure 8}

Surface reconstruction of the braincase and pterygoids of Ophthalmothule cryostea, PMO 224.248 using the $\mu$ CT images.

In (A) dorsal, (B) anterodorsal and (C) lateral views. Abbreviations: aiv; anterior interpterygoid vacuity; ba, basal articulation; bo; basioccipital; boc, basioccipital condyle; bof, basioccipital foramina; bot, basioccipital tuber; dmp, dorsal median pit; ex-op; exoccipital-opisthotic; fo; fenestra ovalis; hsc, horizontal semicircular canal; pbs, parabasisphenoid; pitf, pituitary fossa; piv, posterior interpterygoid vacuity; pop, paraoccipital process; pro, prootic; pt, pterygoid; vsc, vertical semicircular canal. Scale bar equals $2 \mathrm{~cm}$. 

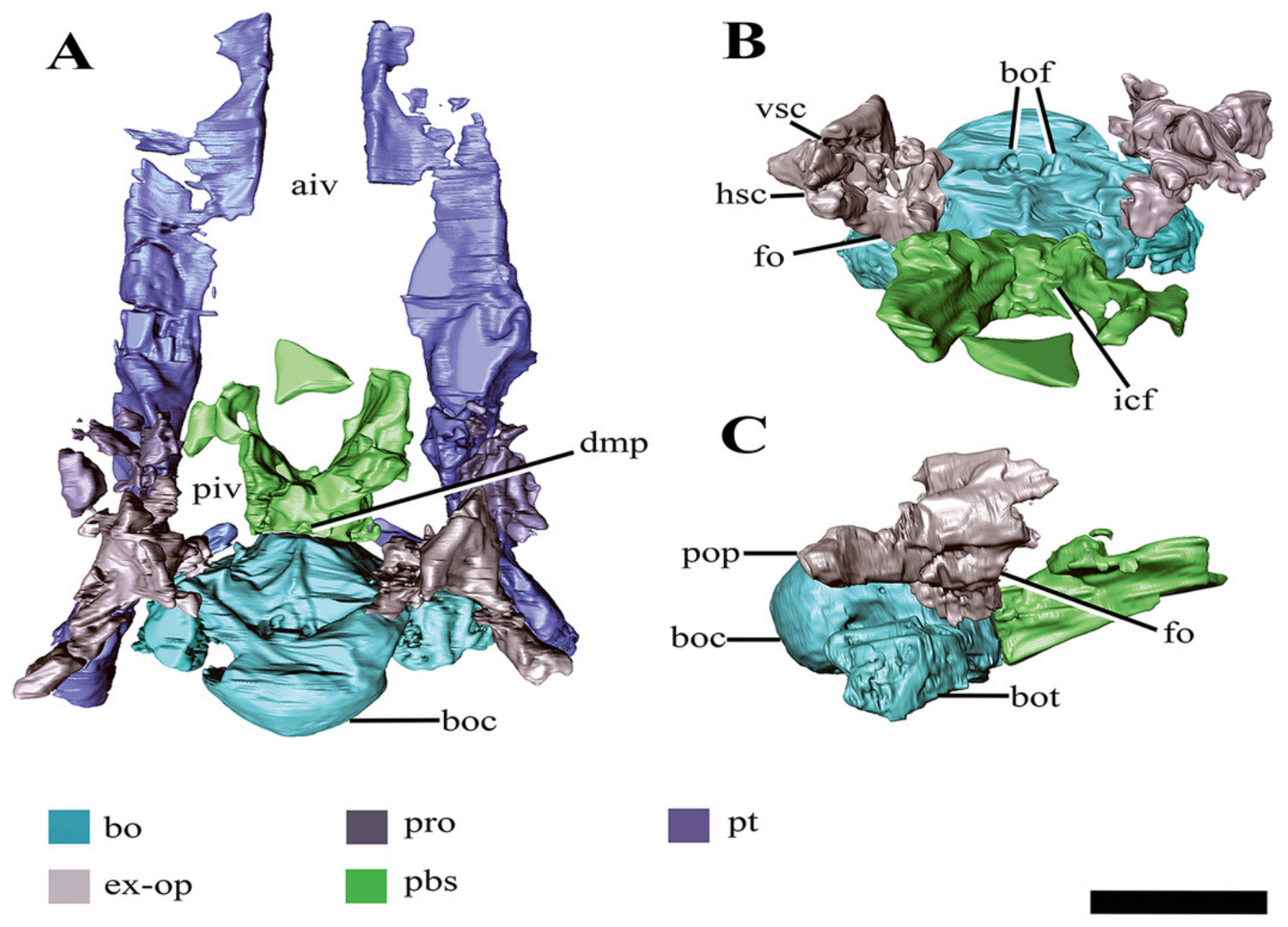


\section{Figure 9}

The right exoccipital-opisthotic of Ophthalmothule cryostea, PMO 224.248 segmented out from $\mu \mathrm{CT}$ images.

In (A) posterior, (B) lateral, (C) anterior and (D) medial views. Abbreviations: bof, position of basioccipital facet; fo, position of fenestra ovalis; hsc, horizontal semicircular canal; pop, paraoccipital process; prof, position of prootic facet; sof, position of supraoccipital facet; sqf, position of squamosal facet; ut, utriculus; vsc, posterior vertical semicircular canal; $X$, position of cranial nerve openings. Scale bar equals $\sim 1 \mathrm{~cm}$ 

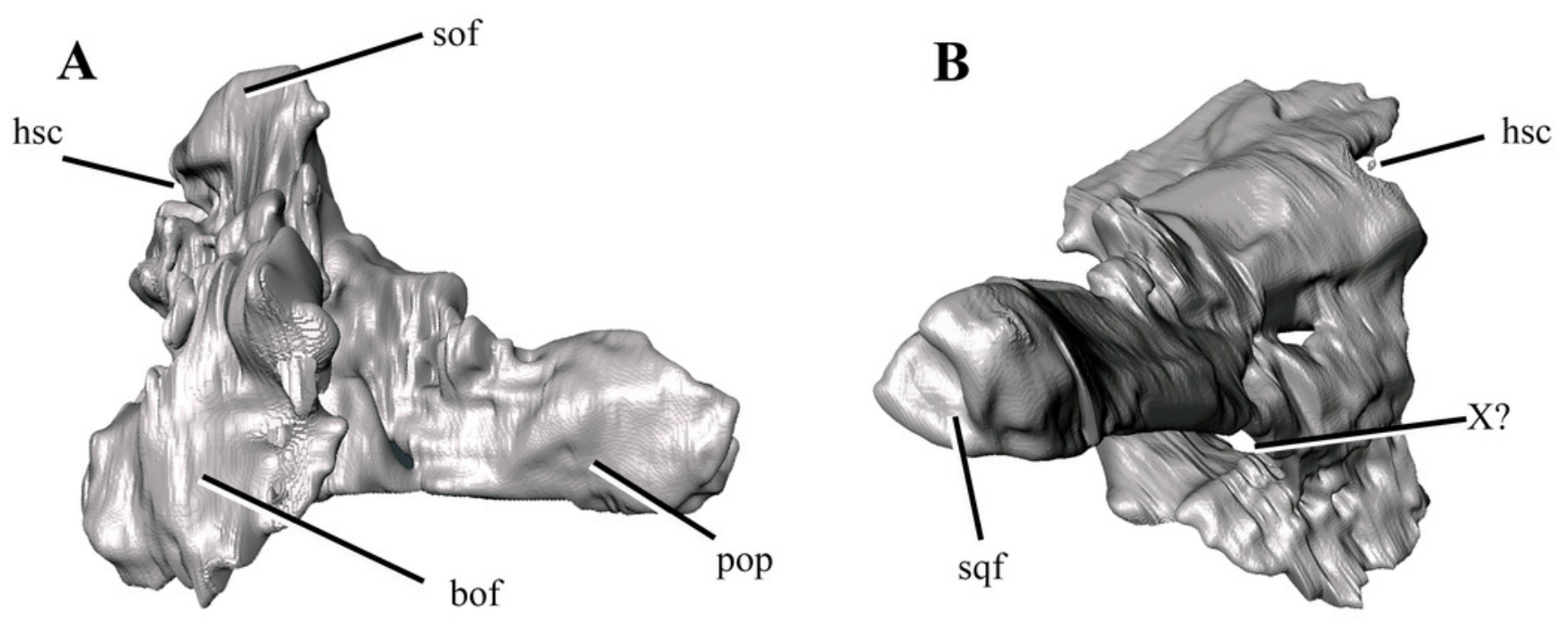

C
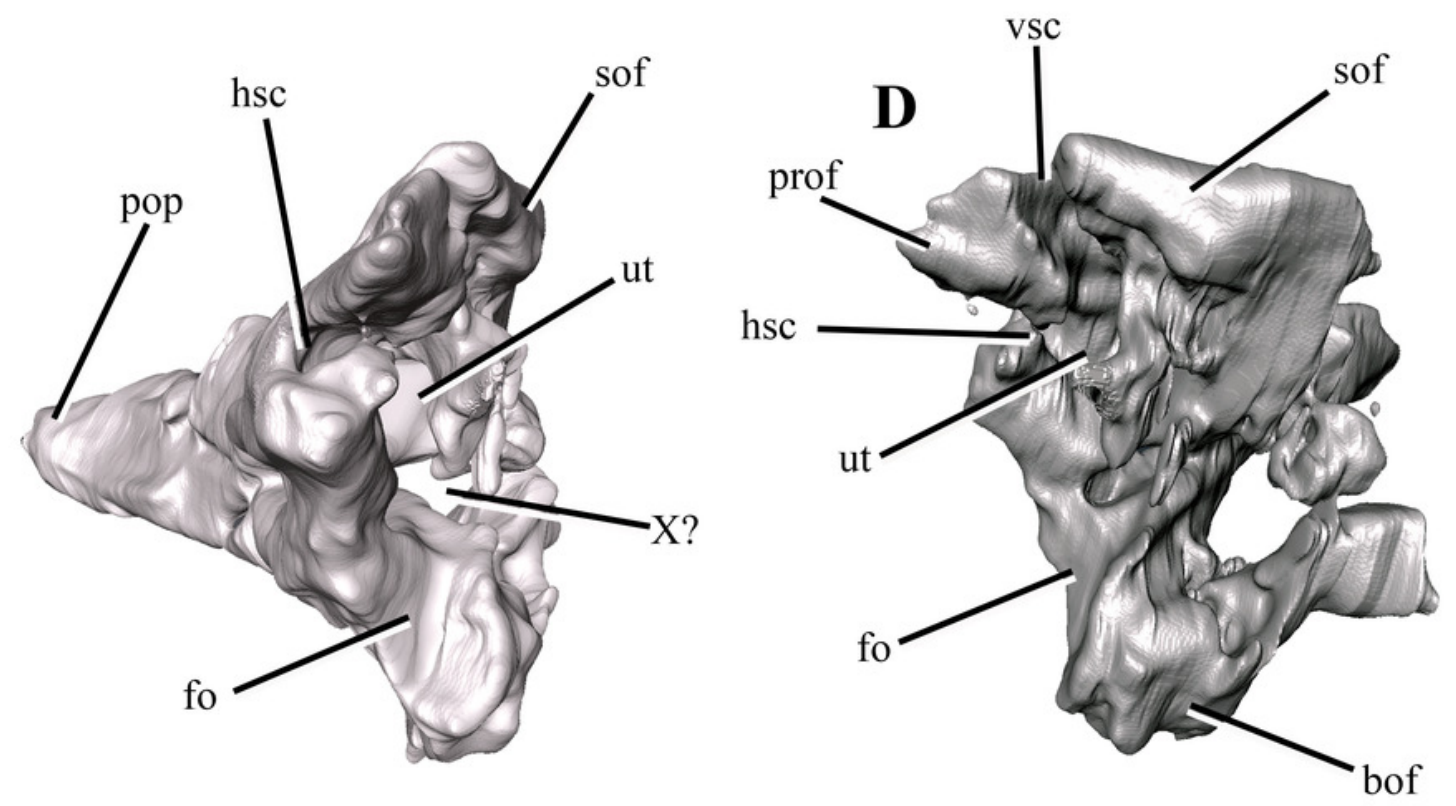


\section{Figure 10}

The left mandible of Ophthalmothule cryostea, PMO 224.248 shown as the computed tomography surface rendering and interpretations.

In (A-B) medial, (C-D) dorsal and (E-F) lateral views. Abbreviations: a, angular; alv, alveolus; art, articular; $\mathrm{cp}$, coronoid process; d, dentary; sa, surangular; $\mathrm{sp}$, splenial. Scale bar equals 2 $\mathrm{cm}$. Reconstructions and drawings by Aubrey Jane Roberts 
A

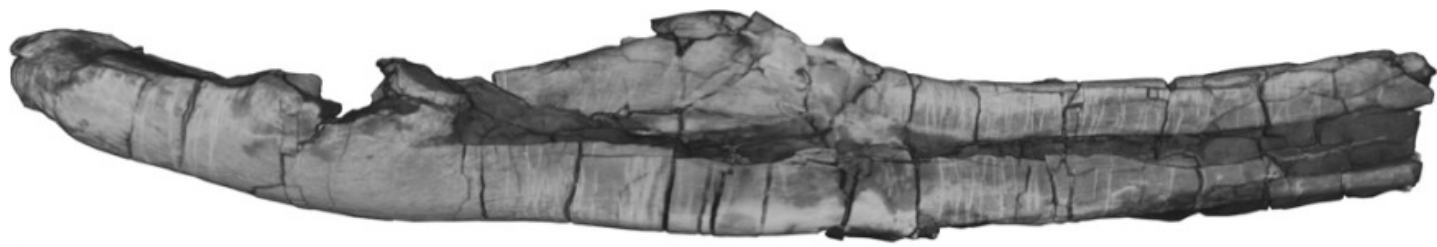

B
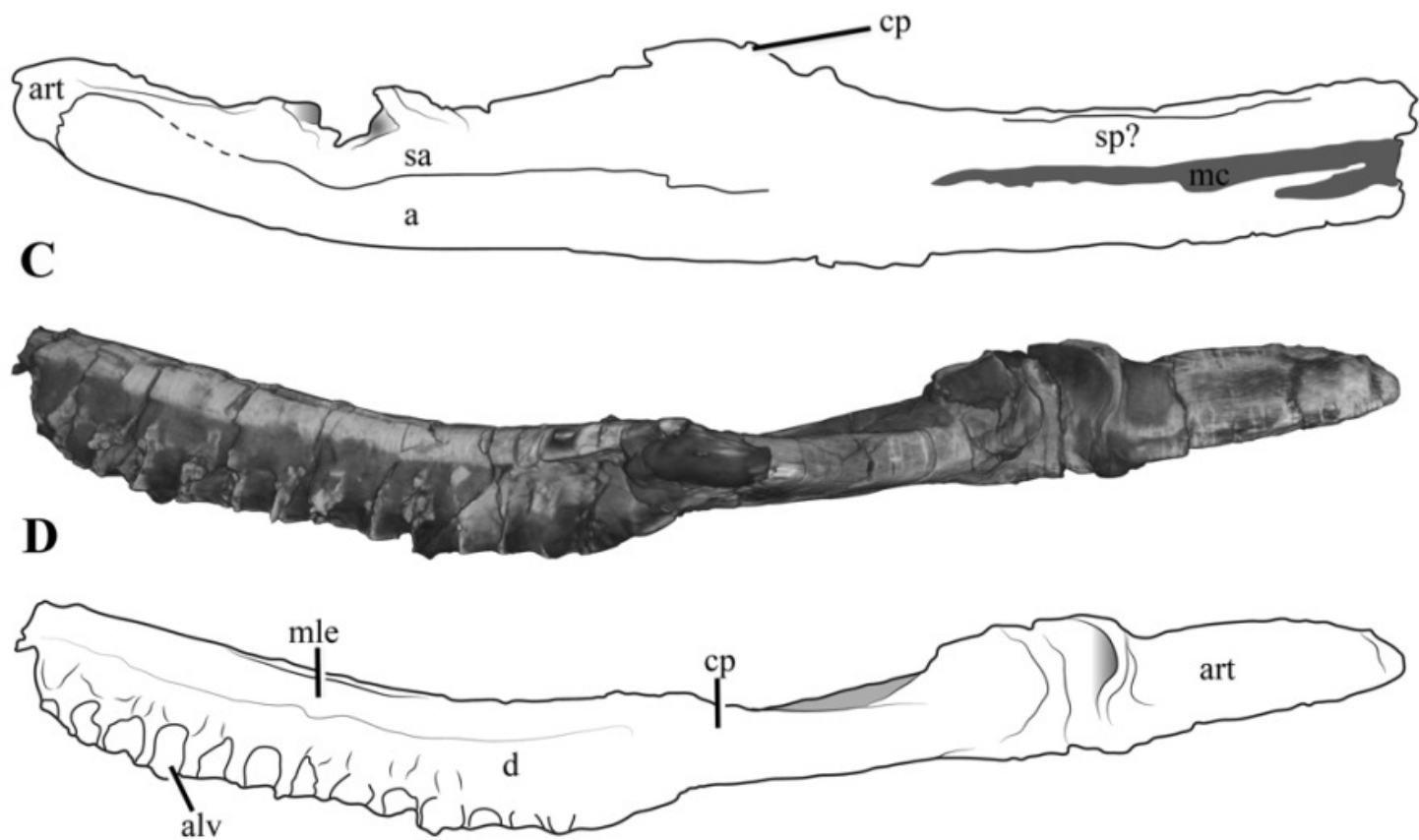

E

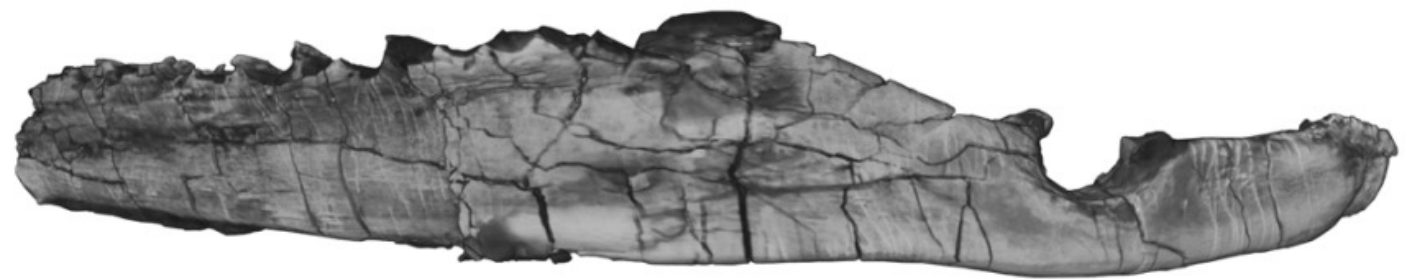

F

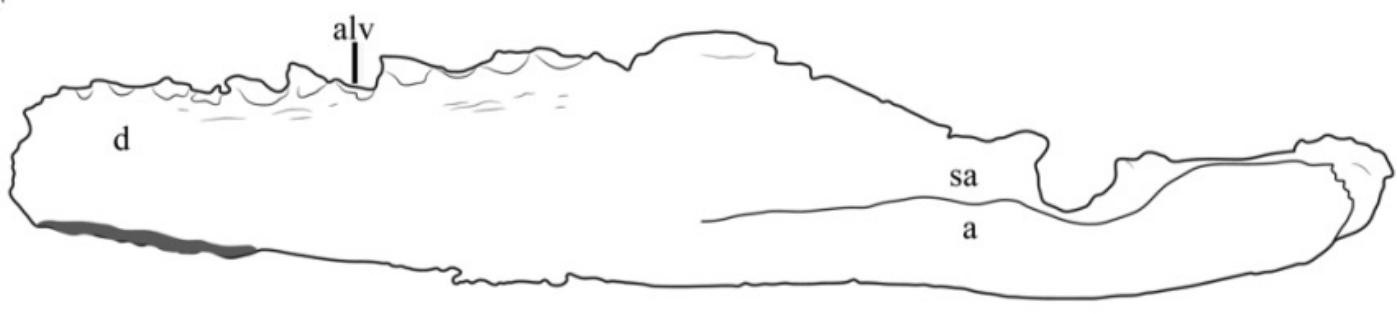




\section{Figure 11}

Isolated teeth of Ophthalmothule cryostea, PMO 224.248.

(A) the most complete tooth in axial view; (B-E) an incomplete tooth in (B,D) axial, $(C)$, lingual and $(E)$, labial views with a cross section of the tooth. Abbreviations: be, broken edge; rt, root tip. Scale bar equals $0.5 \mathrm{~cm}$. Photography by Aubrey Jane Roberts

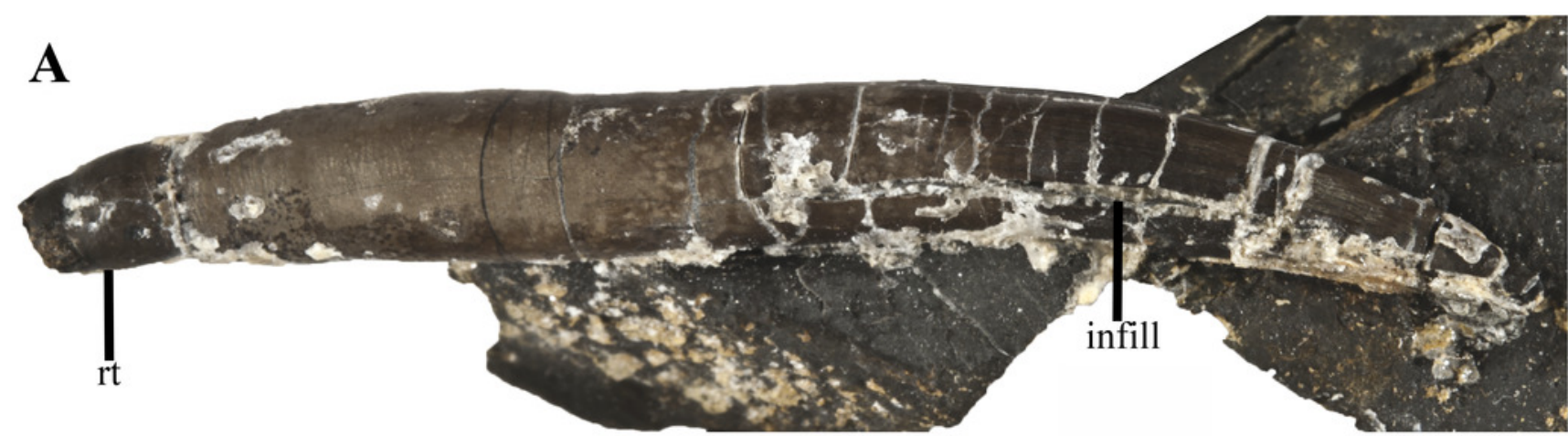

B

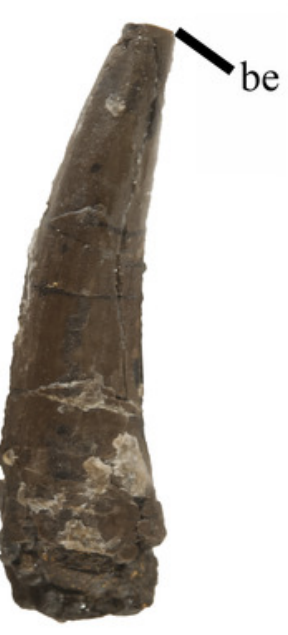

C

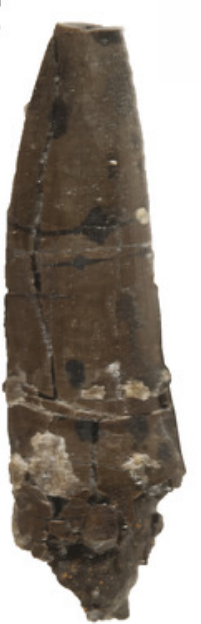

D

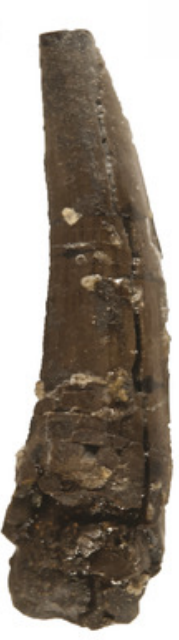

$\mathbf{E}$

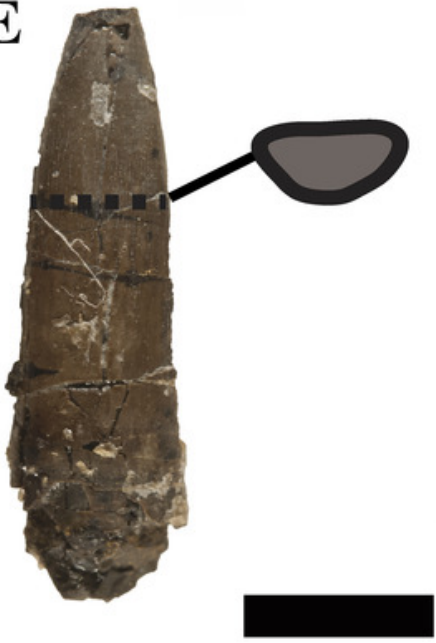




\section{Figure 12}

Photos and interpretations of the atlas-axis complex of Ophthalmothule cryostea, PMO 224.268.

In (A-B) anterior, (C-D) lateral, (E-F) posterior and (G-H), ventral views. Abbreviations: aas, atlas-axis suture; atc, atlas centrum; atr, atlantal rib; axc, axial centrum; axr, axial rib; hyp, hypophyseal ridge; ns, neural spine; poz, postzygapophysis. Scale bar equals $1 \mathrm{~cm}$. Photography and drawings by Aubrey Jane Roberts.

A

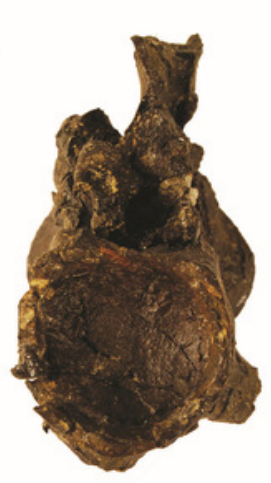

$\mathbf{E}$

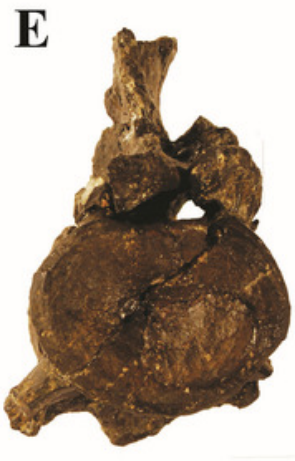

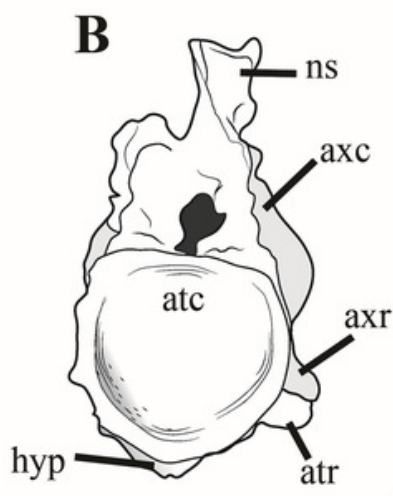

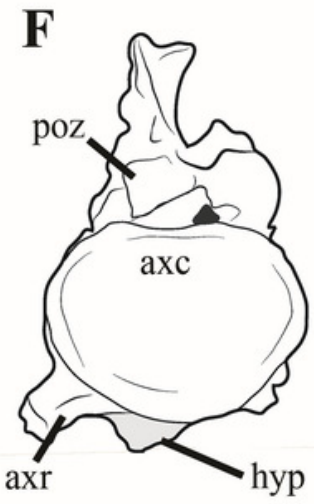

C

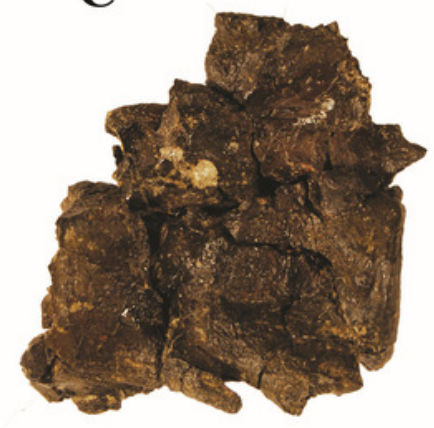

G

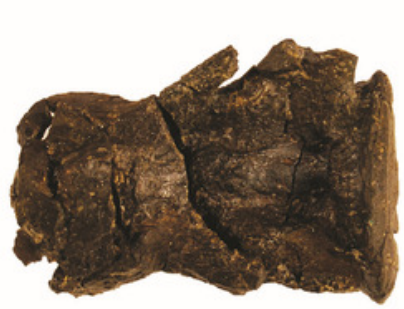

D

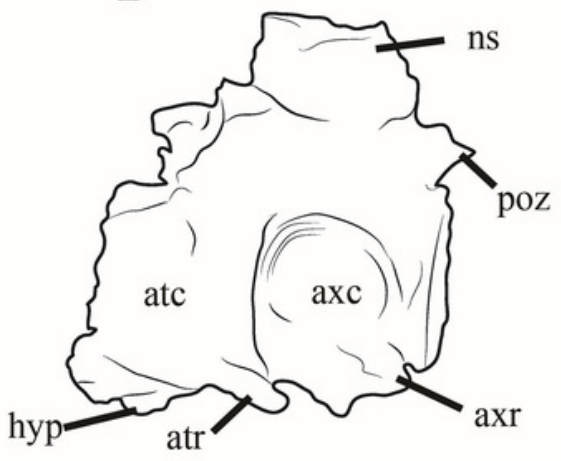

H

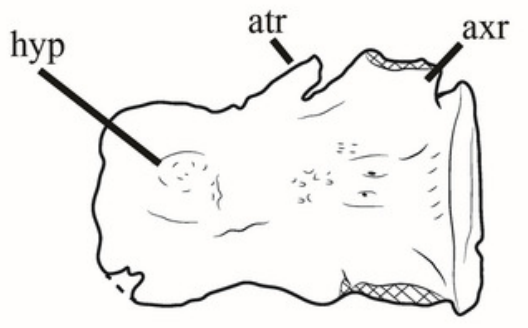




\section{Figure 13}

Selected anterior - mid cervical vertebrae of Ophthalmothule cryostea, PMO 224.248.

The $4^{\text {th }}$ cervical vertebrae in (A) anterior, (B) lateral, (C) dorsal and (D) ventral views. (E) the $7^{\text {th }}$ and $8^{\text {th }}$ articulated cervical vertebrae in lateral view. (F) the articulated $14^{\text {th }}$ and $15^{\text {th }}$ cervical vertebrae in lateral view. $(\mathrm{G})$ the $15^{\text {th }}$ cervical in dorsal view. The $17^{\text {th }}$ vertebrae in $(H)$ anterior and (I) ventral views. Abbreviations: $3^{\text {rd }} \mathrm{ns}$, neural spine from the $3^{\text {rd }}$ cervical vertebrae; nc, neural canal; ns, neural spine; poz, postzygapophyses, prz, prezygapophyses, ri, ventral ridge; scf, subcentral foramina. Scale bar equals $4 \mathrm{~cm}$. Photography by Aubrey Jane Roberts 

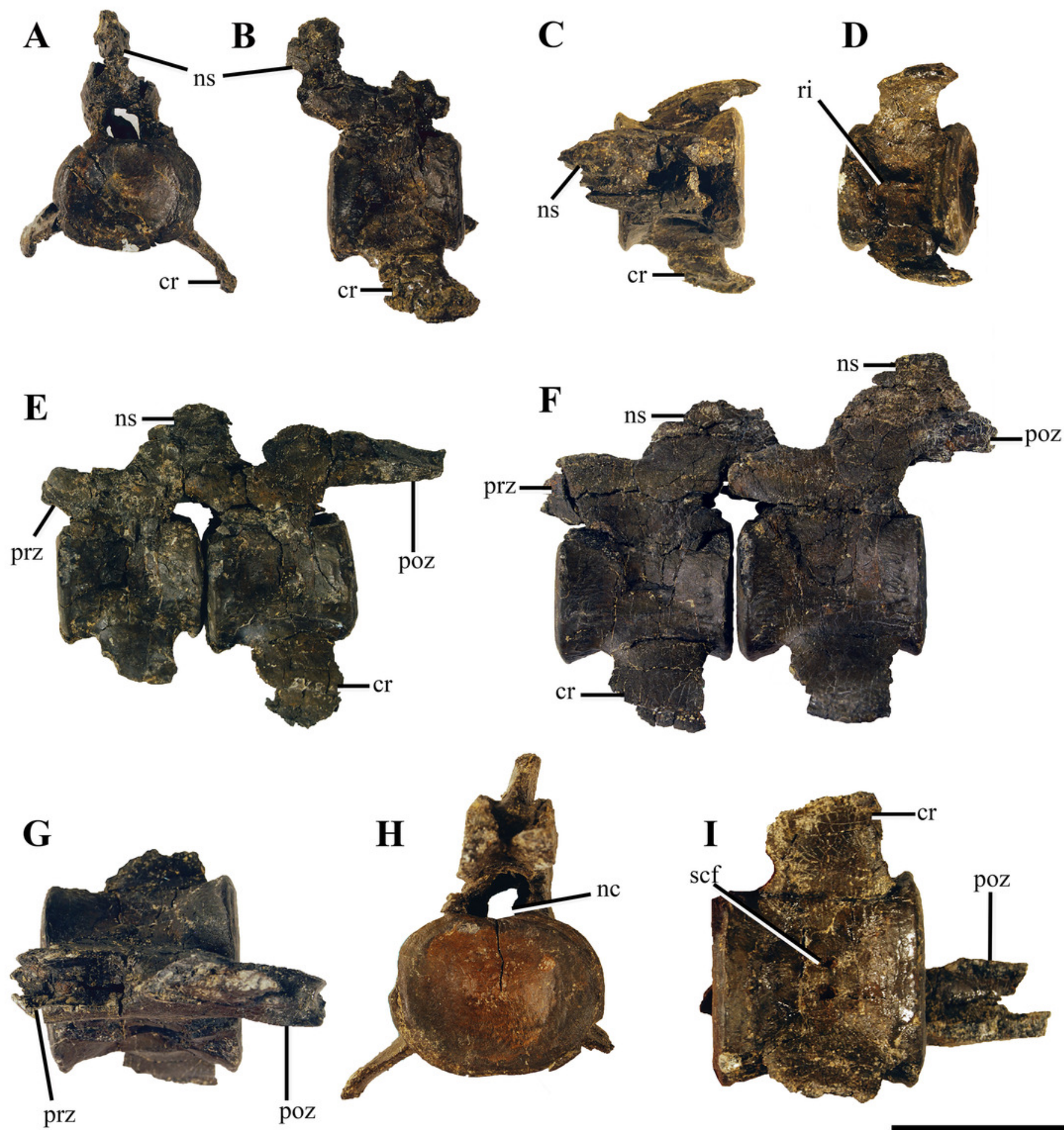


\section{Figure 14}

Two posterior cervical vertebrae of Ophthalmothule cryostea, PMO 224.248.

The $29^{\text {th }}$ cervical vertebra in (A) anterior, (B) posterior and (C) lateral views. The $44^{\text {th }}$ cervical vertebra in (D) anterior, (E) dorsal and (F) ventral views. Abbreviations: cr, cervical rib; Irr, longitudinal rib ridge; nc, neural canal; nf, nutritive foramina; ns, neural spine; poz, postzygapophyses; prz, prezygapophyses; scf, subcentral foramina. Scale bar equals $4 \mathrm{~cm}$. Photography by Aubrey Jane Roberts

A
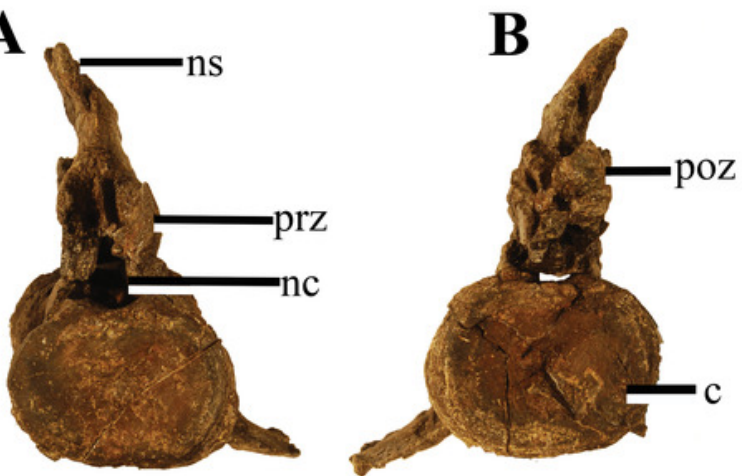

$\mathbf{E}$

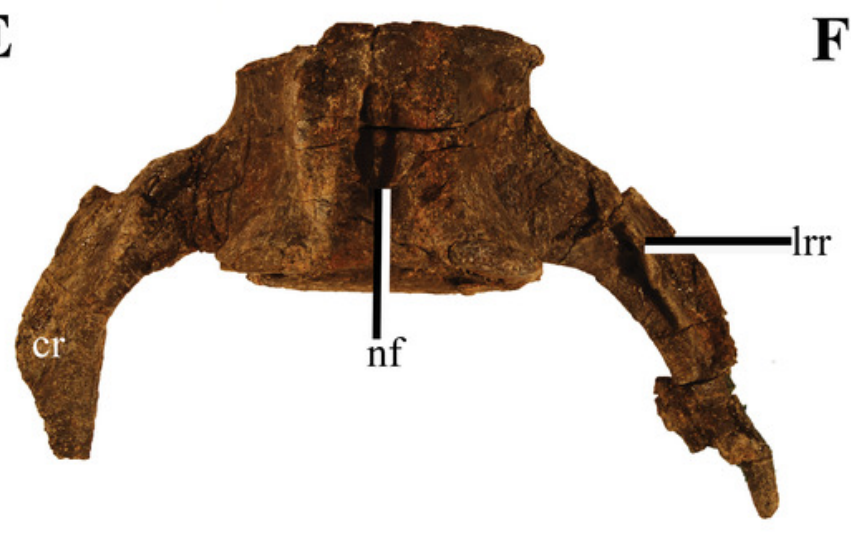

$\mathbf{F}$

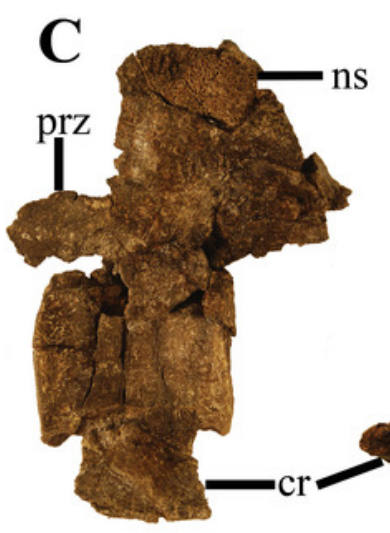

D

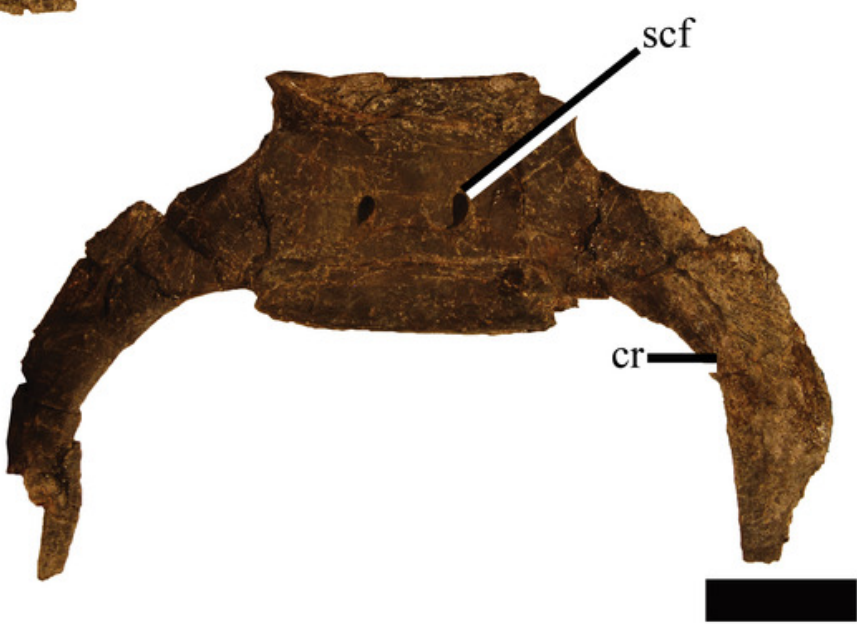




\section{Figure 15}

Pectoral vertebrae and pectoral ribs of Ophthalmothule cryostea, PMO 224.248.

The $1^{\text {st }}$ pectoral in (A) anterior, (B) dorsal and (C) lateral views. The $2^{\text {nd }}$ pectoral in (D) anterior, (E) ventral and (F) lateral views. (G), the $3^{\text {rd }}$ pectoral vertebrae in posterior view.

The $1^{\text {st }}$ pectoral rib in (H) anterior, (I) posterior and (J) dorsal views. Abbreviations: fa, facet for the pectoral rib; Irr, longitudinal rib ridge; nf, nutritive foramina; rf, rib facet; scf, subcentral foramen. Scale equals $4 \mathrm{~cm}$. Photography by Aubrey Jane Roberts 
A

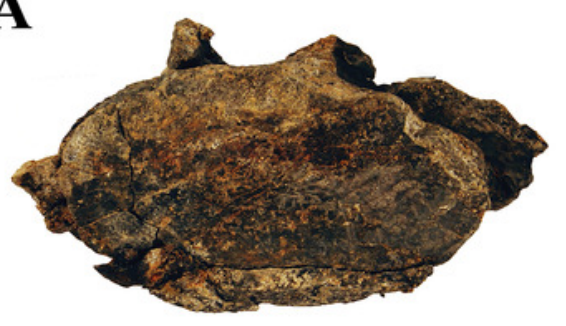

D

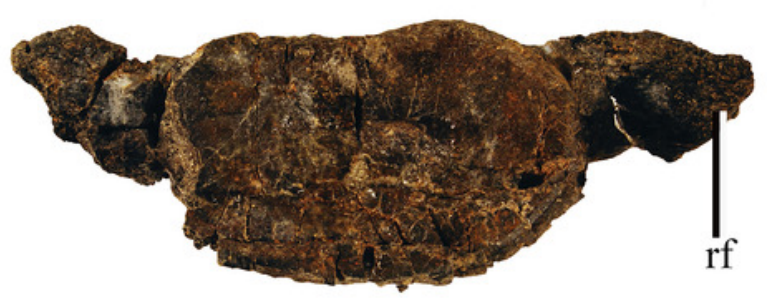

F

H

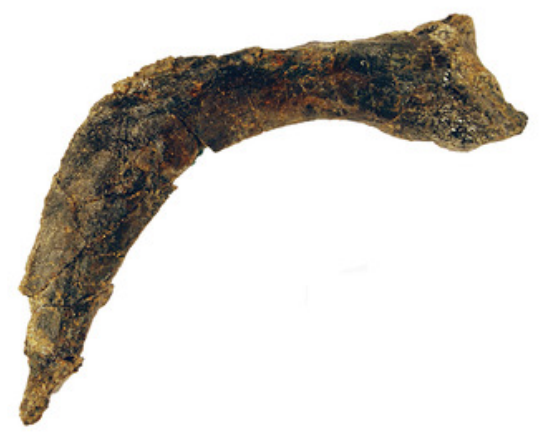

I
B

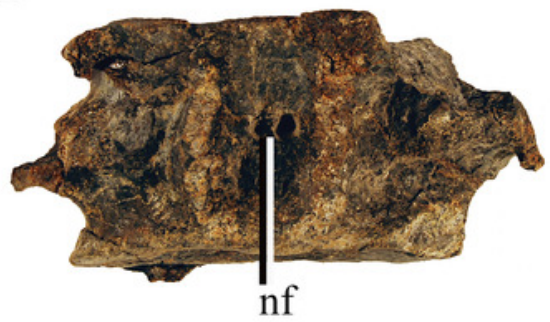

C

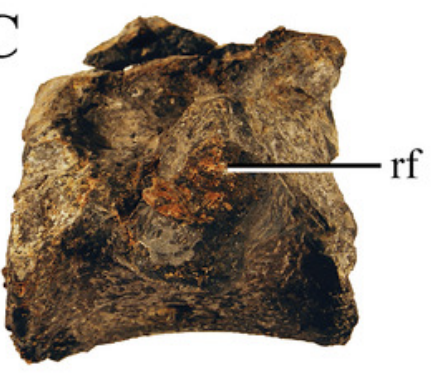

E

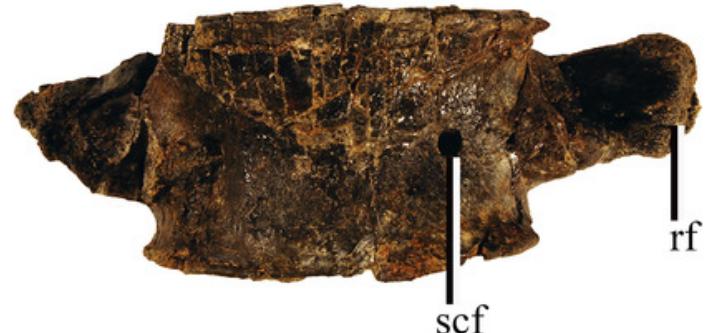

G
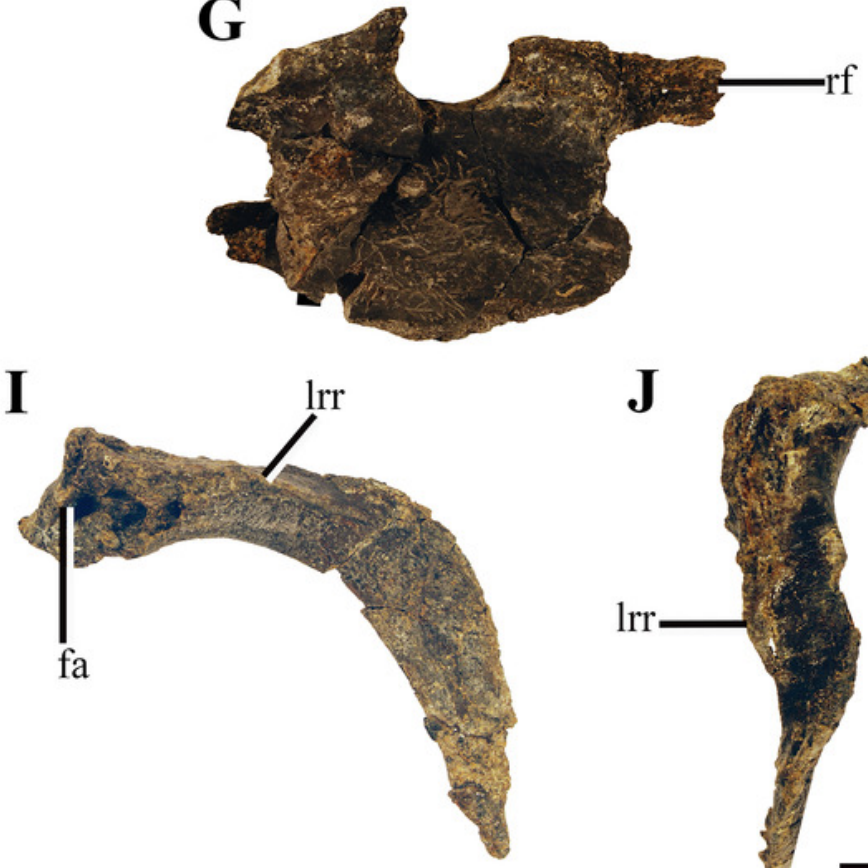

J

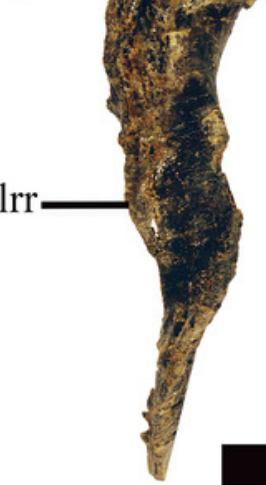




\section{Figure 16}

Dorsal vertebrae and ribs of Ophthalmothule cryostea, PMO 224.248.

The $1^{\text {st }}$ dorsal vertebrae in $(A)$ anterior and $(B)$ ventral views. The $2^{\text {nd }}$ dorsal vertebrae in (C) anterior, $(D)$ lateral and $(E)$ ventral views. The $3^{\text {rd }}$ dorsal vertebrae in $(F)$ anterior and $(G)$ ventral views. (H) a right anterior dorsal rib head in proximal view. (I) a complete rib in anterior view. Abbreviations: ph, proximal head; Irr, longitudinal rib ridge; scf, subcentral foramina; tp, transverse process. Scale equals $5 \mathrm{~cm}$. Photography by Aubrey Jane Roberts 
A

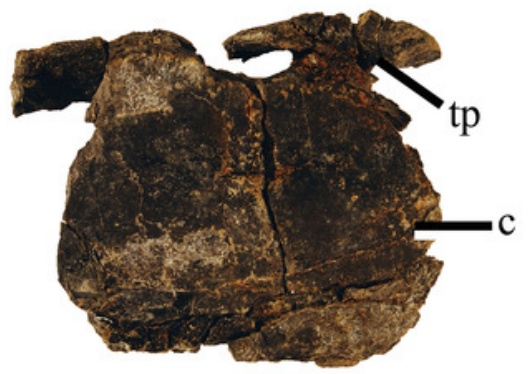

B

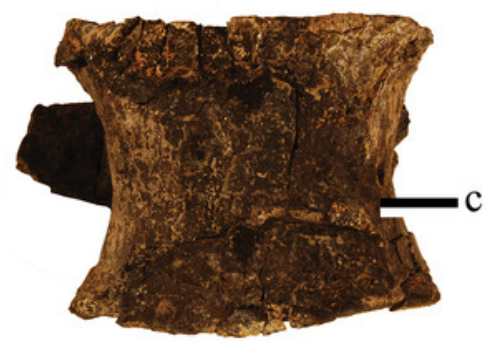

C

D
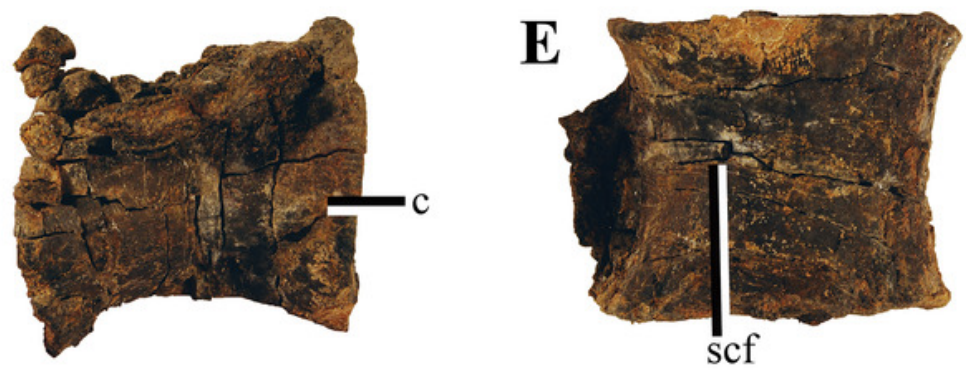

F

G

H
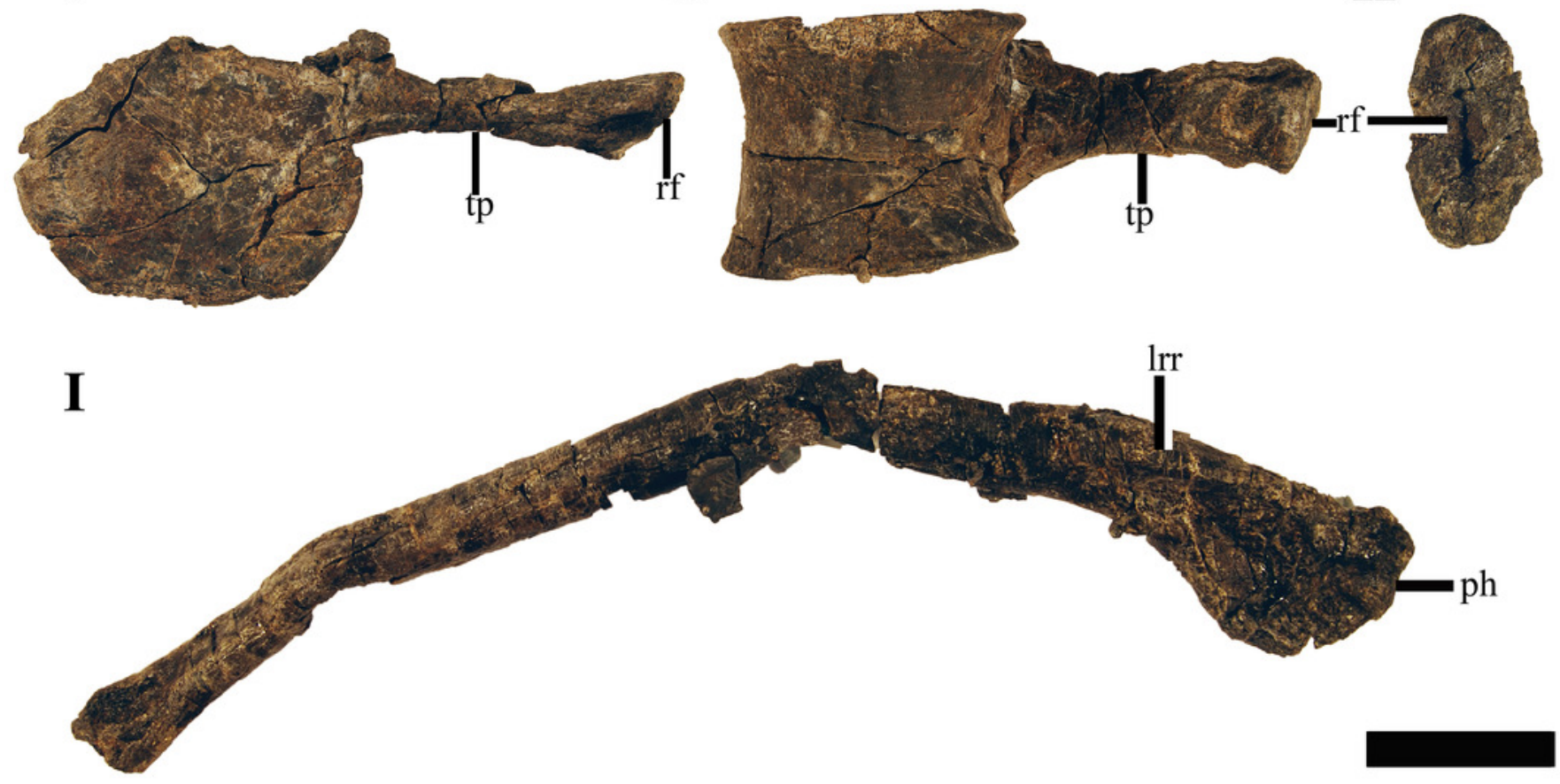


\section{Figure 17}

The pectoral girdle of Ophthalmothule cryostea, PMO 224.248.

(A) the complete pectoral girdle, (B) interpretation and (C) reconstruction. Abbreviations:

amp, anteromedial process of the coracoid; c, coracoid; cc, coracoid cornu; icl, interclavicle; pfn, pectoral fenestra; sc, scapula. Scale equals $5 \mathrm{~cm}$. Photography and drawings by Aubrey Jane Roberts.

A

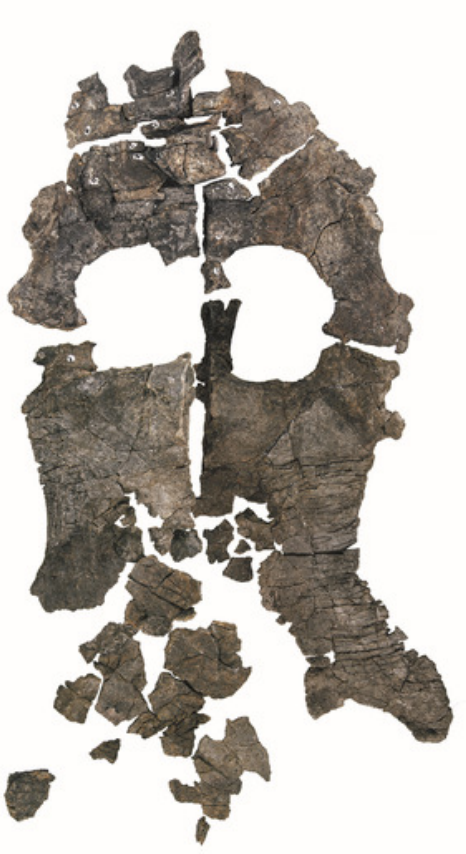

B

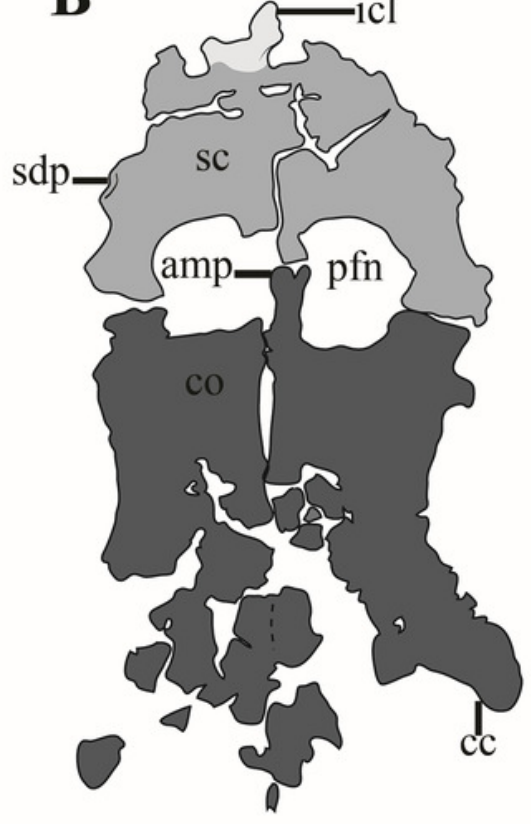

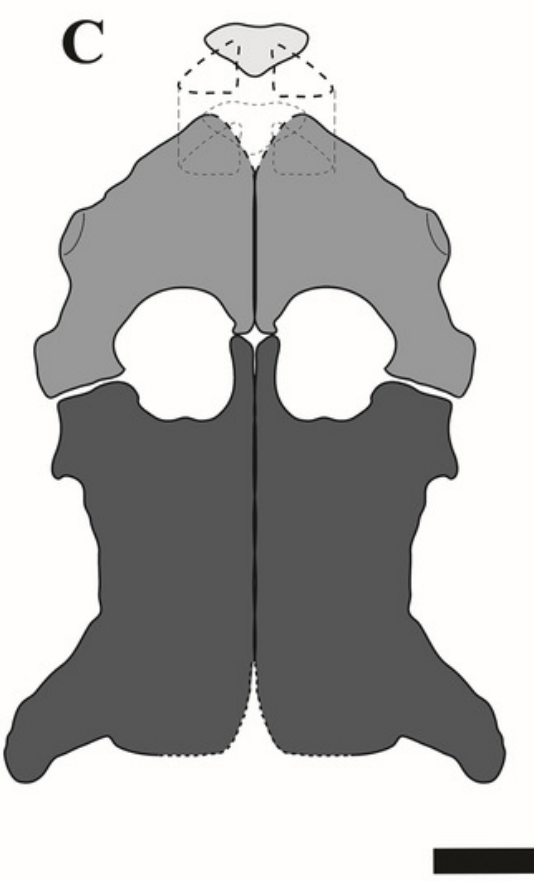




\section{Figure 18}

The left humerus and proximal limb elements of Ophthalmothule cryostea, PMO 224.248.

(A) the left forelimb with the proximal elements articulated in dorsal view. The left humerus

in (B) ventral, (C) anterior, (D) proximal, (E) posterior and (F) distal views. Abbreviations; apf, additional postaxial facet; ca, capitilum; hu, humerus; i, intermedium; nf, nutritive foramina, paf, postaxial flange; pao, postaxial ossicle; praf, preaxial facet; $r$, radius; ra, radiale; rf, radius facet; ru, rugosity; u, ulna; uf, ulna facet; ul, ulnare. Scale bar equals $5 \mathrm{~cm}$. Photography by Aubrey Jane Roberts 
A

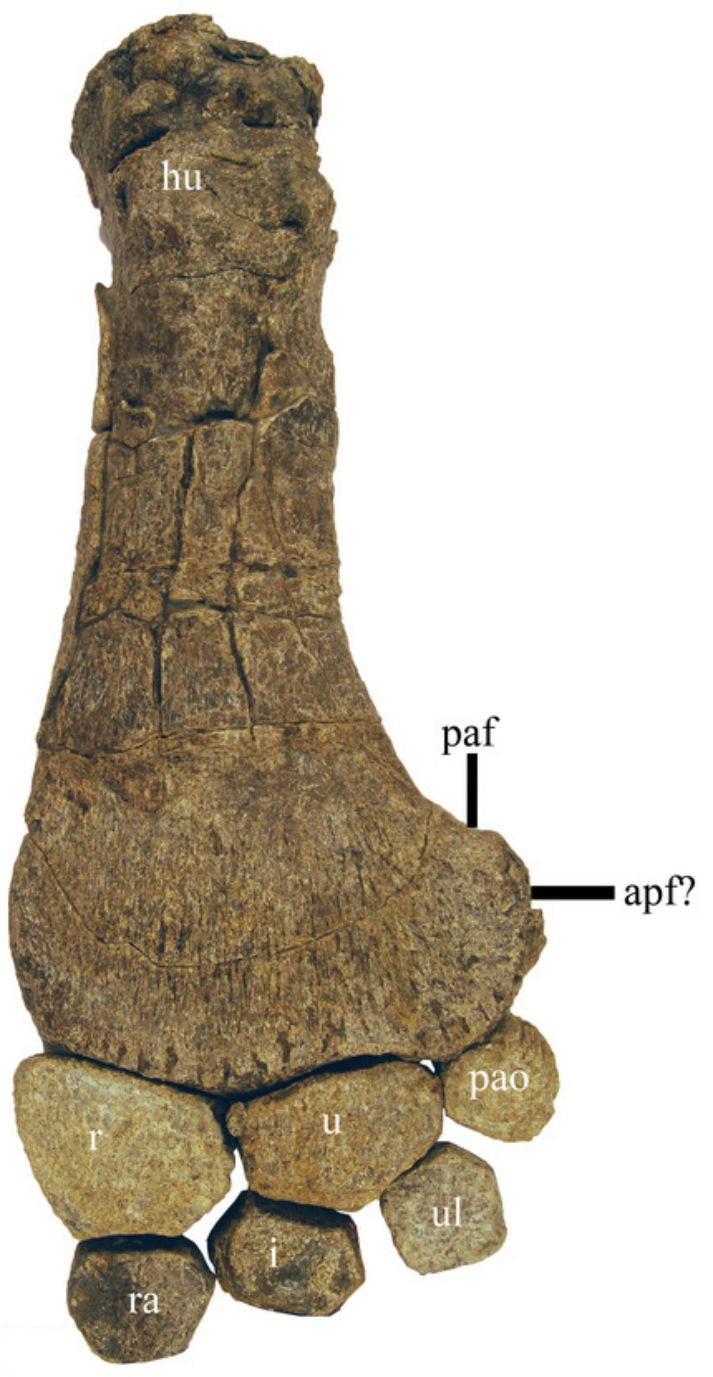

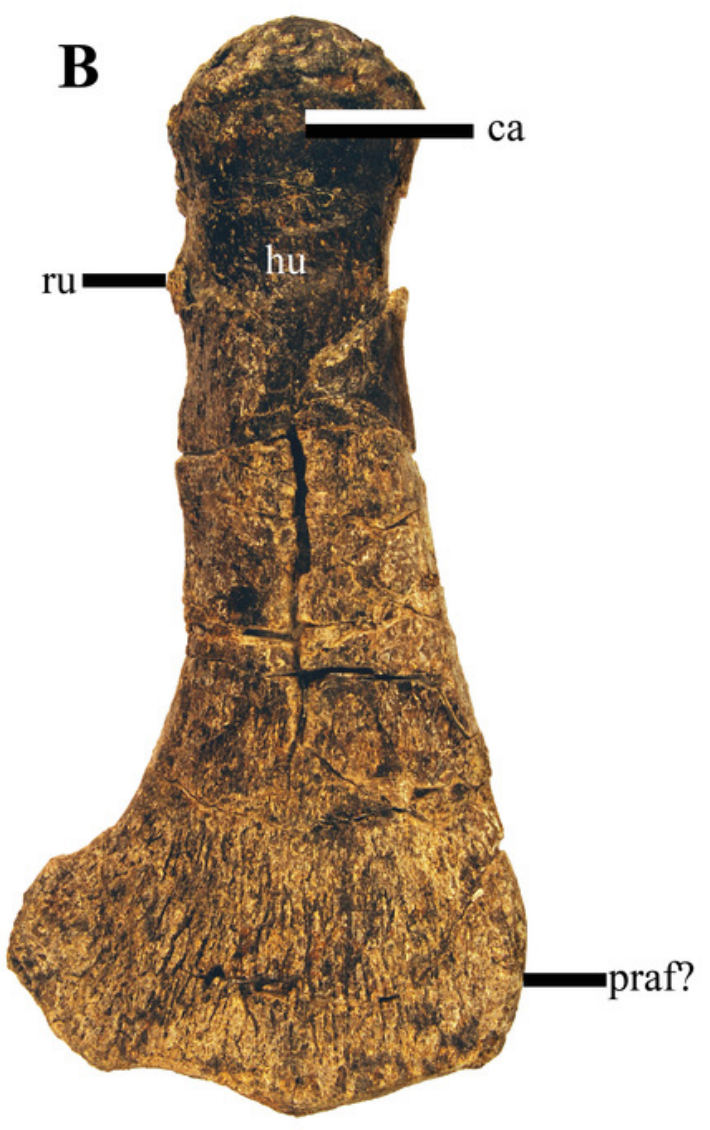

C

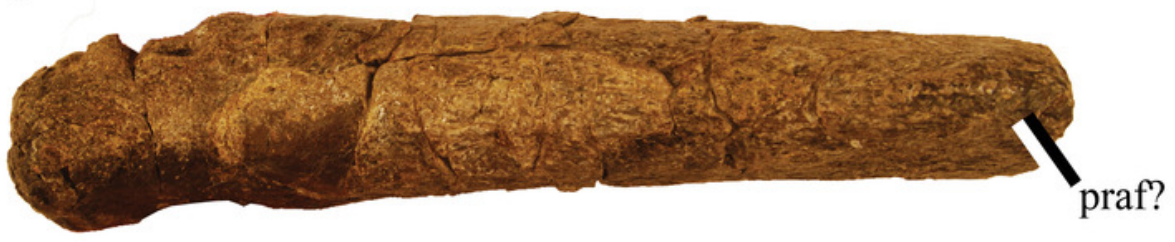

D

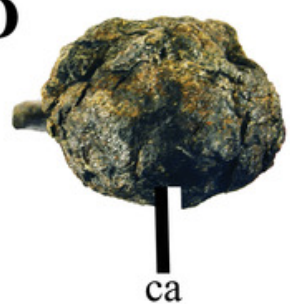

$\mathbf{E}$

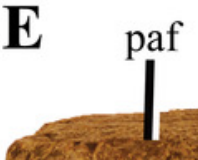

paf

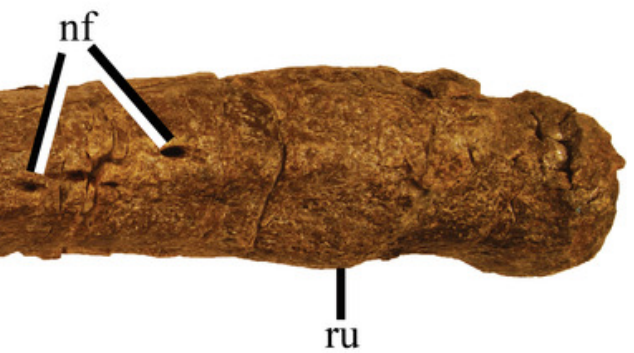

F

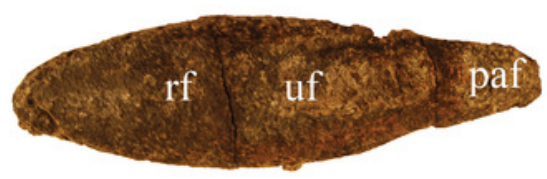




\section{Figure 19}

Time scaled strict consensus tree of Plesiosauria with a focus on cryptoclidids.

Strict consensus tree of 144 MPTs with a tree length of $1321(\mathrm{Cl}=0.299$ and $\mathrm{RI}=0.663)$.

Bremer support is shown below the clade branches. A more complete tree including Xenopsaria is available in ssupplementary information (Fig. S.14). 


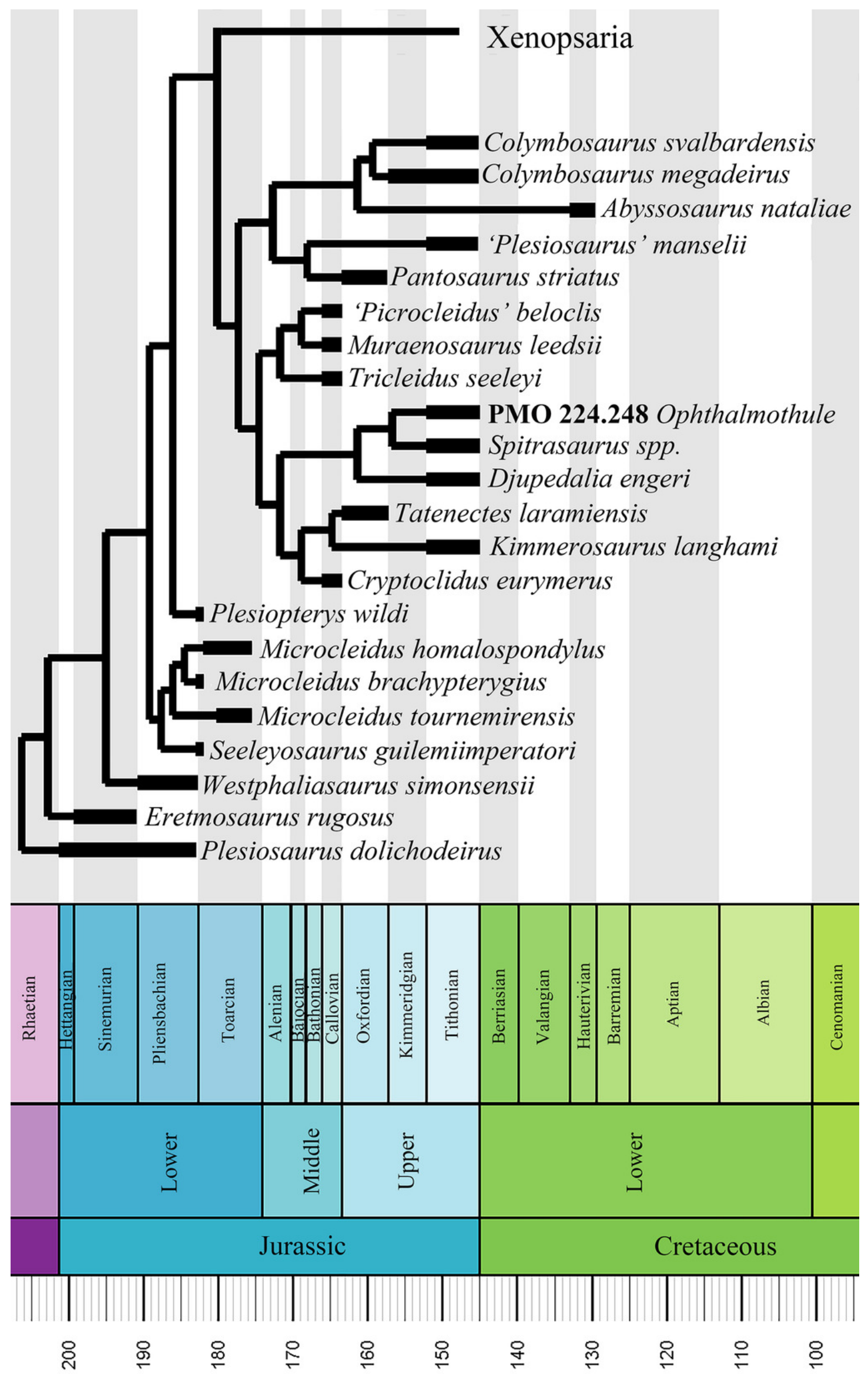


Figure 20

A reconstruction of Ophthalmothule cryostea in its natural environment.

Illustration by Esther van Hulsen. 


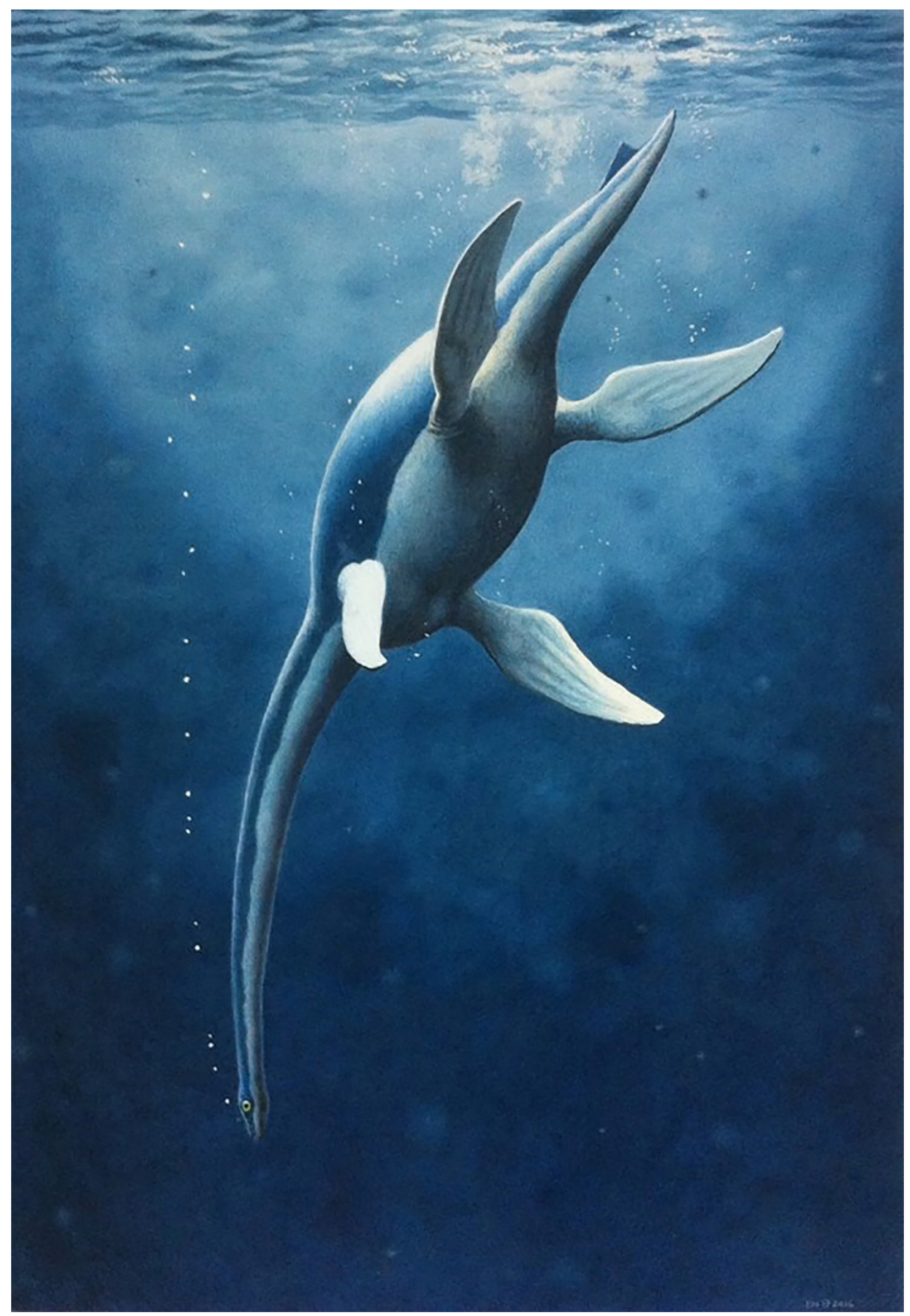

